Final Phase II Technical Report

\title{
THERMOACOUSTIC LIQUEFACTION OF COAL MINE METHANE TO PRODUCE LNG FOR HEAVY VEHICLE APPLICATIONS
}

Prepared for

\author{
U. S. DEPARTMENT OF ENERGY \\ MORGANTOWN ENERGY TECHNOLOGY CENTER \\ 3610 COLLINS FERRY ROAD \\ MORGANTOWN, WV 26507 \\ IN ACCORDANCE WITH \\ CONTRACT NO. DE-AC21-95MC32185
}

PREPARED BY

The WVU NATIONAL RESEARCH CENTER FOR COAL and ENERGY

and

APPALACHIAN-PACIFIC COAL MINE METHANE POWER COMPANY, LLC

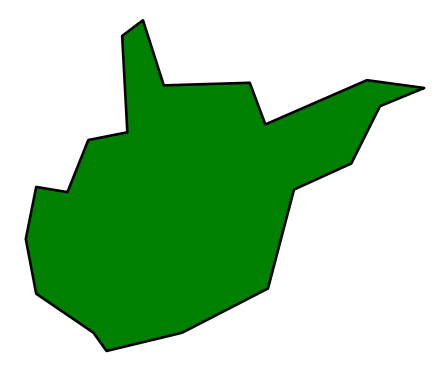

October 29, 1999 
This topical report was prepared by:

Dr. Kashi Aminian, West Virginia University

Dr. Lloyd English, West Virginia University

Dr. Douglas Patchen, West Virginia University

Dr. Hema Siriwardane, West Virginia University

and

Mr. Charles D. Estes; Appalachian-Pacific, Washington, DC

Dr. Raymond L. Zahradnik, Appalachian-Pacific, Washington, DC

\section{Acknowledgement is also made of the contributions to this report by:}

Dr. Richard Bajura, Director of NRCCE.

Jody Stirewalt; President, Automotive Research Technologies, Inc.

Alissa Oppenheimer, GRI 


\section{EXECUTIVE SUMMARY}

This Draft Technical Report is being submitted in accordance with the terms of the contract for this work, METC Contract No. DE-AC21-95MC32185.

This report describes a project to convert approximately 1.4 million cubic feet per day of Coal Mine Methane (CMM) into LNG at a site near Fairmont, West Virginia. The CMM is provided by Invitation Energy, Inc. and is being produced from abandoned mines in the area. About 10,000 gal per day of LNG will be produced and marketed as transportation fuel for the I-79 corridor in cooperation with an existing vendor of alternative fuels.

The technology for the project to produce LNG from CMM consists of three parts:

1. A cryogenic liquefier (TASHER) for methane.

2. A gas conditioning plant which conditions the raw CMM to the specifications of the TASHER unit.

3. On-site storage for the LNG and a distribution system to deliver the LNG to markets.

Beyond the technical components noted above, the demonstration project will develop data related to the economic optimization of construction and operating expenses for subsequent commercial projects. In addition, as the first eastern US LNG project dedicated to producing and distributing transportation fuels, the demonstration project is intended to define and resolve regulatory issues and prepare the heavy duty fleet vehicle market for subsequent adoption of LNG on a broader scale.

Market preparation activities integral to the proposed project will include: safety and utilization education and training for potential customers and their employees, insurance against customer equipment failure or loss of service, and initial distribution of LNG from backup suppliers to ascertain market readiness before a final decision to invest in the demonstration equipment.

The project would be accomplished over a period of 36 months once the ongoing 500 gallon-per-day TASHER tests are satisfactorily completed by Cryenco, the technology developer. In June 2000 the project would initiate acquisition of LNG from a backup supplier and begin to market the fuel to heavy vehicle fleet operators in northern West Virginia and southwestern Pennsylvania. Decisions to purchase major equipment would be confirmed if total customer commitments to purchase LNG exceed 2,500 gallons-per-day by September 2000. Assuming fabrication of the TASHER beginning in October 2000, delivery of the liquefier would occur the following May, with initial startup of the unit in June 2001. Optimization of the TASHER to operate on CMM, and particularly refinement of gas conditioning processes, is expected to require up to one year. A follow-up year of stable operations would conclude the demonstration project in June 2003. 
The proposed demonstration to convert CMM into LNG will deliver substantial direct and indirect environmental benefits. First, as the methane in CMM is a potent greenhouse gas with 24.6 times the radiative impact of carbon dioxide, its capture and use by the 10,000 gpd TASHER project at a rate of 1.4 million scf-per-day equates to 225,000 metric tons of $\mathrm{CO}_{2}$ avoidance each year. In other terms, the greenhouse gas reduction benefits of this one relatively small liquefier are equal to the carbon sequestration of $11,500,000$ Silver Maple trees. In addition to these direct benefits of the demonstration project, the domestic potential exists for dozens of similar commercial projects using CMM in Appalachia, Illinois, Colorado and Utah. Hundreds of additional TASHERS could be deployed overseas in gassy coal mining areas throughout eastern and northwestern China where LNG could be transported to remote villages and vaporized for off-grid use where pipelines are not practical. Eastern Europe also offers potential for transportation uses of LNG derived from CMM.

Indirect environmental benefits would also be achieved by the substitution of LNG in transportation applications for diesel fuel which contains approximately 20 percent more carbon for an equivalent Btu content. Additionally, particulate emissions would be nearly eliminated by the use of LNG.

Market studies confirm the potential for selling the LNG product of the demonstration plant within a 100 mile radius of the project site. This potential is enhanced by a West Virginia tax credit of up to $\$ 50,000$ per vehicle to purchase or convert heavy vehicles to alternative fuels such as LNG. Federal tax incentives, other financial assistance as well as technical assistance also are available in the project area. The market potential is also advantaged by the presence of a DOE-sponsored seven vehicle "real world" demonstration of LNG operations and a fueling facility at Waste Management's Washington, Pennsylvania landfill.

The team proposing the demonstration project is composed of Appalachian-Pacific Coal Mine Methane Power Company; West Virginia University, including the National Alternate Fuels Training Consortium and Cryenco, the TASHER technology owner and equipment vendor. The team will be supported by Gregg Swift, Los Alamos National Laboratory; Alissa Oppenheimer, Gas Research Institute; Waste Management of Washington, Pennsylvania; Invitation Energy, Mannington, West Virginia; and the State of West Virginia, among others. Appalachian-Pacific, a West Virginia limited liability company established in 1996 for the purpose of producing and marketing products from $\mathrm{CMM}$, will be the prime contractor and project manager.

Appalachian-Pacific has negotiated with Cryenco and has secured exclusive worldwide rights to use and market the TASHER technology for CMM applications. In addition, Appalachian-Pacific has negotiated exclusive rights to use and market the TASHER technology operating on any practical feedstock for the production of transportation fuels in certain states in the eastern US.

The proposed CMM to LNG project will have a total cost of $\$ 10,018,879$. This total includes a capital cost of $\$ 7,340,394$, of which the State of West Virginia will 
provide an estimated $\$ 4,000,000$. The DOE is being asked to provide one half the remainder of the Capital Cost and to share equally in the 24-month operating cost. This will bring the total requested from the DOE to approximately $\$ 3$ million, or less than one third of the total project cost. 


\section{TABLE OF CONTENTS}

Introduction

$\frac{\text { Page }}{9}$

1.0 Project History ........................................................ 10

2.0 Development of Current Project...................................... 13

3.0 Summary of Technical and Financial Considerations for an LNG

Project................................................................ 16

3.1 Technical C onsiderations............................................... 16

3.2 Financial Considerations ............................................. 17

4.0 Evaluation of the Initial Coal Mine Methane Reserve..................... 18

4.1 Coal Mine Methane .................................................... 18

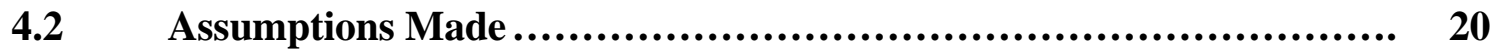

4.3 Coal Mine Gas Volume Estimates...................................... 20

5.0 Practical Use of Coal Mine Methane ................................... 23

5.1 CMM Composition Discussion.......................................... 23

6.0 Rational for Project configuration...................................... 29

6.1 TASHER Discussion..................................................... 31

6.2 Gas Conditioning Discussion......................................... 34

7.0 Technical Description of Project......................................... 44

7.1 Overall Process Diagram - Heat and Material Balances................. 44

7.2.0 Description of Individual Processes..................................... 49

7.2.1 TASHER ................................................................ 49

7.2.2 Gas Conditioning System........................................... 54

8.0 Project Site........................................................... 55

8.1 Demonstration Project Utility Requirements, Plot Plan, Installation, Permitting and Financial Considerations ............................. 59

8.1.1 Utilities Required for a 10,000 gpd TASHER Demonstration........ 59

8.1.2 Plot Plan for the LNG demonstration Equipment...................... 59

8.1.3 Alternatives for Siting the Plot Plan at Invitation Energy's Whetstone Portal....................................................... $\quad 61$

8.2 Cost Estimates and Evaluations for Site Preparation.................... 69

8.2.1 References for Cost Estimates of Site Preparation....................... 71

8.2.2 Description of Site Layout ............................................... 71

$9.0 \quad$ Financial Analysis.................................................... 73

9.1 Capital and Operating Cost Estimates................................. 73

9.1.1 Capital Cost Estimates................................................. 73

9.1.2 Operation and Maintenance Cost Estimates............................. 73

9.2 Project Financing and Financial Performance.......................... 145

10.0 Market Survey and Analysis of Demonstration Project LNG Sales Issues............................................................. $\quad 74$

10.1 Market Survey in Northern West Virginia and Southwestern Pennsylvania............................................................. 74

10.1.1 Introduction............................................................ 74

10.1.2 Background Data...................................................... 74

10.1.3 Background, LNG Equipment Cost and Use.......................... 75

10.1.4 Survey Design........................................................ 76 
10.1.5 Survey Results......................................................... $\quad 76$

10.2 Regulatory Issues................................................ 78

10.2.2 Regulatory Issues Associated with Transporting LNG through Marion County............................................. $\quad 78$

10.2.3 Regulatory Issues Relating to Distribution from a Mobile Refueling Station................................................................... 79

10.2.4 Regulatory Issues Related to the Use of LNG in Vehicles............... 79

10.3 Marketing Strategy: Demonstration Project and Subsequent Commercial Sales......................................................... $\quad 80$

10.3.1 Define the Project's Market Area........................................ 149

10.3.2 Potential Customers in Market Radius ................................... 149

10.3.3 Potential Competitors Other than Diesel Marketers ................... 150

10.3.4 Market Area Education Plan............................................ 152

10.3.5 Strategy for Fueling the Initial LNG Market........................ 153

10.4 Commercial Potential.................................................... 81

11.0 Project Development....................................................... 83

11.1 Organization and Key Personnel..................................... 83

11.2 Project Schedule......................................................... 85

11.2.1 Statement of Work for Cryenco Test Program.......................... 85

11.2.2 Statement of Work for Demonstration Project.......................... 86

12.0 Environmental Considerations and Benefits........................... 88

12.1 Demonstration Project site Impact Analysis........................... 88

12.1.1 Gas Reserve......................................................... 88

12.1.2 Potential Water Pollution.............................................. 88

12.1.3 Potential Soil Damage from Leakage of Lubricants.................... 88

\section{LIST OF TABLES}

Table 1 Required Selling Price for Gob Gas Under Various Scenarios... 11

Table 2 Project Cost Summary ............................................. 17

Table 3 Gas Volume Estimates at the Mine Site............................ 21

Table 4 Assumed Gas Content Data for the Mine ......................... 22

Table 5 Composition of CMM from Various Sources...................... 26

Table 6 Calculated Equilibrium Conditions for Ternary $\mathrm{CH}_{4}-\mathbf{O}_{2}-\mathbf{N}_{2}$ System.......................................................... 40

Table $7 \quad$ Heat and Material Balances for Project............................ 45

Table 8 Cost Estimates for Site Preparation................................ 69

Table 9 Estimates of Project Capital Cost................................ 145

Table $10 \quad$ Estimates for Project Operating Cost............................ 146

Table $11 \quad$ Project Pro Forma............................................... 147

Table 12 Total LNG Demonstration Project Funding ........................ 73

Table 13 Fuel Properties Comparison (Source: ALT Brochure 1998)...... 75

Table 14 LNG Production Facilities in Nearby States........................ 151 


\section{LIST OF FIGURES}

Page

Figure 1 Block Diagram of Process to Upgrade CMM to PQ Gas

Figure 2

Increase in Value Added to Gob Gas at Various Stages in the

Process.

Figure 3

Total Gob Gas Production.

Figure 4

Figure 5

Carbon Dioxide Variation with Time for Several CMM Source... 24

Figure 6

Figure 7

Flow Variations of Individual Sources.

Average Daily Production of CMM from All Sites................. 25

Figure 7a

Figure 8

Plots of $\mathrm{CO}_{2}$ and Nitrogen Over Time at Four Sites................ 27

Figure 9

Figure 10

Schematic of Proposed CMM Project.............................. 30

Figure 11

Block Diagram of Gas Constituent Removal from CMM...

35

Typical Flow Diagram of Absorbing Systems ........................ 37

Figure 12

Typical Flow Diagram of Adsorption Systems (Molecular Sieves). 38

Comparison of Equilibrium Data and Raoult's Law for $\mathrm{CH}_{4}-\mathrm{N}_{2}$

System.

Figure 13

Comparison of Equilibrium Data and Raoult's Law for $\mathrm{CH}_{4}-\mathrm{N}_{2}$

System.....

Figure 14

Illustration of Removal of LNG and Uncondensed Gases from

TASHER.

Figure 15

Removal of Oxygen from the inlet CMM Can Be Avoided.

Figure 16

Block Diagram of Gas Conditioning System Using Molecular

Sieves

Figure 17

Alternate Block Diagram of Gas Conditioning System Using

Molecular Sieves

Figure 18

Proposed Project Flow Diagram.

Figure 19

Figure 20

DEA Gas Conditioning Process..

OPC Engineering DRIZO Dehydration Process.................. 47

Figure 21

Figure 22

Figure 23

Figure 23a

Alternative Gas Conditioning System.

Schematic of 10,000 Gallon per Day TASHER Unit............... 50

Schematic of TASHER Recirculation Loop....................... 51

Figure 23b

Thermoacoustic Driver Illustration............................. 52

Figure 24

Figure 25

Figure 26

Figure 27

Figure 28

Figure 29

Figure 30

Orifice Pulse Tube Refrigerator Illustration....................... 53

Map: Pittsburgh Coal Seam Base Elevations, Consol No. 9 Mine. 56

Map: Topographic Conditions in Immediate Project Area........ 57

Core Sample, Plum Run Hole \#6.

Proposed Project Layout on Site 2................................. 60

Illustration of Five Candidate Sites.............................. 62

Potential LNG Market with Fuel Use Growth...................... 77

Figure 31

Sensitivity of LNG Project to Gas Purchase Cost and LNG Sales

Price.............................................................. 81

Figure 32

Figure 33

Project Profitability After DOE Funding Ends ................... 82

Project Team Organization Chart ................................. 84

Planned Project Schedule ......................................... 90 


\section{LIST OF PICTURES}

$\underline{\text { Page }}$

Picture 1 Potential Project Site \#1........................................... 63

Picture 2 Preferred Project Site \#2........................................ 64

Picture 3 Potential Project Site \#3.......................................... 65

Picture 4 Potential Project Site \#4............................................ 66

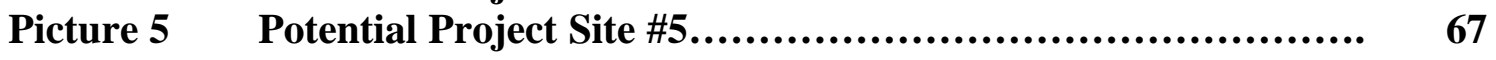

Picture 6 Site \#2 Drainage .................................................. 68

\section{Appendices}

Resumes of Key Personnel.

Appendix 1

Introduction of Appalachian-Pacific Coal Mine Methane

Power Company, LLC.....................................................

Letters of Cooperators and Letters of Endorsement.

Appendix 2

West Virginia Alternative Fuel Vehicle Tax Credit....

Appendix 3

Calculation for Greenhouse Gas Impact of LNG Project...............

Technical Papers Related to Thermoacoustic Liquefier Technology..

Company Profiles: CRYENCO/Chart Industries........................

Price Quote on Cooling Towers ..........................................

Financial Analysis of Project

Appendix 4

Appendix 5

Appendix 6

Appendix 7

Appendix 8

Marketing Strategy for Project.

Appendix 9

Identification and Qualification of Potential Market for LNG

Appendix 10

For Transportation Fuel in the Morgantown, West Virginia area.....

Appendix 11 


\section{Introduction}

This report describes the activity undertaken by the project members under METC contract No. DE-AC21-95MC32185 to develop a project that will provide a commercial use for Coal Mine Methane (CMM).

In particular, the report describes a project to convert CMM into LNG and to market that LNG to the transportation sector in and around the I-79 corridor near Morgantown, West Virginia.

The report discusses the sources of CMM and provides estimates of the extent of the resource specifically dedicated to the project. It discusses the novel refrigeration technology that will be employed to convert the CMM to LNG and the gas conditioning technology that will be used to bring the raw CMM up to cryogenic processing specifications.

Summary capital and operating cost estimates are furnished for the project and specific monetary and schedule requirements are identified so the project can be examined in its entirety.

The report discusses the immediate market potential for the successful commercial sale of LNG into the nearby market and provides estimates of future market penetration into local, regional and wider markets.

Lastly, the report comments on the environmental effects of the project and extrapolates these benefits to future markets. One of the driving forces for the project is the reduction of environmentally harmful greenhouse gases currently escaping unchecked into the atmosphere. This final section analyzes the TASHER technology's potential net environmental benefits both in terms of greenhouse gases and criteria pollutants. 


\subsection{Project History}

In the Topical Report for this project, dated July 21, 1995 (3), it was pointed out that there are a number of options for the commercial utilization of CMM. The CMM could be sold as is to a pipeline as Near Pipeline Quality (NPQ) gas, or it could be conditioned to meet pipeline specifications and sold into the pipeline as a commodity Pipeline Quality (PQ) gas. The use of CMM as a "cushion" gas in a commercial gas storage reservoir was discussed, and the option of using CMM to generate on-site electricity was described in detail.

It may be useful to recall the technology required to condition CMM to PQ gas. Figure 1 is a simplified block diagram of the steps involved. The most difficult and costly step in the process is the Nitrogen Rejection Unit (NRU). For NRU's, the $\mathrm{CO}_{2}$ content of the inlet gas must be reduced below 200 ppmv, normally through the use of an amine type treating unit. Essentially, all of the water must be removed by utilizing a molecular sieve process. The NRU process results in a residue stream at a very low pressure requiring significant horsepower to recompress the gas for sale to a pipeline.

In the topical Report, the cost of this processing was estimated using capital and cost information provided by Purvin and Gertz (6). Their capital costs for the NRU were based upon dehydration with a molecular sieve and enough horsepower to return the residual gas to a pipeline at $800 \mathrm{psig}$. The costs did not include an upstream amine unit to remove $\mathrm{CO}_{2}$ or an upstream glycol unit to reduce the load on the molecular sieve. So typical DEA and glycol plants were inserted, and their cost estimated for a water-saturated, $2.5 \%$ acid gas from data provided by Purvin and Gertz. 


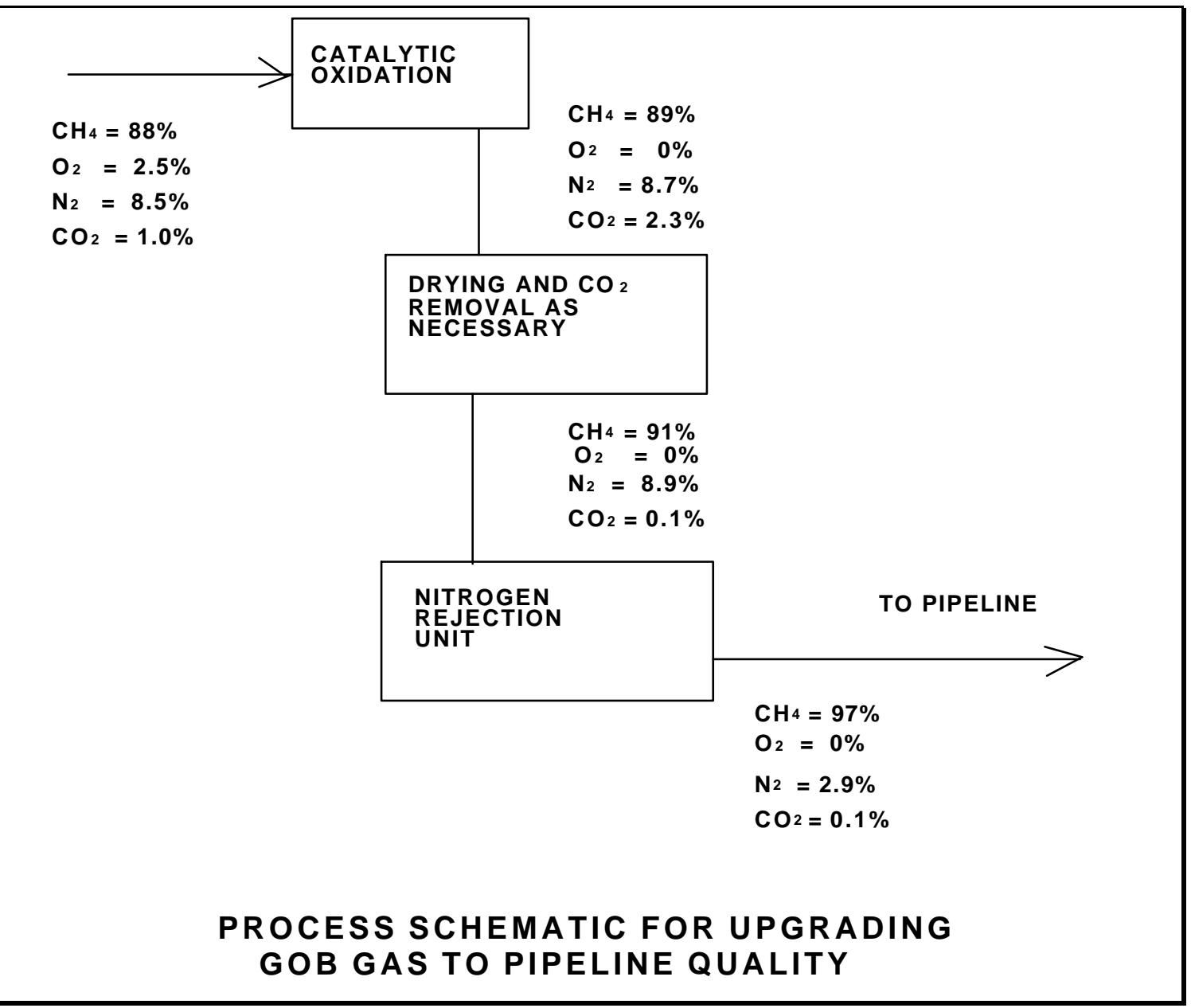

\section{Figure 1 Block Diagram of process to Upgrade CMM to PQ Gas}

The Topical Report provided a basis for evaluating the required selling prices for the various options. The conclusions at that time are provided here in Table 1 and graphically as Figure 2.

USE

NPQ GAS TO POWER PLANT

NPQ GAS TO PIPELINE

PQ GAS TO PIPELINE
$\$ / M C F$

0.87

1.13

2.01

Table 1 Required Selling Price for Gob Gas Under Various Scenarios, with Consistent Financial Assumptions. (These Numbers are Specific to the Emerald Mine, with Storage at the Kirby Reservoir.) 
Some brief explanation of Table 1 is in order. The required selling prices of the gas streams indicated in the table represent the cost to the project of providing the gob gas to the point in question. Thus, all situations require purchase, gathering and transmission of the gob gas to some point. If that point is the fence of an on site power generation unit, the price of the sale would be $\$ 0.87 / \mathrm{MCF}$. If, however, the point of sale were to a pipeline, the gas would have to be further conditioned. It would have to be compressed, in the case of the NPQ sale, requiring a price of \$1.13. If, on the other hand, the gas were to be conditioned to pipeline specifications, requiring a processing plant, the required selling price would be $\$ 2.01 / \mathrm{MCF}$. In other words, the conditioning of the raw gas that would go to a power plant to PQ gas increases its value by (costs the project) \$1.14/MCF.

On the other hand, if the power plant were part of the project, the sale of electricity at 4.5 cents/kWh is equivalent to selling gas at $\$ 3 / \mathrm{MCF}$. It is possible to express this situation in a graphical way by attributing to the gas an increased value as it passes through the process of being collected, transmitted to storage, stored, and transmitted to its end use. Figure 2 shows this.

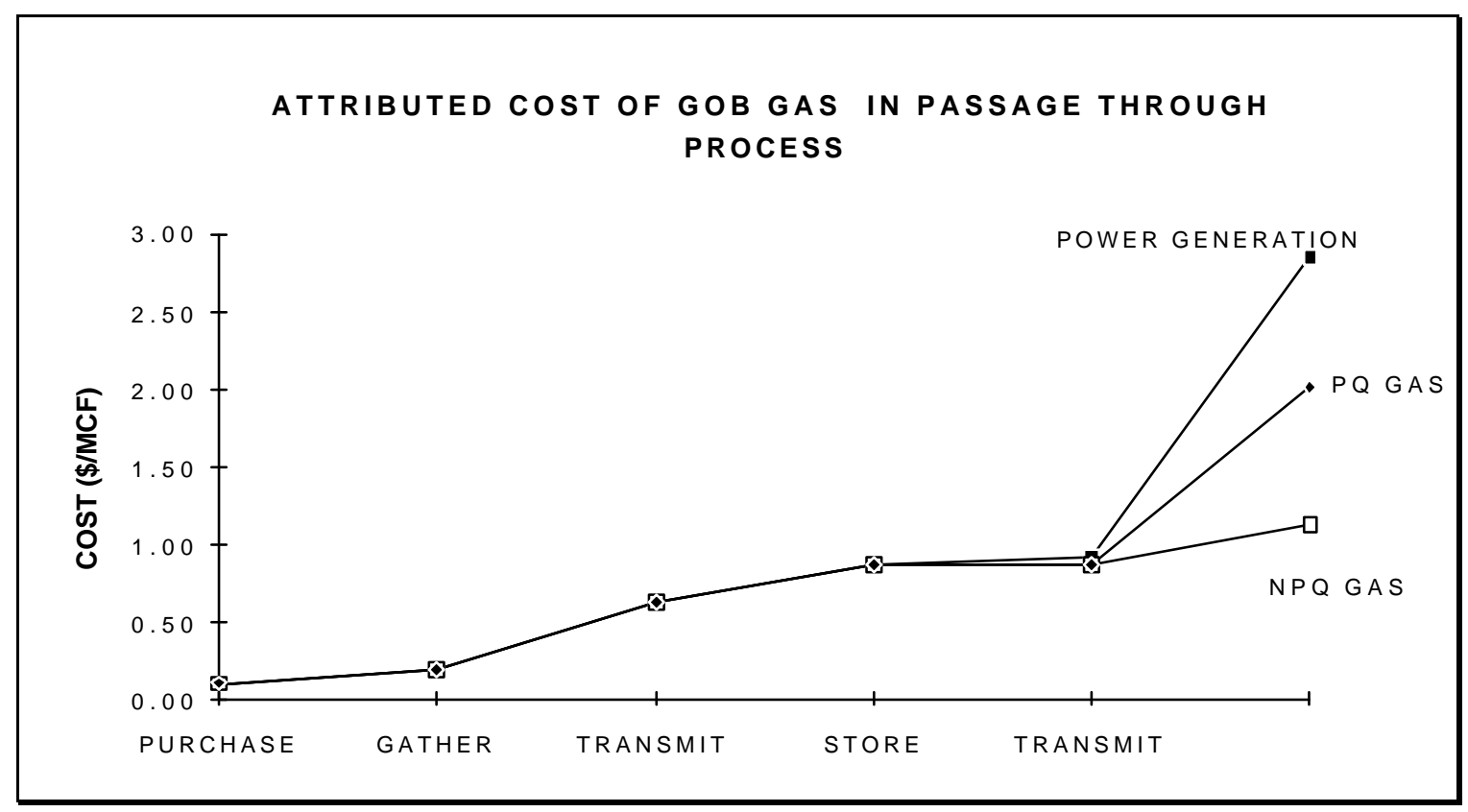

Figure 2. Increase in value added to gob gas at various stages in the process.

At the time of the writing of the Topical Report, July 21, 1995, all four of these options were open to the project, as the Report stated. Using Figure 2 and Table 1 together, it is easy to get a general idea about the various options. The generation of electricity represents the highest value of the gas for the options considered. The feed gas 
to the power option represents the lowest cost for the gas, conditioned to that use. This option also represents the greatest project investment.

On the basis of the work leading up to and subsequent to the Topical Report, a Project Partnership Agreement was completed between Appalachian-Pacific LLC and Equitrans, Inc. to develop a project at the Emerald mine and/or the Cumberland mine, utilizing the Kirby gas storage reservoir.

Among the early project configurations considered by the partnership was the sale of NPQ gas or pipeline quality gas into the Equitable gas utility distributuion system. After some study, Equitrans informed the partnership that it was not interested in purchasing either NPQ or PQ gas from the project.

Thereafter, the partnership concentrated on the option to generate on-site electricity and to sell some or all of this electricity to the Emerald mine and/or the Cumberland mine. The project developed detailed capital and operating cost projections for this option and carried out an extensive study of the gas production potential at the two mines. This work resulted in a number of proposals being made to Cyprus/Amax, in the summer of 1996 and in early 1997. These proposals were turned down by Cyprus/Amax which concurrently negotiated with Allegheny Power for a reduction in the price of electric service for their mine operations. Consequently, the project began to search for new CMM sites and new project options.

\subsection{Development of Current Project}

As described above and reported to the DOE in May and June 1998, the failure to reach an agreement with Cyprus/Amax concerning the use of their gob gas (or any other $\mathrm{CMM}$ ) from either the Cumberland or the Emerald mine forced a search for other sources of CMM and a reexamination of alternate project configurations.

As a result of that search, the project team concluded that acquisition of CMM from a third party offered several advantages over securing a source of supply directly from a mine site. Foremost among these advantages is the fact that third party owners of CMM generally are in business principally to sell that resource while the project team's experience is that coal mining companies are focused strictly on their mining operations. Consequently, it has proven difficult to persuade coal mine operators to consider with alacrity even a venture such as the proposal to Cyprus/Amax which offered an attractive rate of return (ca. 20 percent) and which had pre-clearance from Equitrans for project financing. Apparent reasons for many mine operators' hesitance to enter into ventures producing electric power from their CMM resource include: first, potential electric sales or savings represent a relatively small percent of a large mine's revenue stream $(<1$ percent), gob gas collection, in particular, represents continuing and changing surface activities with no benefit to mine operations (e.g. ventilation) which are their primary concern. (CMM collected by installing pre-mining degasification wells can offer significant benefits to mine operations; however, as detailed elsewhere in this report, the 
highest and best use of CMM from this relatively pure source is probably sale to a pipeline instead of fuel for an electric power generator.) Second, production and/or use of electricity is not their business: it is a distraction. Third, and perhaps most important, coal mine operators are in business to mine coal for sale principally ( $>90$ percent) to customers who make electricity. Consequently, the mine operators are very reluctant to be perceived, even in a minor way, as competing with their dominant customers.

Our search for a new project site and project structure was further guided by the teams' conviction developed during the Cyprus Emerald and Cumberland mine studies that, due to the variabilities of CMM gas production, on-site storage of the gas is essential for the practical operation of any coal mine methane project. See Figure 3 for an illustration of gob gas production variability rates at a typical multi-well site. While it is possible to size and operate an electric power generation project at maximum or minimum CMM flow rates, neither is practical. Minimum scale projects tend to have high capital costs per unit of power produced and, therefore, generally are not competitive in the generation market. Power generation projects which are scaled to use peak, or near peak, CMM flows will regularly under-perform their rated capacity with generation following the fluctuations noted in Figure 3. There is little demand for power that may or may not be available when customers need it. 


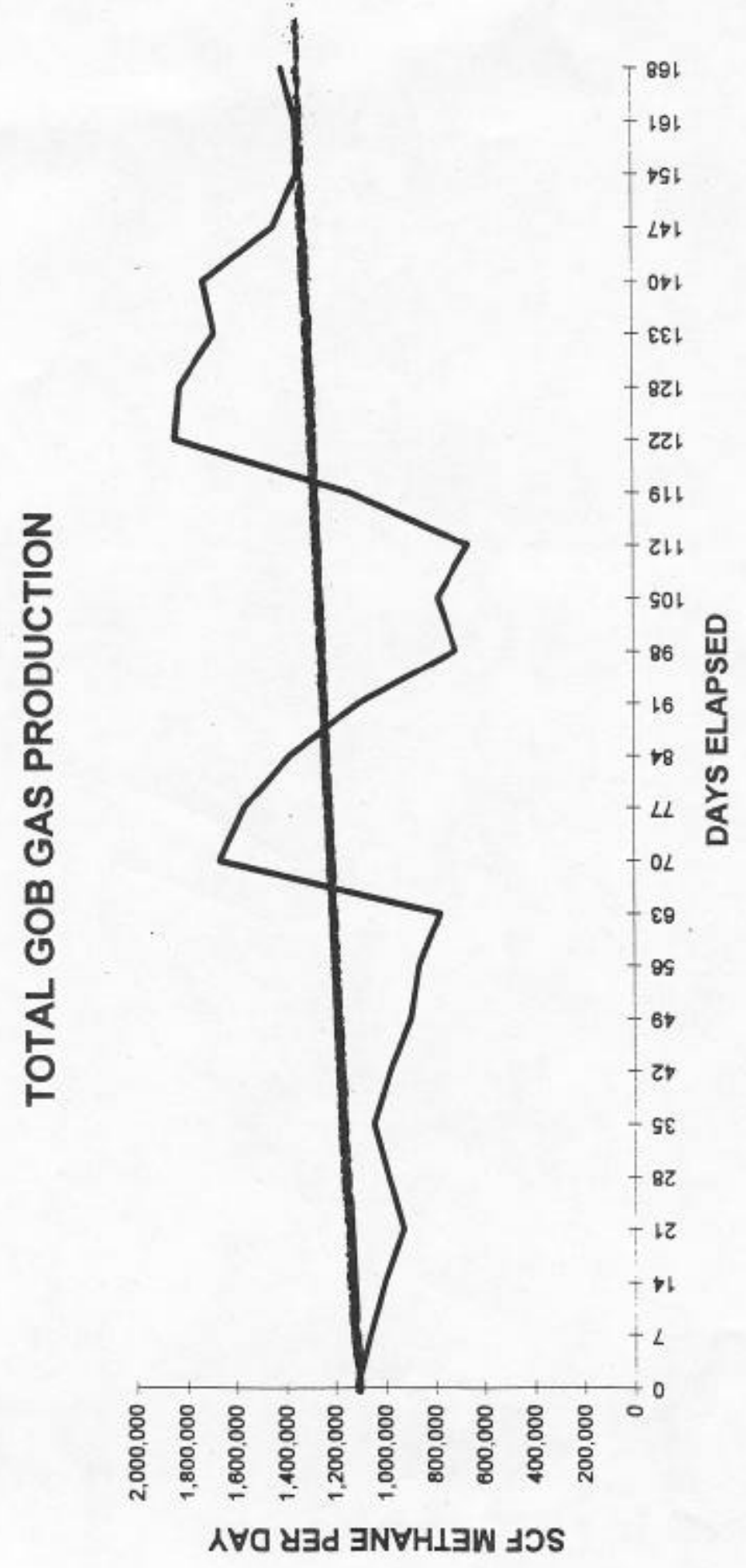


Having determined that on-site gas storage is essential, it is also clear that colocation of suitable underground gas storage facilities with large, gassy coal mines is an unusual occurrence. Moreover, existing or new gas storage reservoirs are expensive to acquire and operate. Also, alternative storage in abandoned underground mines has some risk of leakage and contamination. The project team concludes that both storage options, by nature, are generally impractical to support a CMM-fueled electric power generator of any size less than ten megawatts. Underground storage requirements, then, place severe limitations on candidate CMM project sites and scales.

The project team's concerns noted above regarding underground storage of CMM lead us to explore other options for the storage and supply of CMM in a condition and at a rate as demanded by project operations. A small gas liquefier to produce storable liquefied natural gas from CMM was selected as the optimum solution for the project's storage requirements. Not only does the liquefier permit flexibility of project location, it opens significant, new, high-valued markets for products of CMM as will be discussed later in this report.

Further, the desire to deal with a "third party" CMM gas supplier with access to multiple sources of CMM in northern West Virginia, close to these new markets lead Appalachian-Pacific, a member of the project team, to negotiate with Invitation Energy of Mannington, West Virginia for a stable supply of CMM. An agreement was reached with Invitation Energy in April 1999. Relevant details of that agreement are included in Appendix 4.

\subsection{Summary of Technical and Financial Considerations for an LNG Project}

\subsection{Technical Considerations}

CMM will be purchased by the project from Invitation Energy, Inc., which has the ability to produce the CMM from various operating and abandoned coal mines in, or near, Marion County, West Virginia. This gas is then processed in a Gas Conditioning unit, which will condition the gas to acceptable specs for the process side (refrigeration section) of the TASHER. The CMM will also be used as fuel gas to the TASHER combustor and to other process heaters and perhaps to a small engine/generator set power unit.

In the TASHER combustor, as well as in the other process heaters, the CMM fuel gas will be burned with air, creating a hot (200-300 deg F) flue gas, which would be discharged to the atmosphere in an environmentally acceptable way.

The CMM, conditioned to meet TASHER specs, will be supplied to the TASHER as process gas, where it will be converted to LNG, stored and shipped to market. The cooling requirements of the TASHER will be provided by cooling water, which is chilled on site by means of a cooling tower. 
The electrical requirements for this operation may be provided by purchased electricity or by electricity generated in a small (ca. $300 \mathrm{~kW}$ ) gen. set.

\subsection{Financial Considerations}

A CMM to LNG project is being proposed that will have a total cost of $\$ 10,018,879$. This total includes a capital cost of $\$ 7,340,394$, of which the State of West Virginia will provide $\$ 4,000,000$. The DOE is being asked to provide one-half the remainder of the Capital Cost and to share equally in the two year operating cost. This will bring the amount requested from the DOE to approximately $\$ 3$ million, less than one third of the total project cost.

\begin{tabular}{|l|r|}
\hline TOTAL PROJECT & $\$ 10,018,879$ \\
\hline STATE & $\$ 4,000,000$ \\
\hline TOTAL DOE & $\$ 2,950,000$ \\
\hline DIFFERENCE & $\$ 3,068,879$ \\
\hline (PAID BYPROJECT) & \\
\hline
\end{tabular}

Table 2 Project Cost Summary

While Appendix 4 shows that members of the project team have negotiated specific quantities and conditions for a supply of CMM to fuel this demonstration project, for assurance purposes the team also conducted an analysis of potential gas availability at Invitation Energy's sites. A separate study of the anticipated composition and deliverability of that gas was also conducted. The results of those studies follow. 


\subsection{Evaluation of the Initial Coal Mine Methane Reserve}

The principal mine under consideration for this analysis, Consolidated No. 9, has been closed for more than 30 years. Since the beginning of the mining activity at this site, the coal mine methane produced at the site has been vented to the atmosphere. Since coal mine methane has been liberated over many years, the remaining gas reserve is unknown. In this section of the report, the original gas reserve is estimated based on several assumptions that are presented below. The onsite utilization of coal mine gas would have reduced the methane gas that has been vented to the atmosphere. In that sense, the estimated gas reserve would show the extent of the environmental problem, if the coal mine gas was vented to the atmosphere.

During the mining activity, the primary coal seam is extracted in the mine, which leaves a large unsupported underground cavity. The extraction ratio in certain sections of the mine is $100 \%$, while this ratio typically varies between $40 \%$ to $60 \%$ over the remaining area as shown in Figure 4. One major consequence of mining is the fracture zone generated by the removal of the primary coal seam. During the roof collapse, the rock strata above the mine roof are fractured and broken. The extent of the fracture zone above a mine panel can depend on many factors. The size of the fracture zone is normally unknown. The actual size of the fracture zone needs to be determined from field measurements.

\subsection{Coal Mine Methane}

The methane concentration at the mine face is an important factor related to the safety of mine workers. The coal mine methane gas could be released from the primary coal seam and the nearby gas bearing strata located within the fracture zone. The methane concentration at the underground mine is lowered by introducing air into the underground mine ventilation system. Moreover, wells are installed to vent coal mine methane released (or generated) in the fracture zone so that it would not enter the mine ventilation system. In view of the high quality of the coal mine methane it can be used for on-site power generation or for other commercial purposes.

While the source of coal mine methane is unknown, it is assumed that the gas could be released from the gas bearing strata located in the fracture zone above the mine roof. The exact size of the fracture zone is also unknown, and the exact size needs to be determined from field measurements. The strata permeability to gas flow in the fracture zone can be expected to be higher than that of the intact overburden rock in view of the post-mining fractures generated during roof collapse. Increase in the strata permeability can facilitate the release of gas contained in other gas-bearing strata located within the fracture zone. Therefore, the evaluation of coal mine gas potential at a mine site needs to be based on the factors such as the size of the fracture and the gas content of strata located in this zone. 


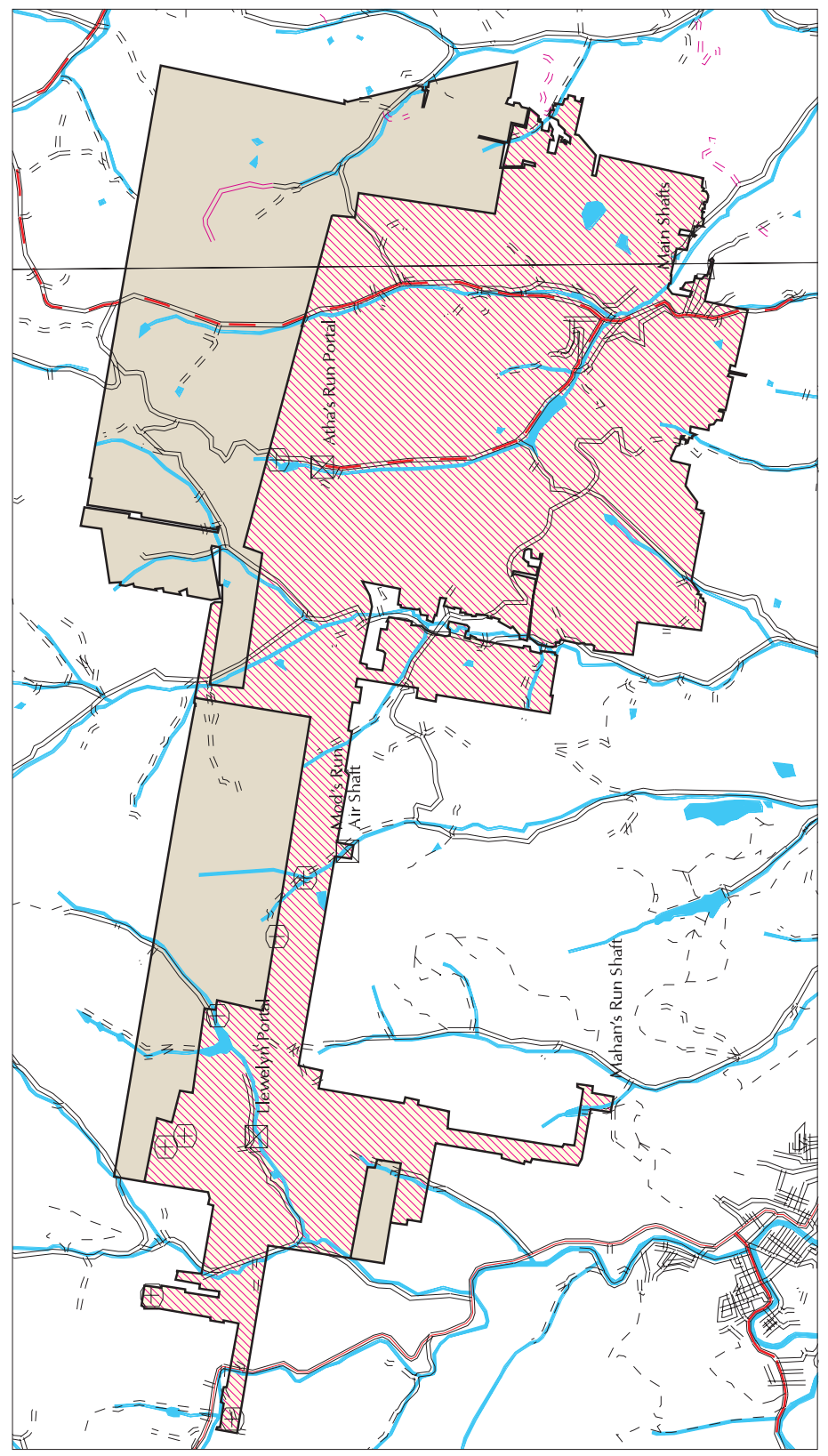


In this report, the initial reserve of coal mine methane gas is estimated for the Consolidated No. 9 mine located in Mannington, West Virginia. A core sample providing geologic information at the mine site is presented in Figure 5. The estimates are based on the following assumptions.

\subsection{Assumptions Made}

1. It is assumed that the gas is generated only from secondary coal seams found in the overburden. The gas potential from other gas bearing strata, if any, is neglected.

2. The gas content information on secondary coal seams is not available at the mine site. It is assumed that the gas content of all secondary seams is the same.

(a) The gas content of secondary coal seams is assumed to be 100 cubic feet/ton.

(b) The gas content of the primary coal seam is assumed to be 150 feet/ton.

3. The height of the fracture is assumed as 350 feet. The extent of gas reservoir is assumed as the area of the mine under consideration.

4. The unit weight of the primary and secondary coal seams was assumed as $84 \mathrm{lb} / \mathrm{ft}^{3}$.

\subsection{Coal Mine Gas Volume Estimates}

A map of the mine is shown in Figure 6. The gas reservoir is assumed to cover the area of the entire mine. The thickness of the primary coal seam is assumed as 6 feet. The gas potential from the primary coal seam is reported elsewhere in the report. The cumulative thickness of secondary coal seams located in the overburden is estimated as 13.33 feet over a distance of 300 feet above the mine floor. Assuming that the gas is produced from all of the secondary coal seams located within the fracture zone, the total gas potential was calculated and the estimates are shown in Table 3. This table presents estimates based on the assumed gas content data shown in Table 4.

As can be seen from this Table, the initial coal mine gas potential is substantial at the mine. The remaining gas volume is unknown at this time. The usage of this gas in power generation will contribute towards a reduction of methane - a greenhouse gas - vented to the atmosphere. 


\begin{tabular}{||l|l|l|l||}
\hline Panel Identification & $\begin{array}{l}\text { Gas Volume Based on } \\
40 \% \text { extraction ratio for the } \\
\text { primary seam in area 2 }\end{array}$ & $\begin{array}{l}\text { Gas Volume Based on } \\
60 \% \text { extraction ratio for the } \\
\text { primary seam in area 2 } \\
\text { (cubic feet) }\end{array}$ & Comments \\
\hline $\begin{array}{l}\text { Contribution from } \\
\text { remaining primary coal } \\
\text { seam }\end{array}$ & $4,823,902,755$ & $3,215,935,170$ & \\
\hline $\begin{array}{l}\text { Contribution from the } \\
\text { secondary coal seams }\end{array}$ & $19,206,279,637$ & $19,206,279,637$ & \\
\hline & & $22,422,214,807$ & \\
\hline Initial Gas Potential & $24,030,182,392$ & & \\
\hline & & & \\
\hline
\end{tabular}

\section{Table 3 Gas Volume Estimates at the Mine site}

Area of the gas reservoir for secondary coal seams $=343,055,043 \mathrm{ft}^{2}$

Area of the gas reservoir for the remaining primary coal seam

For extraction ratio $=40 \%, \mathrm{~A}=127,616,475 \mathrm{ft}^{2}$

For extraction ratio $=60 \%, \mathrm{~A}=85,077,650 \mathrm{ft}^{2}$ 


\begin{tabular}{||l|l|l|l||}
\hline Coal Seam & Thickness (ft) & $\begin{array}{l}\text { Gas Content } \\
\text { (Cubic feet/ton) }\end{array}$ & Comment \\
\hline & & & \\
\hline $\begin{array}{l}\text { Primary Seam: Pittsburgh } \\
\text { coal }\end{array}$ & 6.0 & 150 & \\
\hline & & & \\
\hline Secondary Seams: & & 100 & \\
\hline Pittsburgh Riders & 2.00 & 100 & \\
\hline Waynesburg & 3.92 & 100 & \\
\hline Swickley & 5.5 & 100 & \\
\hline Fishport & 0.83 & 100 & \\
\hline Redstone & 1.08 & & \\
\hline & $\begin{array}{l}\text { Total secondary } \\
\text { Coal Thickness }= \\
13.33 \mathrm{ft}\end{array}$ & & \\
\hline
\end{tabular}

Table 4 Assumed Gas Content Data for the Mine 


\subsection{Practical Use of Coal Mine Methane}

\subsection{CMM Composition Discussion}

CMM recovered from abandoned coal mines may indeed have a different composition from the gob gases at the Cumberland/Emerald mines. To determine what composition shut in mine gases might have, CMM data produced from abandoned mines near the project area were analyzed. Basically, the results of this analysis suggest that a gas with a Carbon Dioxide composition less than $1 \%$ and nitrogen content less than $2.5 \%$ may be expected (see Figure 5 and Table 5). If CMM can indeed be delivered to the project at these composition levels, then the gas conditioning step could be simplified, with attendant reduction in the estimated capital and operating costs.

Gas of this mean composition could be conditioned to meet TASHER specs in a simpler and less expensive way than gas of the composition of the Cumberland/Emerald mine gob gases. For example, it may be possible to use only a molecular sieve unit.

Although the average $\mathrm{CO}_{2}$ composition may be able to be handled by a simplified gas conditioning step, it is important to examine the variation in time of the $\mathrm{CO}_{2}$ levels. Figure 5 shows the variation with time of the $\mathrm{CO}_{2}$ levels from the various tracking points for the data being discussed. Note that with the exception of the Hill and Dillie data, most of the other measurements indicate a $\mathrm{CO}_{2}$ level below $1 \%$, with only minor (timewise) excursions above that level. Again, this trend suggests that a simplified gas processing step may be sufficient to condition the gas to TASHER specs.

Figure 6 shows the flow variation of various CMM sources with time. Figure 7 is a composite of the individual flow rates as a function of time. It is not clear that the changes in flow that occur over time are the result of natural causes or whether the flows were purposely adjusted to meet demand. (In other words, was the total (and individual) flow deliberately restricted at various times in order to maintain composition relatively constant.) In any case, it is clear that for both the TASHER Demo project and for subsequent commercial operations a constant delivery of CMM will be necessary. Whether such levelizing will cause a corresponding wider variation in composition than displayed in the data analyzed in this report is not clear at this time. 


\section{Carbon Dioxide Variation with Time for Several CMM Sources}

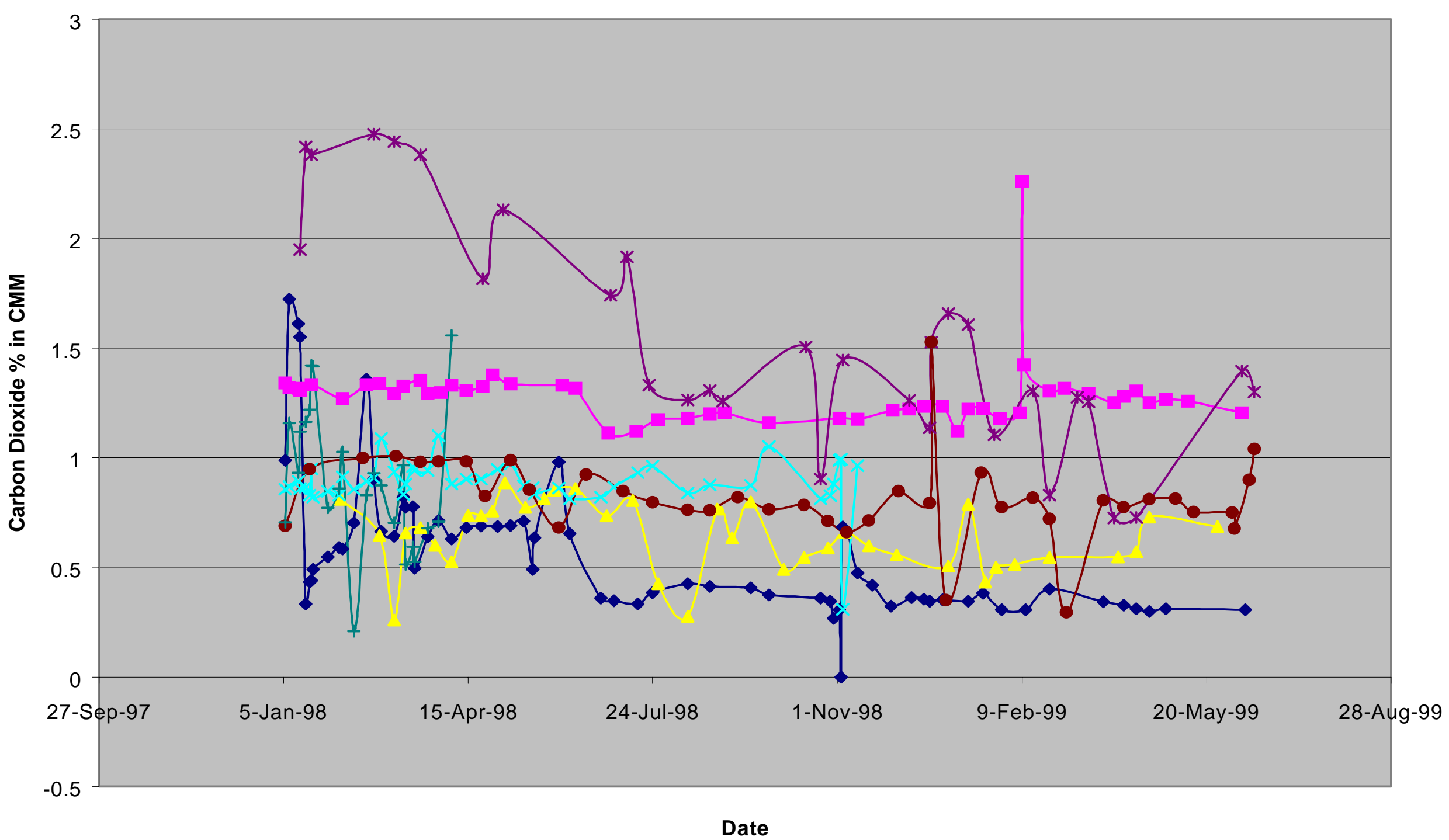

Figure 5 

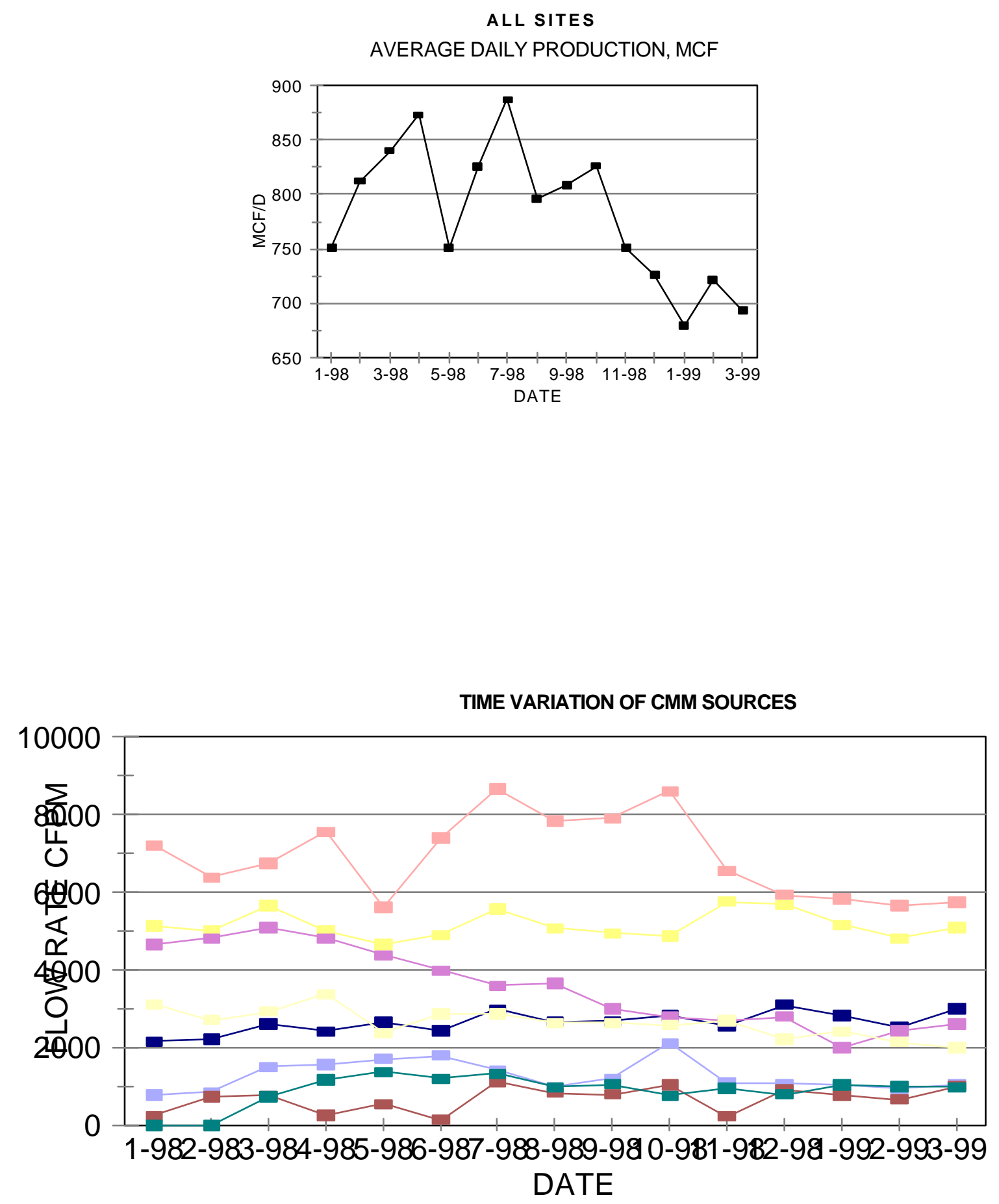


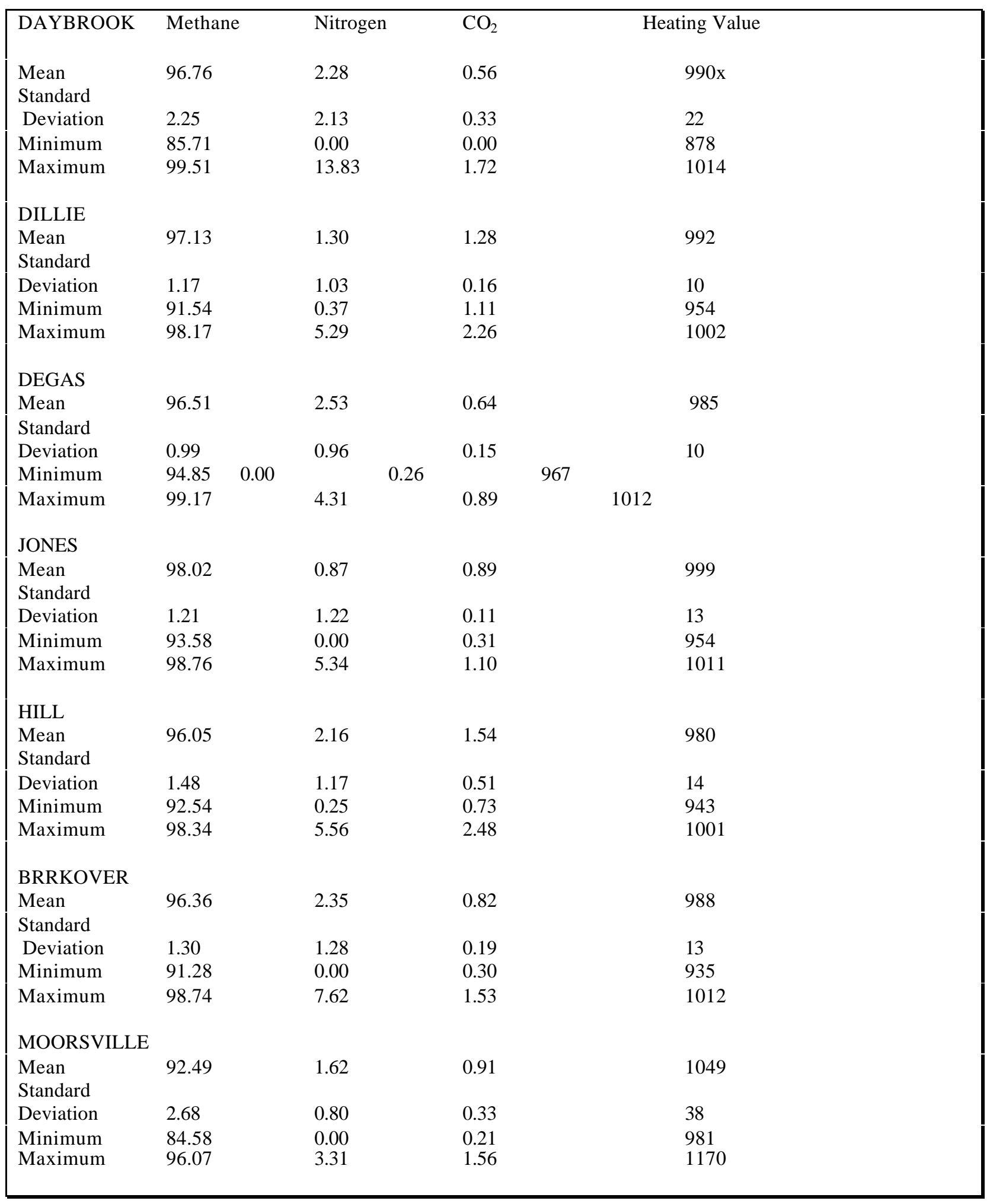

Table 5 Composition of CMM from Various Sources 


\section{Figure 7a Composition of CMM from Four Selected Sources}

brkrvvr
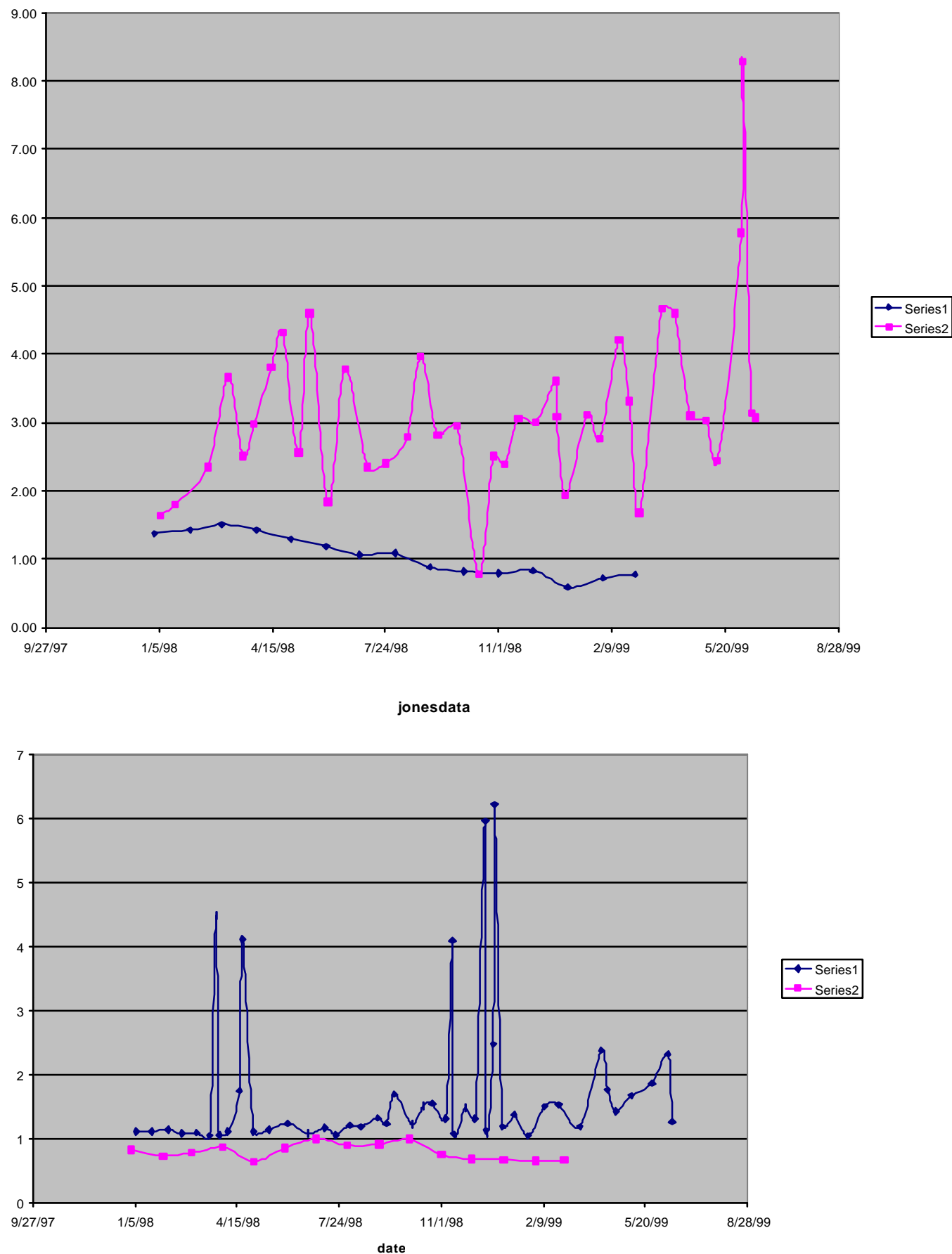

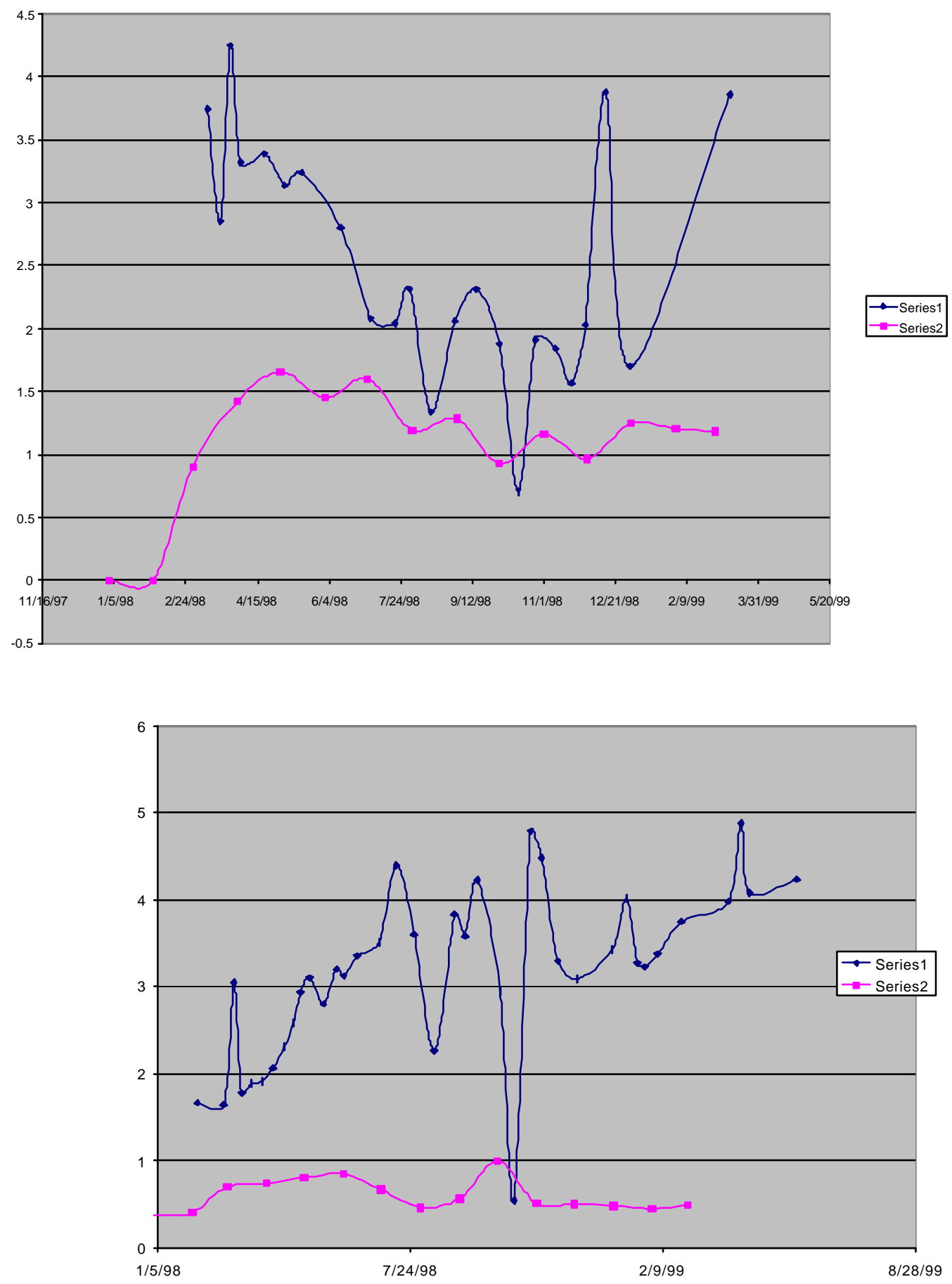

Another way of dealing with composition variability is to provide some storage capacity on site to dampen out the variations. If the feed gas to the project is made up of the discharge from several locations, this dampening effect may occur naturally. On the other hand, on-site storage may be the only positive way to ensure that composition variability is kept to a minimum. The cost effectiveness of this approach vs. having 
excess adsorbent capacity vs. having a back up DEA unit needs to be considered once a CMM gas composition representative of the project has been identified.

A complete analysis of this data awaits more erudite scrutiny, but the above 4 plots are of the time variations of flow and the sum of $\mathrm{CO}_{2}$ and $\mathrm{N}_{2}$. It appears that there may be some correlation between these two variables, suggesting that perhaps the flow is backed off if the $\mathrm{CO}_{2}$ plus $\mathrm{N}_{2}$ approaches the pipeline spec of $4 \%$.

\subsection{Rationale for Project Configuration}

In the course of investigating possible commercial uses for coal mine methane (CMM), the liquefaction of CMM to Liquefied Natural Gas (LNG) for use in the transportation sector emerged as a viable opportunity. This would be true especially if a low cost and efficient liquefier were available and the price of the feed gas were accommodating.

To illustrate this point further, LNG sold at 40 cents/gal. would correspond to about $\$ 3.50$ - $\$ 4.00 / \mathrm{MCF}$ on Figure 2, representing a value potential at least as great as power generation. If the project can secure low cost CMM and condition it to meet liquefier specs, there is a potential for an economically viable project.

As it turns out, a low cost, highly efficient liquefier is being developed by researchers at Los Alamos National Laboratory (LASL) and Cryenco. The basic feature of this unit is a Thermo-Acoustic Stirling Heat Engine and Refrigerator (TASHER). Cryenco is developing this technology for liquefying natural and industrial Gases.

The TASHER appears to offer low capital and operating costs at small scale (ca. $10,000 \mathrm{gal} /$ day) and would be an excellent fit with the needs of CMM projects, promising to produce LNG from appropriate CMM sources at selling prices that will be competitive in the transportation market as well as for on-site gas storage requirements of CMM electric generators.

The presently envisioned project will utilize Coal Mine Methane from an abandoned coal mine(s) and convert it to LNG by means of a thermoacoustic natural gas liquefier (TASHER). The LNG so produced will be distributed and sold primarily as transportation fuel to the trucking industry throughout the I-79 corridor in the vicinity of Morgantown, WV.

Appalachian-Pacific (AP) and Cryenco have signed an agreement confirming their intention to cooperate in a demonstration program that will include the construction and testing of a "second generation" TASHER at a scale of at least 500 gallons per day at Cryenco's Denver facility. If this demonstration meets certain technical and financial objectives, AP will purchase, install and operate a ca. 10,000 gal/day TASHER as part of Phase III of its project with DOE. 
Cryenco's current test plan for the 500 gal/day demonstration is based on a system which converts pipeline quality natural gas to LNG. Successful test results will represent a significant technological advance. However, the proposed demonstration requires additional elements for the technology to be applicable to CMM and to contribute to greenhouse gas reduction; namely, the inclusion of a cost effective, small gas cleanup system, and a marketing plan that will permit the successful selling of the LNG so produced.

A schematic diagram for the proposed CMM to LNG project is provided in Figure 8.

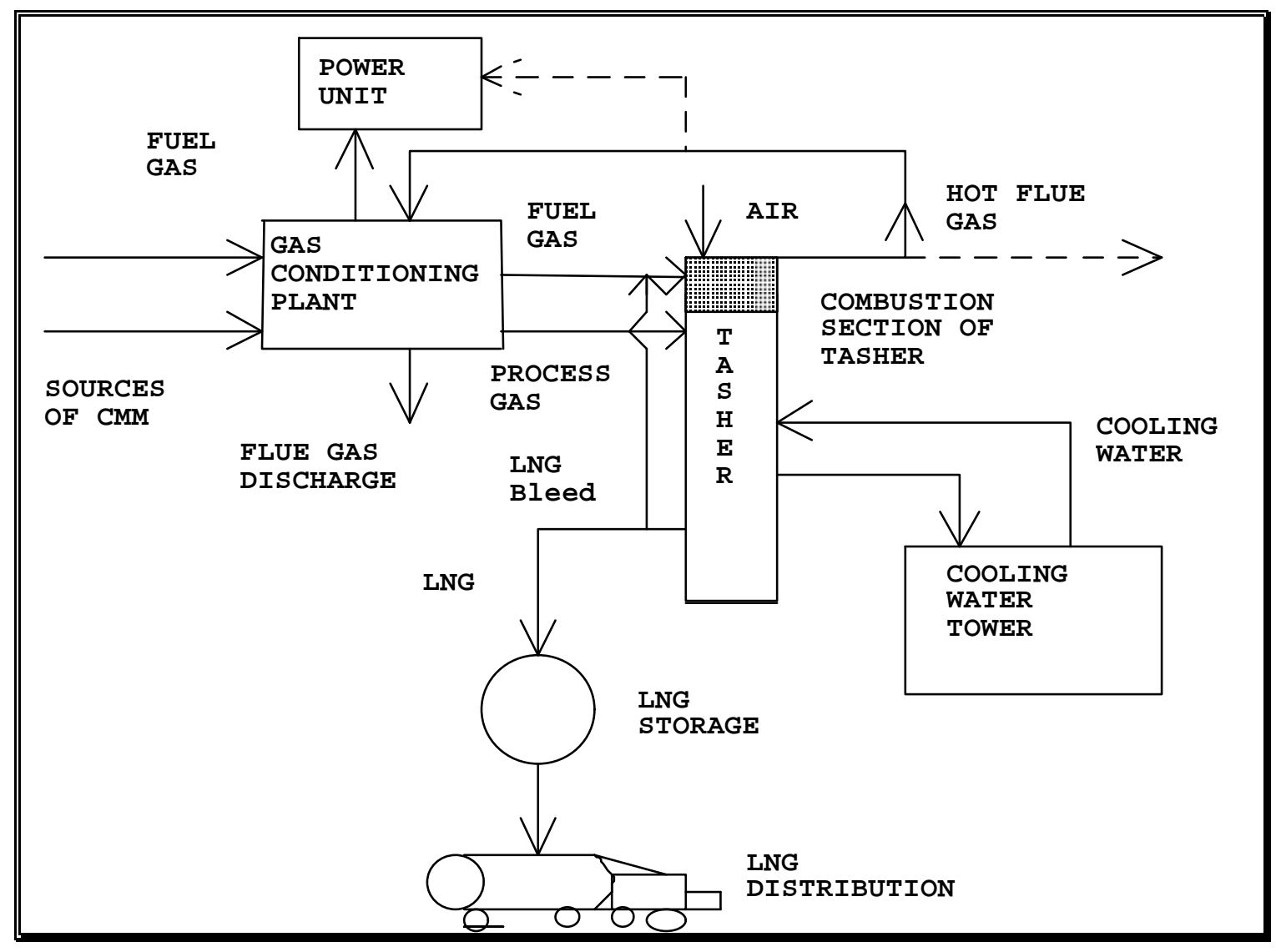

\section{Figure 8 Schematic of proposed CMM project}

For the project as currently envisioned, CMM would be provided from one or more sources to the Gas Conditioning unit, which would condition the gas to acceptable specs for the process side of the TASHER. The CMM also would be provided as fuel gas to the TASHER combustor and the power unit. In the TASHER combustor, the CMM fuel gas would be burned with air, creating a hot (200-300 deg F) flue gas. Some or all of this flue gas, discharged from the TASHER combustion chamber, could be recycled (if appropriate) to the Gas Conditioning Unit to regenerate spent sorbents. Similarly, the CMM fuel gas and air that combust in the power generation units also would create a hot flue gas that could be used as a waste heat source for either the TASHER or the gas conditioning unit. 


\subsection{TASHER Discussion}

A general description of the TADOPTR technology, which is the foundation for the TASHER development, is provided in the words of Cryenco on the following two pages.

Also, several papers discussing the physics of the TASHER and the TADOPTR are provided in Appendix 5 of this report and various illustrations may be found in section 7.2.1. 


\section{Cryenca}

TADOPTR Program

\section{Overview}

In 1994, Cryenco obtained the licensing rights to a new cryogenic refrigeration technology Thermoacoustically Driven Orifice Pulse Tube Refrigeration (TADOPTR). This technology has the unique capability of producing refrigeration power at cryogenic temperatures with no moving parts. Cryenco is developing this technology for application of liquefying natural and industrial gases. The technology is well suited for liquefaction capacities in the range of roughly 500 to 10,000 gallons per day. There are no technical barriers to developing systems with larger capacities.

\section{Program}

Cryenco's development program for TADOPTR has been divided into two phases. Phase I: development of a system with a liquefaction capacity of nominally 500 gallons per day (GPD). Phase II: development of a system with a liquefaction capacity of 5,000 - 10,000 GPD. These systems will fit on a standard, flat bed truck. At the end of 1996, Cryenco passed a significant milestone in Phase I; an engineering prototype TADOPTR successfully liquefied a stream of natural gas. Cryenco plans to complete the development of the 500 GPD TADOPTR in 1997.

\section{Background}

Thermoacoustically driven orifice pulse tube refrigeration was first demonstrated in 1989 by scientists from Los Alamos National Laboratory (LANL) and the National Institute of Standards and Technology (NIST). This demonstration was the successful marriage of two separate, but synergistic technologies - Thermoacoustic Drivers (TADs) developed at LANL and Orifice Pulse Tube Refrigeration (OPTR) developed at NIST. The synergy is that neither technology requires any moving parts.

The first demonstration unit at LANL reached a temperature of $-240^{\circ} \mathrm{F}$ with a refrigeration power

\section{Joliet Street \\ Denver, Colorado 80239}

(303) 371-6332

Fax: (303) 371-0267

equivalent to only about a $1 / 4^{\text {th }}$ of a gallon per day. The TADOPTR was patented by LANL. As part of the technology transfer program of the national laboratories, licensing rights to the technology were made available to private industry interested in commercialization. In 1993, Cryenco entered into a licensing agreement with LANL for the technology for the liquefaction of gases.

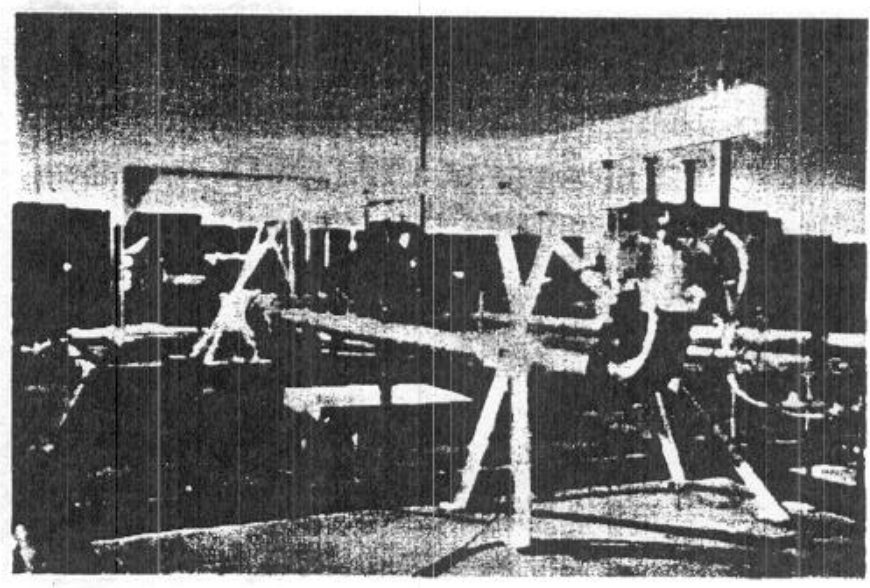

\section{Operation}

\section{The TADOPTR}

The TADOPTR consists of three major components.

1. The power source, a natural gas burner.

2. The TAD, a converter which changes the thermal input power to acoustic power, i.e. a pressure oscillation.

3. The OPTR, another converter which changes the acoustic power into heat removal, or thermal extraction power.

Heating one end of the TADOPTR to $1,400^{\circ} \mathrm{F}$ or higher, the other end cools to $-240^{\circ} \mathrm{F}$ or below. The only thing moving within the system is the working gas, typically helium. By creating a large temperature difference across a short section of a pipe filled with a working gas, the gas goes into spontaneous pressure oscillations. These oscillations are sustained by maintaining the required temperature difference with the continuous input of heat by a burner. 
ine Ur IK operates on a modined stirling refrigeration cycle, but the cold, moving displacer in a Stirling system is replaced by a gas column (or pulse tube), an orifice and a reservoir; all static components. These components are capable of cycling the working gas between a cold, heat extracting heat exchanger when the gas has been expanded and cooled by the TAD, and a warm, heat rejection heat exchanger when the gas has been subsequently compressed and heated by the TAD. Thus, the OPTR pumps thermal energy from a cold reservoir to a warm reservoir like any refrigeration device. The initial performance target for the TADOPTR is to burn $30 \%$ of an incoming natural gas stream to liquefy the remaining $70 \%$. This is projected to improve as development continues.

\section{Description}

The three components of a TADOPTR have three different characteristic dimensions. The OPTR is small; a 500 GPD unit has a characteristic dimension of a few feet. The burner is mediumsized, its length is 5 to 10 feet. The TAD is large, its length is roughly 40 feet. (Its width is only a couple of feet.) The TAD length is a function of the operating frequency chosen for the TADOPTR system, which, in turn, is a function of optimization of a number of system operating parameters. A picture of the first, large scale TADOPTR built by Cryenco is shown on the front page. The OPTR is the vertical section at the front, the TAD is the long tube in the middle, and the natural gas burner is at the back end of the TAD. This unit is designed to produce about 100 GPD of liquefied natural gas (LNG).

\section{Financing}

After Cryenco obtained the licensing rights to TADOPTR, it raised $\$ 800,000$ in private venture capital funds to support the initiation of Phase I. In May 1995, Cryenco received a contract for $\$ 452,500$ from the Advanced Research Program Agency of the U.S. Government, most of which has been directed toward supporting Phase I TADOPTR development. In addition to these sources, Cryenco has invested considerable internal funds in support of the program. The U.S. Department of Energy provides funding to LANL to pursue fundamental research on thermoacoustics in parallel with Cryenco's commercialization efforts.

\section{Markets}

Cryenco is investigating numerous potential market applications for the TADOPTR, for both the small scale, 500 GPD units and the large scale, 10,000 GPD units. Those market applications include: natural gas liquefaction at remote gas and oil wells, natural gas liquefaction at offshore oil wells, natural or industrial boil-off gas reliquefaction at large scale storage facilities, industrial gas liquefaction in conjunction with air separation systems, natural gas liquefaction from landfill and waste water treatment facilities, natural gas liquefaction from pipeline gas for application to the transportation and other industries. Each of these potential markets has its own unique criteria and operating conditions that will have to be addressed. For the

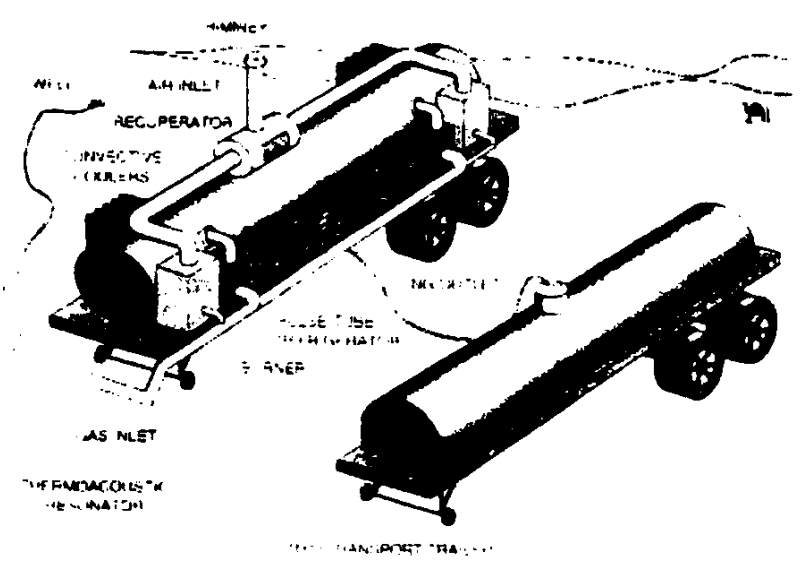

\section{Artist's rendering of the TADOPTR}

natural gas liquefaction applications, another attractive feature of this technology is that the power source is also natural gas.

\section{Related Activities}

During the development of the TADOPTR, Cryenco has expanded its program to include smaller scale, OPTR-based, refrigeration/ liquefaction systems which use an alternative, electrical input power source. These systems, Orifice Pule Tube Refrigeration Liquefiers (LOPTRs) are being developed with liquefaction capabilities from roughly 10 to 500 GPD, although there are no technical limits on going to larger sizes. These systems are expected to address additional markets which require cryogenic liquids. 


\subsection{Gas Conditioning Discussion}

The CMM, conditioned to meet TASHER specs, would be supplied to the TASHER as process gas, where it would be converted to LNG, stored and shipped to market. The cooling requirements of the TASHER will be provided by cooling water, which is cooled on site by means of a cooling tower.

The electrical requirements for this operation may be provided by purchased electricity or by electricity generated in a small (ca. $300 \mathrm{~kW}$ ) gen. set.

The specs for the CMM to be converted to LNG would be similar to those for the feed gas in cryogenic processes, generally. The CMM will have to be dried to a dew point of -150 degrees $\mathrm{F}$, and the $\mathrm{CO}_{2}$ content must be reduced to about $50 \mathrm{ppm}$ to avoid the formation of dry ice in the orifice refrigeration section of the TASHER. Depending upon the amount of higher hydrocarbons in the CMM, it could be advisable to remove them (e.g. by mechanical refrigeration) from the CMM prior to its injection into the TASHER.

A block flow diagram for accomplishing this conditioning, based upon the composition of the gob gas which the project team sampled during its earlier studies of the Cumberland mine, is shown on Figure 9. Also shown for comparison purposes are the gas conditioning steps needed to achieve pipeline quality standards. Notice the similarity to the Block Flow Diagram for conditioning CMM to PQ gas. The project now being developed avoids the initial gathering, storage and transmission steps, but most of the gas conditioning processes seem to be needed. Actually, while the specifications on the TASHER feed are quite stringent with respect to water and carbon dioxide, they may be more relaxed with respect to nitrogen, offering the possibility of avoiding the costly NRU step. 


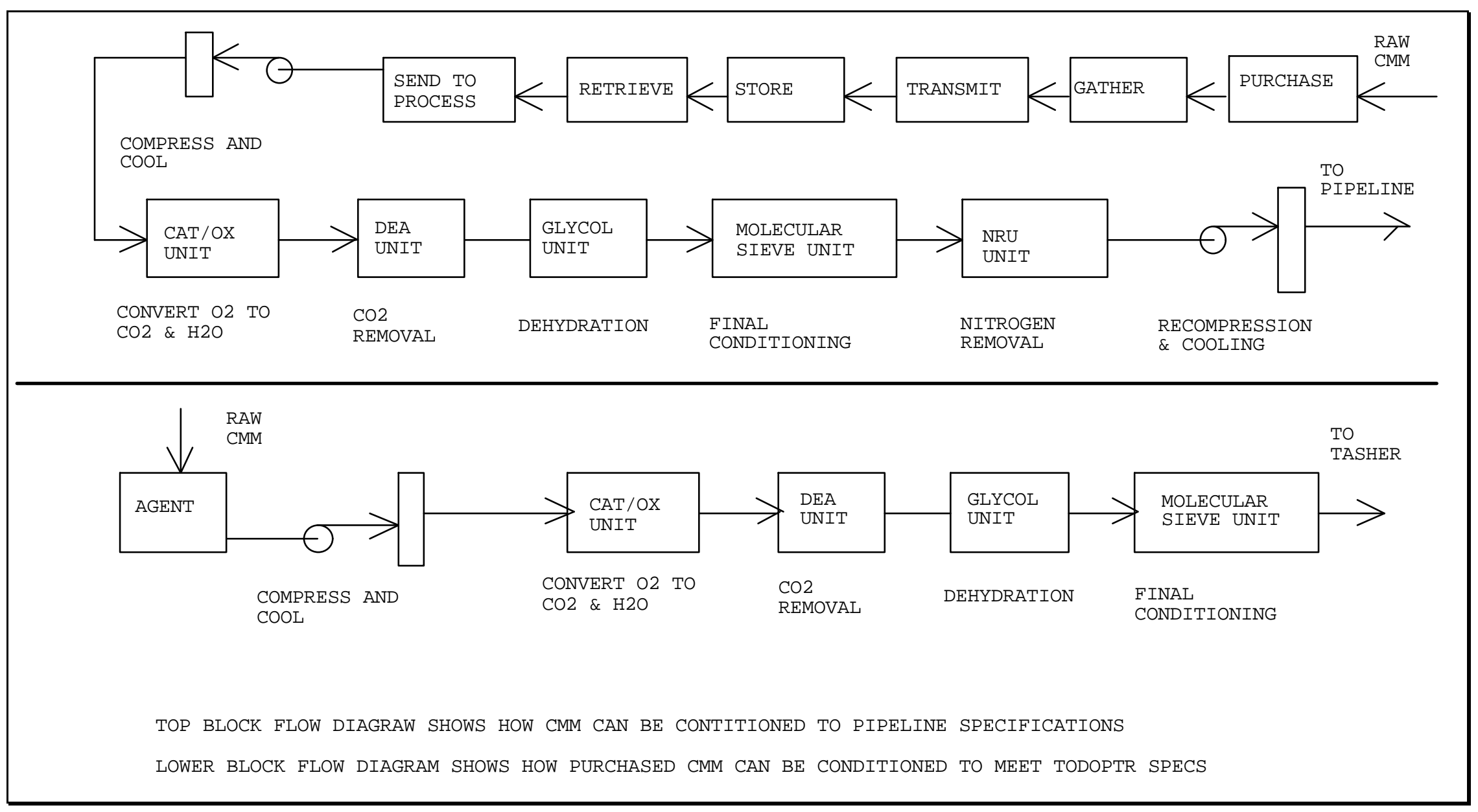

Figure 9 Block Diagram of Gas Constituent Removal from CMM 


\subsection{1 $\mathrm{CO}_{2} \& \mathrm{H}_{2} \mathrm{O}$ Removal Processes}

There are several commercial processes for removing $\mathrm{CO}_{2}$ from gas streams. Generally these processes remove acid gases $\left(\mathrm{H}_{2} \mathrm{~S}\right.$ and $\left.\mathrm{CO}_{2}\right)$ and find most application in gas sweetening $\left(\mathrm{H}_{2} \mathrm{~S}\right.$ removal). Technically there should be no problem finding a way to condition CMM to meet the specs for the TASHER. The challenge will be to find a process that fits the size of the operation, the remoteness and austerity of the location, the (possible) composition variation in the $\mathrm{CMM}$ and the operational durability required to achieve economic viability.

The following technologies report ability to reduce inlet $\mathrm{CO}_{2}$ to levels at or below 50 ppmv:

- Diethanolamine (Societe Nationale Elf- Aquitaine version)

- Sulfinol

- Benfield (Union-Pure version)

- Catacarb

- Rectisol

- Molecular Sieves

The following technologies report ability to achieve minus 150 degree $\mathrm{F}$ dew point:

- Drizo Process

- Molecular Sieves

Most of these technologies involve the use of an absorbing solvent which contacts the feed gas (in this case the CMM) in an absorber unit at one set of conditions (e.g. high pressure and low temperature) selected to maximize the absorption of the unwanted gas constituent(s) $\left(\mathrm{CO}_{2}\right.$ and $\mathrm{H}_{2} \mathrm{O}$ in our case). The solvent is then circulated to a second unit, the regenerator, where the dissolved gases are released by a combination of heating and pressure release. On the way to the regenerator the solvent passes through a pressure let down drum where some of the dissolved gases are released. This general scheme is depicted in Figure 10. The processes listed above follow this general flow chart, but with exceptions and refinements geared to improving various aspects of the process such as efficiency, cost, selectivity, etc. 


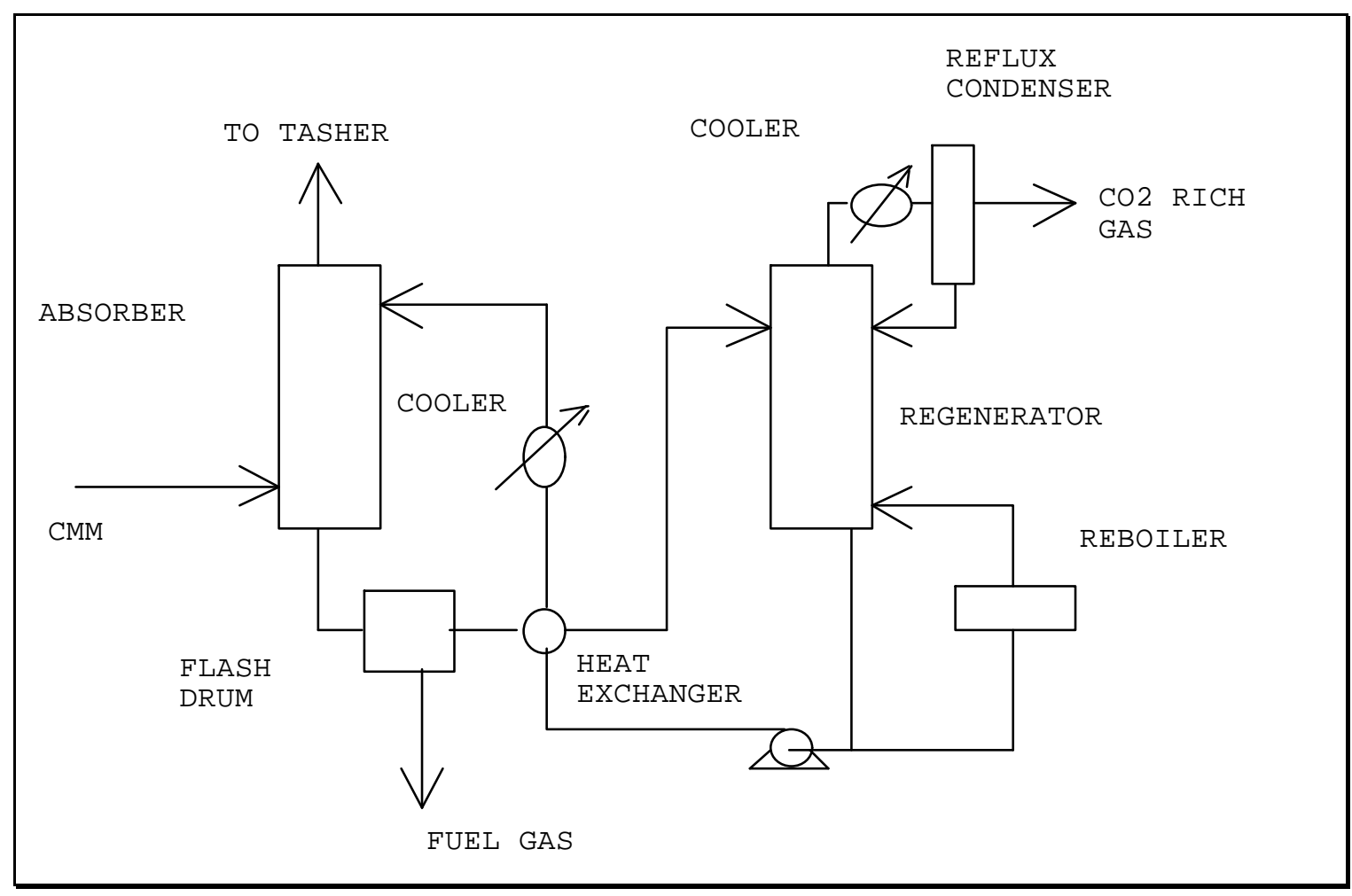

Figure 10 Typical flow diagram of Absorbing Systems 
Molecular sieves (or other solid adsorbents) also follow this general concept except that the sieves themselves are not circulated between an adsorber unit and a regenerator, but rather remain in a given tower which undergoes alternate cycles of adsorption and regeneration. See Figure 11.

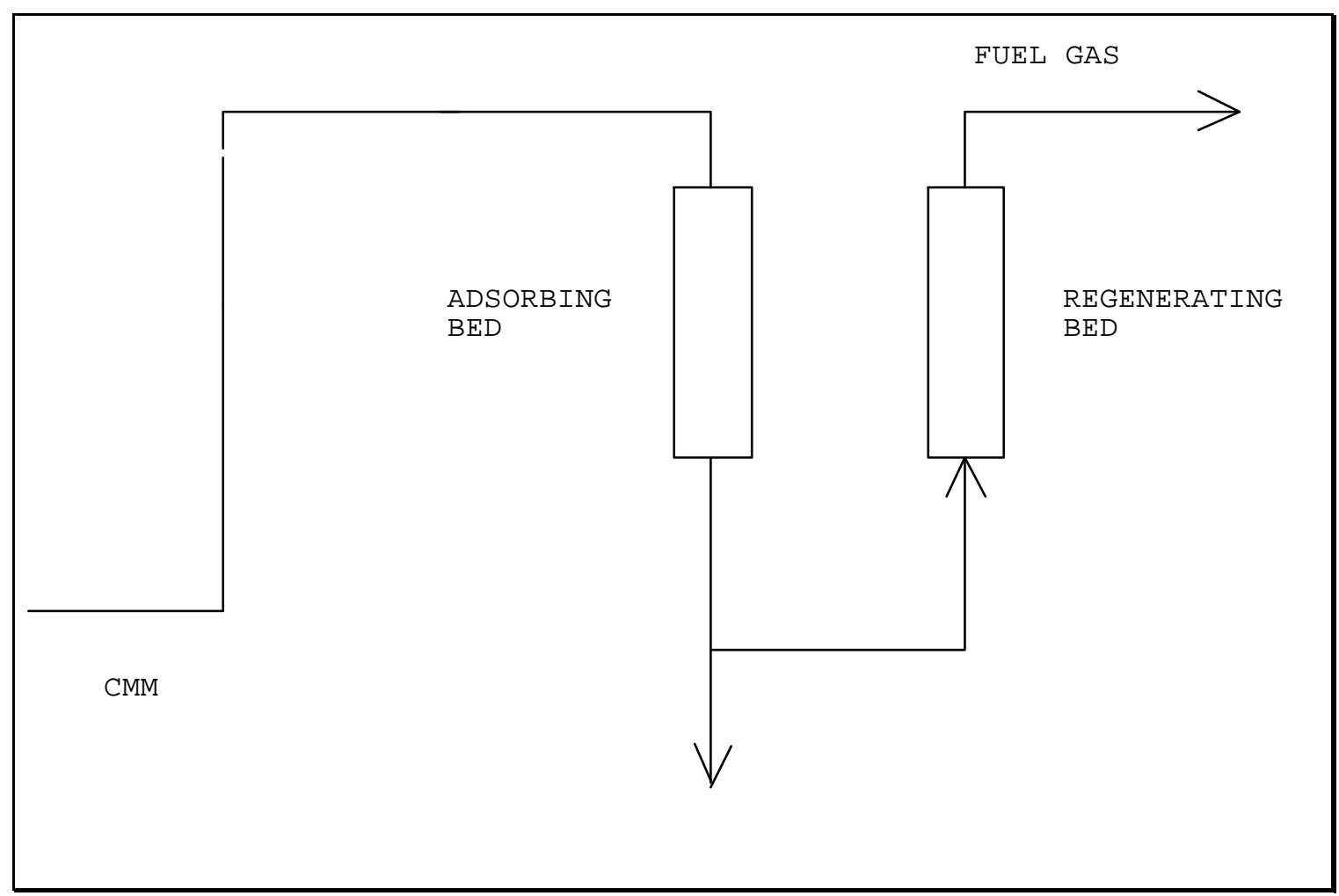

Figure 11 Typical flow diagram of Adsorption Systems (Molecular Sieves)

\subsubsection{Nitrogen Removal Processes}

The presence of nitrogen in the CMM does not appear to present the problem for converting CMM into LNG as it does if CMM is introduced directly into a natural gas pipeline. In the latter case, the nitrogen has to be removed to the level of pipeline specification, using expensive nitrogen rejection processes. For LNG production via the TASHER, the nitrogen is expected to pass mostly uncondensed through the unit without causing major operational problems. This uncondensed gas (which will also contain some methane) can be used as a portion of the fuel gas firing the TASHER.

However, if the oxygen is not removed prior to introduction of CMM to a cryogenic unit, it must be shown that it will not pose a significant safety problem to the entire gas conditioning system. To illustrate that this will not be a problem, the following analysis is provided. Equilibrium data for the nitrogen - methane system are available (7). It is also possible to compute the equilibrium conditions by using Raoult's Law. Figures 12 and 13 show the comparison of the two sets of data for a given temperature. (It is possible to carry out these calculations for other temperatures, and this has been done.) 


\section{COMPARISON OF EQUILIBRIUM DATA AND RAOULT LAW CALCULATION FOR NITROGEN-METHANE SYSTEM AT - 162.2 DEG C}

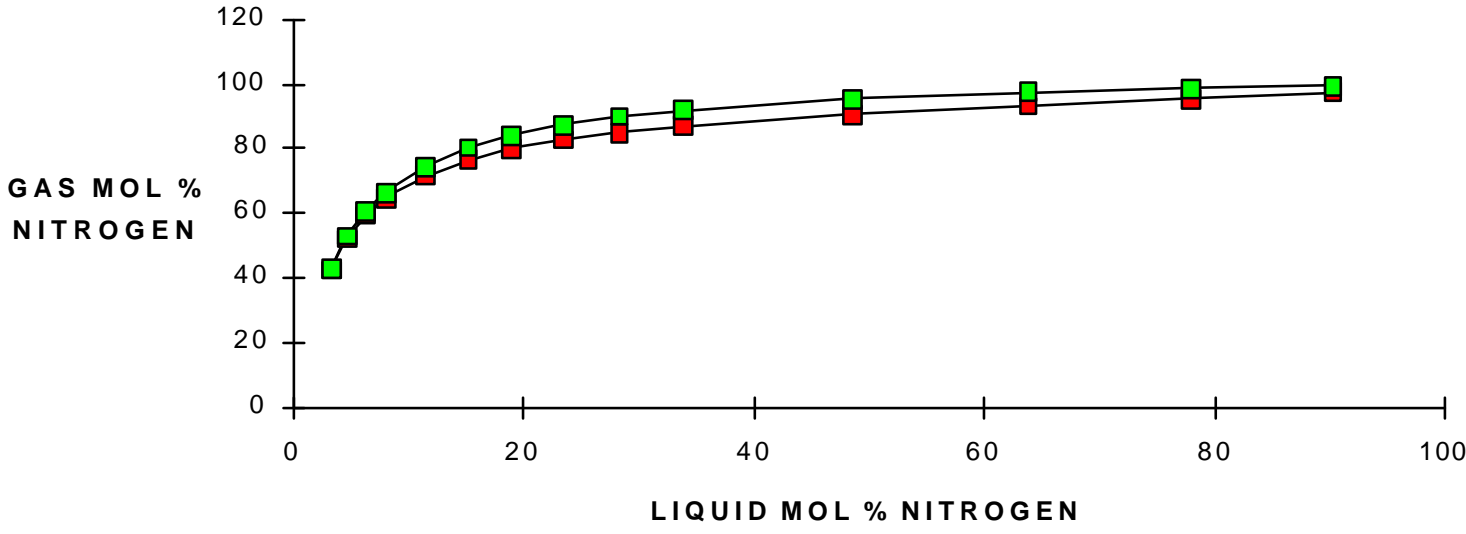

Figure 12 Comparison of Equilibrium data and Raoult's Law for $\mathrm{CH}_{4}-\mathrm{N}_{2}$ system

\section{COMPARISON OF EQUILIBRIUM DATA AND RAOULT LAW CALCULATION FOR NITROGEN-METHANE SYSTEM AT - 162.2 DEG C}

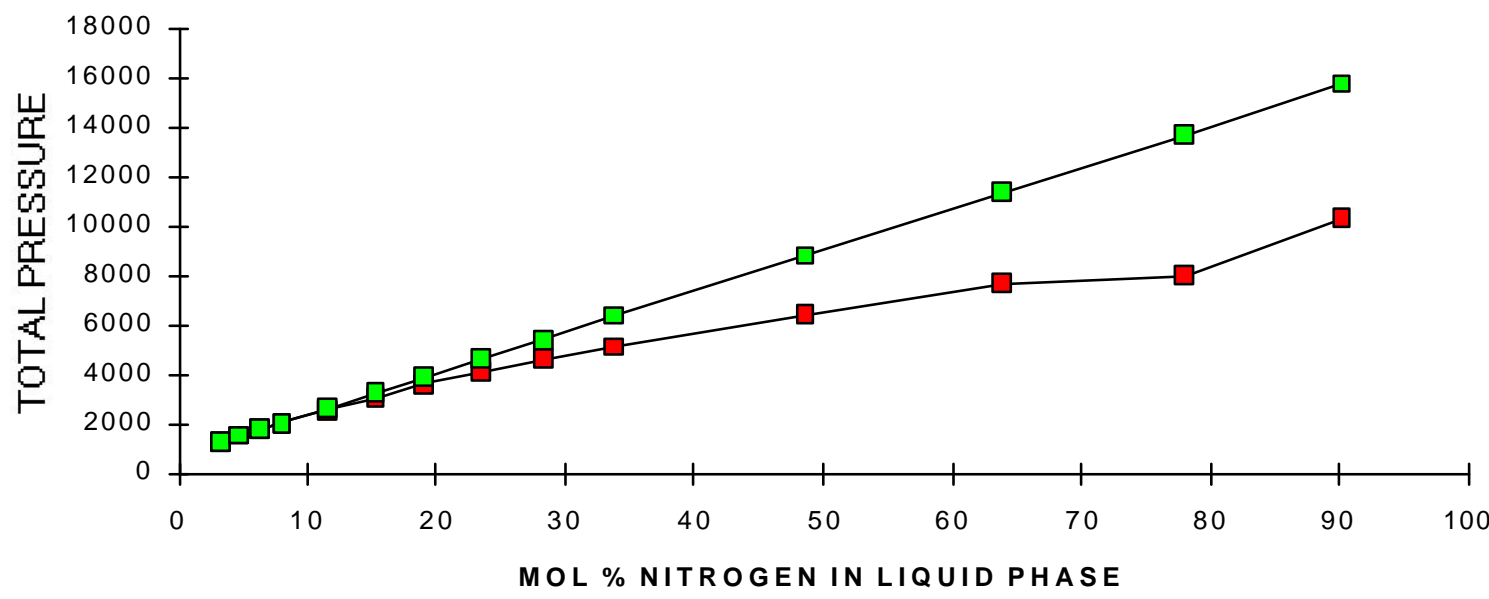

Figure 13 Comparison of Equilibrium data and Raoult's Law for $\mathrm{CH}_{4}-\mathrm{N}_{2}$ system

Examination of the graphs shows a very good agreement between the calculation and the experimental data for nitrogen (liquid) (Figures $12 \& 13$ ) contents below about $20 \%$. This is of course, the region of interest. 


\begin{tabular}{|llllll|}
\hline $\begin{array}{l}\text { Temperature } \\
\text { (deg C) }\end{array}$ & $\begin{array}{l}\text { Pressure } \\
\mathrm{mmHg}\end{array}$ & $\begin{array}{l}\mathrm{N}_{2} \\
(\text { mole\% })\end{array}$ & $\begin{array}{l}\mathrm{O}_{2} \\
(\text { mole\% })\end{array}$ & $\begin{array}{l}\mathrm{CH}_{4} \\
(\mathrm{~mole} \%)\end{array}$ \\
Case 1 -168.8 & 708 & .026 & .017 & .957 \\
Liquid & & .390 & .069 & .541 \\
Vapor & & & & \\
& & & .028 & .017 & .955 \\
Case 2 & -161.5 & 1297 & .373 & .068 & .560 \\
\hline Liquid & & & &
\end{tabular}

Table 6 Calculated Equilibrium Conditions for Ternary $\mathrm{CH}_{4}-\mathrm{O}_{2}-\mathrm{N}_{2}$ System

Table 6 shows the results of calculations based upon Raoult's Law for the ternary system, Nitrogen, Oxygen and Methane, for two temperatures, $-168.8 \mathrm{deg} \mathrm{C}$ and -161.5 $\operatorname{deg} \mathrm{C}$. While the more volatile Nitrogen and Oxygen tend to concentrate more in the vapor phase, the ensuing composition is still more than 50\% methane and less than $7 \%$ Oxygen, which is well above the rich flammability limit. In case 1 the methane to oxygen ratio is 7.96 ; in case 2, this ratio is 8.24 . For methane in oxygen, the higher explosive limit is 1.4 ; for methane in air, the higher flammability limit is 0.2 .

So it can be seen that the Oxygen and Nitrogen, at concentrations such as shown in Table 6, should not provide a flammability problem in the TASHER.

In practice it should be relatively straightforward to carry out this concept. This is illustrated in Figure 14. The effluent from the refrigeration section of the TASHER will enter a storage tank, at a location near the bottom. Uncondensed (or undissolved) gases will bubble through the liquid contents of this tank and exit through a vapor release valve at or near the top of the tank. This vapor will be in equilibrium with the liquid. By maintaining the release valve at a pressure of (say) 25 psig, corresponding to the solution temperature of $-161.5 \operatorname{deg} \mathrm{C}$, the exiting vapor will have the composition given in Table 6 , while the liquid will have the corresponding liquid composition given in the table.

The vapor, well above the rich explosive limit, will be mixed with other gas streams that will be even richer in methane and combusted in the TASHE section of the TASHER. The liquid will be withdrawn from the tank and sent to market. Since the LNG (solution) can only become warmer, any vapor that escapes further from the solution will be even richer in methane than the mixture used in the combustor (the composition given in Table 6), and be even further beyond the rich explosive limits. 


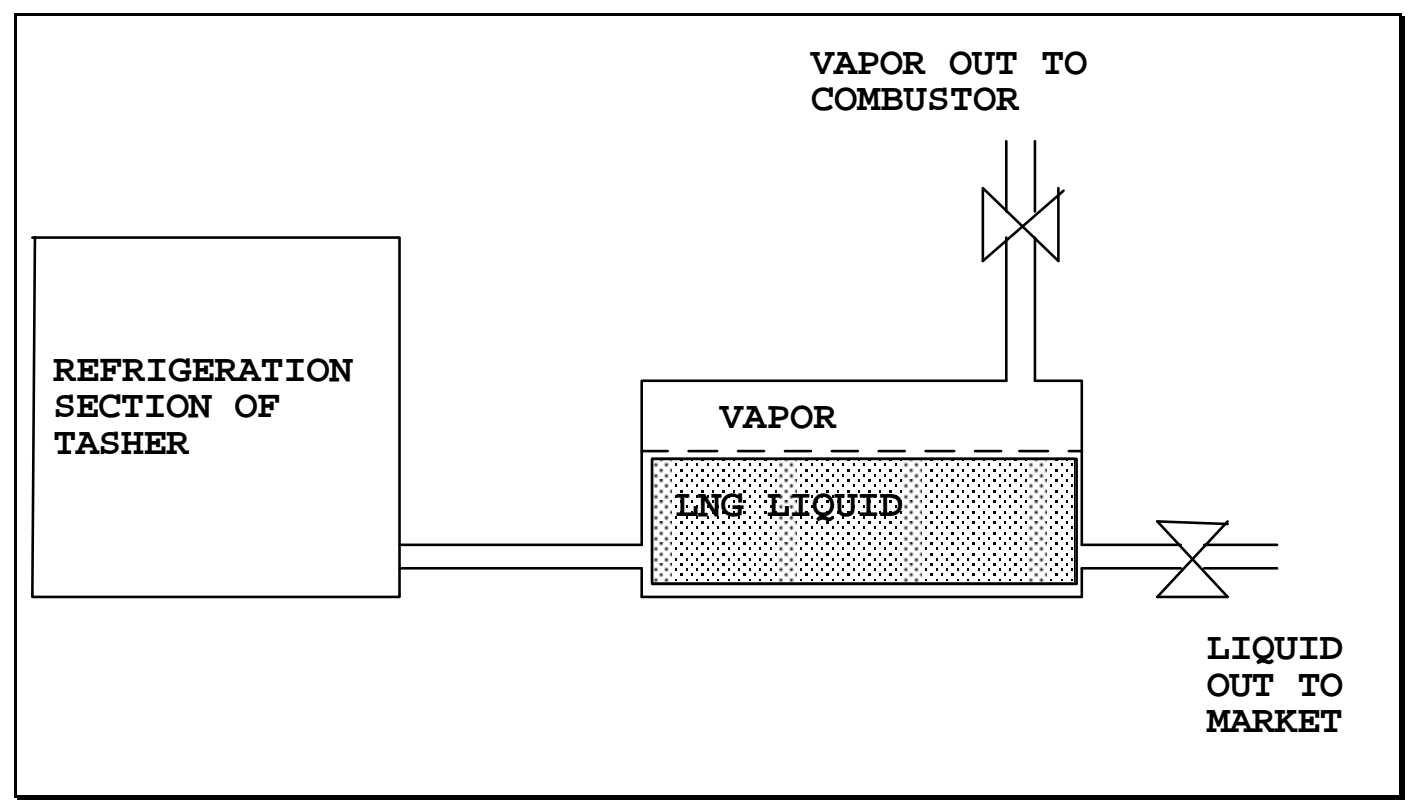

Figure 14 Illustration of Removal of LNG and Uncondensed Gases from TASHER

\subsubsection{Oxygen Removal Process}

The proposed project plans, therefore, to avoid the costly removal of oxygen and nitrogen and the further removal of the Oxygen reduction products, $\mathrm{CO}_{2}$ and $\mathrm{H}_{2} \mathrm{O}$, which are required in order to avoid the formation of solid products (ice and dry ice) in the refrigeration unit. This can be made possible by maintaining the refrigeration temperature at such a level as to liquefy most of the methane, but allow the methane partial pressure to be at such a level, that the uncondensed methane forms a mixture with the oxygen that is above the (high) explosive limit for methane in oxygen. This concept is illustrated in Figure 15.

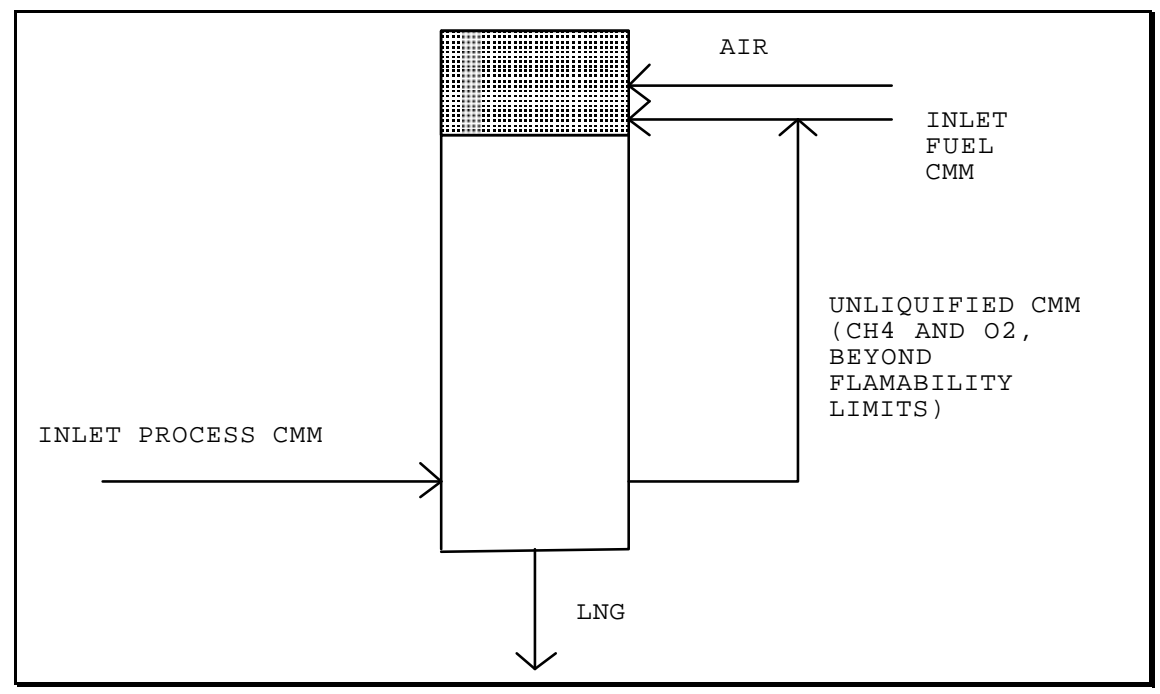

Figure 15 Removal of Oxygen from the inlet CMM can be avoided, if certain precautions are taken. 
However, the presence of oxygen may pose other problems for certain of the gas conditioning processes. When molecular sieves are used, the regeneration is accomplished by heating the bed while passing a stripping gas (at a lower pressures, perhaps, that used during adsorption) through the bed. This stripping gas must be free of $\mathrm{CO}_{2}$ and $\mathrm{H}_{2} \mathrm{O}$. Even the presence of $\mathrm{O}_{2}$ may be disallowed, because it could combust with some of the methane while being heated for the regeneration cycle. If this is the case, a catalytic reduction unit will have to be installed prior to the mol sieve unit - see Figure 16.

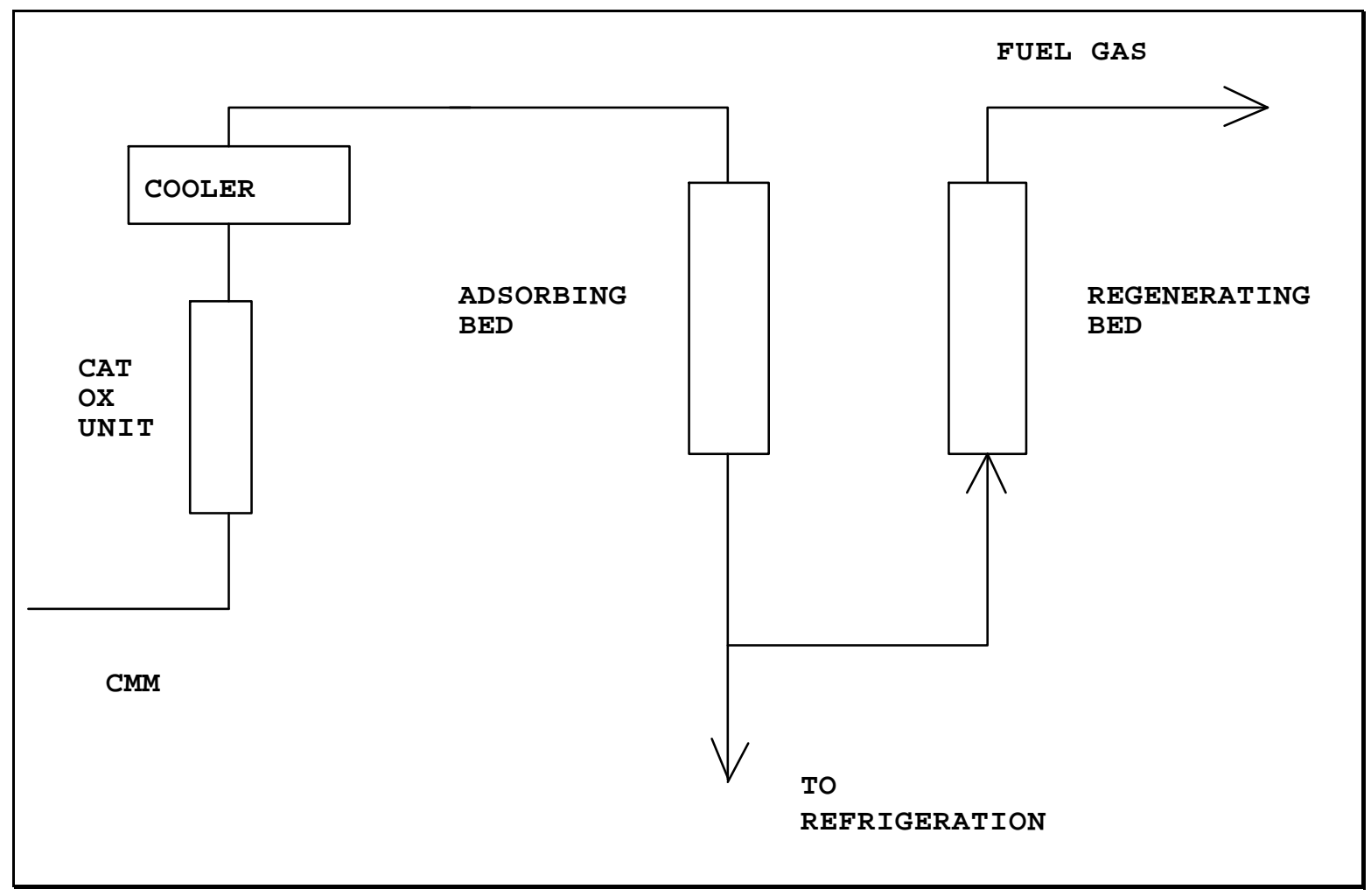

\section{Figure 16 Block diagram of Gas Conditioning System using Molecular Sieves}

The flow scheme in Figure 16 represents several awkward process features. The amount of heat released in the catalytic reduction unit is sizable, and the unit itself may be quite expensive. The whole reason for the reduction is to permit the regeneration gas to be oxygen free. With this in mind, it may be possible to reduce catalytically only that portion of the CMM stream, which is used for regeneration, Figure 17. This allows the cat-red unit to be much smaller (4). However, there is still the need for the gas stream passing through the regenerating bed to provide the heating necessary for regeneration. This may require this stream to be a large fraction of the feed.

In many mol sieve applications, there is a use for this stream. Often, this gas is sent to a pipeline (as in the top case shown earlier in Figure 9) or it can be used as a fuel. While the present project has some need for fuel gas, it is not clear that there is a 
convenient match between the gas required for regenerating the mol sieve beds and the fuel demand of the TASHER.

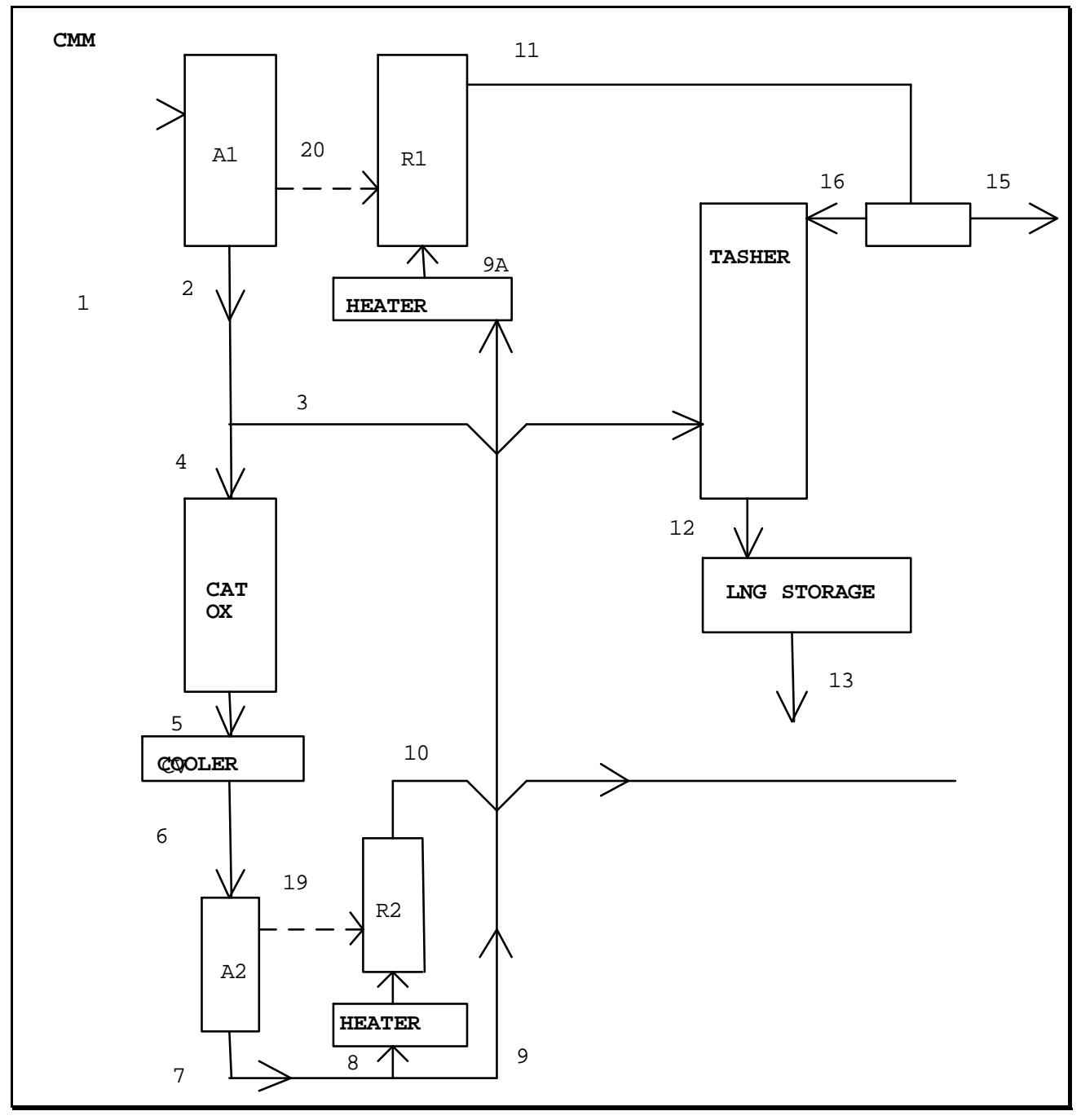

\section{Figure 17 Alternate Block Diagram of Gas Conditioning System Using Molecular Sieves}

So it would appear that the project might be best served by a gas conditioning facility in which regeneration is accomplished without the need to use a considerable portion of the feed gas. However, this conclusion may not be entirely correct if the purification levels of absorbing systems prove to be inadequate or if there is a marked change in gas composition from the base case considered here. There is a definite need to study the problem further and to conduct field tests with the small TASHER prototype (500 gpd PDU) scheduled for operation later this year. 


\subsection{Technical Description of Project}

\subsection{Overall Process Diagram - Heat and Material Balances}

Based upon the general discussion provided in the previous section, the overall process flow diagram for the process is provided in Figure 18. A molecular sieve unit, in and of itself, is not able to provide sufficient conditioning for a CMM of the composition of the Cumberland/Emerald mine gob gas discussed earlier (5).

The raw CMM is compressed to system pressure and cooled to the inlet specification for the DEA process. The project team proposes the SNPA version, a process schematic of which is given in Figure 19. The sweet gas is then sent to a Drizo dehydration unit, which is shown in schematic form in Figure 20. It may be necessary to complete the $\mathrm{CO}_{2}$ and $\mathrm{H}_{2} \mathrm{O}$ removal with a mol sieve unit, but such a unit is not provided for at this time. It may also be necessary to remove oxygen. This provision is not included here either, but technical and cost information continues to be assembled.

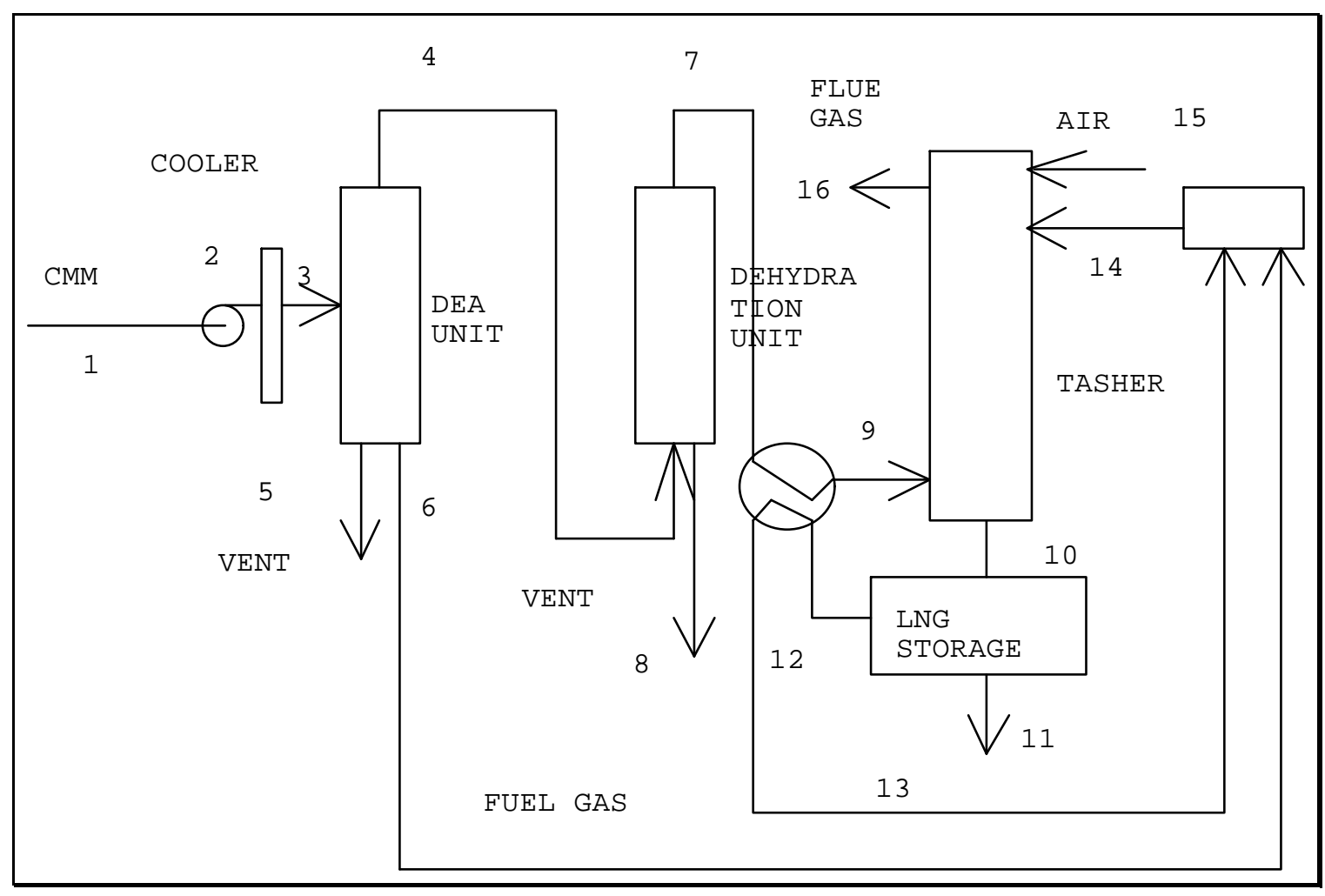

Figure 18 Proposed Project Flow Diagram 
Table 7 provides a heat and material balance for the system depicted in Figure 18.

\begin{tabular}{|c|c|c|c|c|c|c|c|c|c|}
\hline \multirow[t]{33}{*}{ STREAM } & COMPONENT: & $\mathrm{CH}_{4}$ & $\mathrm{~N}_{2}$ & $\mathrm{CO}_{2}$ & $\mathrm{O}_{2}$ & $\mathrm{H}_{2} \mathrm{O}$ & TOTAL & $\begin{array}{r}\text { TEMP } \\
(\mathrm{DEG} \mathrm{K})\end{array}$ & $\begin{array}{l}\text { PRES } \\
\text { (PSI) }\end{array}$ \\
\hline & 1 SCFD & 1242686 & 114284 & 6833 & 0 & 13709 & 1377512 & 294 & 14.7 \\
\hline & KBTU/D & 0 & 0 & 0 & 0 & 0 & 0 & & \\
\hline & 2 SCFD & 1242686 & 114284 & 6833 & 0 & 13709 & 1377512 & 620 & 600 \\
\hline & KBTU/D & 20595 & 1271 & 110 & 0 & 179 & 22155 & & \\
\hline & $3 \mathrm{SCFD}$ & 1242686 & 114284 & 6833 & 0 & 13709 & 1377512 & 294 & 600 \\
\hline & KBTU/D & 0 & 0 & 0 & 0 & 0 & 0 & & \\
\hline & 4 SCFD & 1118417 & 102856 & 0 & 0 & 12338 & 1233611 & 294 & 600 \\
\hline & KBTU/D & 0 & 0 & 0 & 0 & 0 & 0 & & \\
\hline & 5 SCFD & 0 & 0 & 6833 & 0 & 0 & 6833 & 294 & 20 \\
\hline & KBTU/D & 0 & 0 & 0 & 0 & 0 & 0 & & \\
\hline & 6 SCFD & 124269 & 11428 & 6833 & 0 & 1371 & 143901 & 294 & 600 \\
\hline & KBTU/D & 0 & 0 & 0 & 0 & 0 & 0 & & \\
\hline & 7 SCFD & 1006576 & 92570 & 0 & 0 & 0 & 1099146 & 294 & 600 \\
\hline & KBTU/D & 0 & 0 & 0 & 0 & 0 & 0 & & \\
\hline & 8 SCFD & 0 & 0 & 0 & 0 & 12338 & 12338 & 294 & 20 \\
\hline & KBTU/D & 0 & 0 & 0 & 0 & 0 & 0 & & \\
\hline & 9 SCFD & 1006576 & 92570 & 0 & 0 & 0 & 1099146 & 250 & 30 \\
\hline & KBTU/D & -1681 & -134 & 0 & 0 & 0 & -1815 & & \\
\hline & 10 SCFD & 1006576 & 92570 & 0 & 0 & 0 & 1099146 & 112 & 30 \\
\hline & KBTU/D & -15295 & -534 & 0 & 0 & 0 & -15829 & & \\
\hline & 11 SCFD & 825392 & 25528 & 0 & 0 & 0 & 850920 & 112 & 30 \\
\hline & KBTU/D & -12542 & -147 & 0 & 0 & 0 & -12689 & & \\
\hline & 12 SCFD & 181184 & 67043 & 0 & 0 & 0 & 248226 & 112 & 30 \\
\hline & KBTU/D & -1076 & -386 & 0 & 0 & 0 & -1463 & & \\
\hline & 13 SCFD & 181184 & 67043 & 0 & 0 & 0 & 248226 & 250 & 30 \\
\hline & KBTU/D & -303 & -97 & 0 & 0 & 0 & -400 & & \\
\hline & 14 SCFD & 305452 & 78471 & 6833 & 0 & 1371 & 392127 & 294 & 30 \\
\hline & KBTU/D & 0 & 0 & 0 & 0 & 0 & 0 & & \\
\hline & 15 SCFD & 0 & 2757797 & 0 & 733085 & 0 & 3490882 & 294 & 30 \\
\hline & KBTU/D & 0 & 0 & 0 & 0 & 0 & 0 & & \\
\hline & 16 SCFD & 0 & 2836268 & 312285 & 146617 & 612275 & 3907446 & 294 & 30 \\
\hline & KBTU/D & 0 & 0 & 0 & 0 & 0 & 0 & & \\
\hline
\end{tabular}

Table 7 Heat and Material Balances for Project 


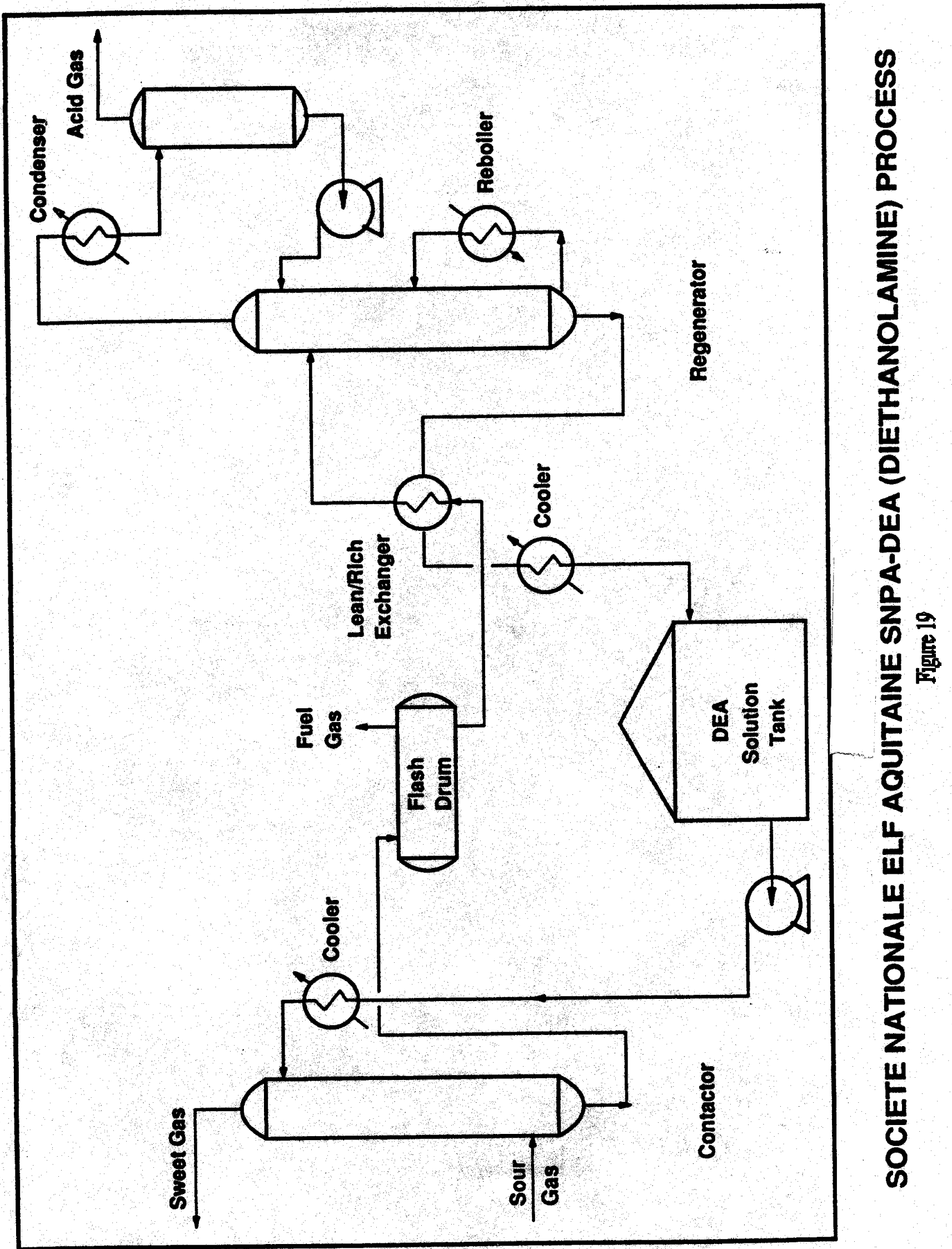




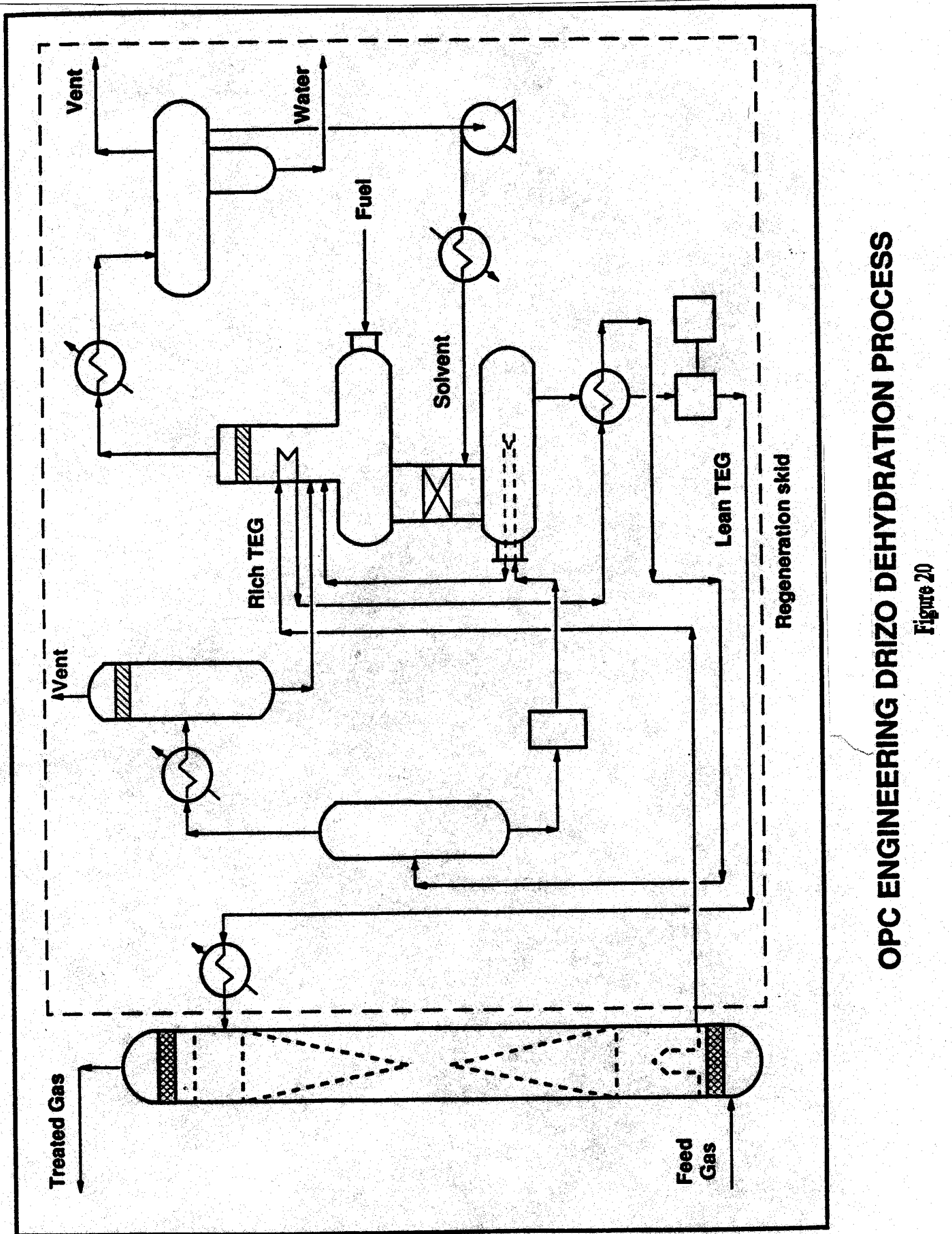


An alternative to the configuration shown in Figure 18 is provided in Figure 21 and is worth a brief discussion. If the CMM that is finally used in the project is really free of oxygen, then it would be possible to treat it with a less sophisticated DEA and glycol system, followed by a final clean-up with a molecular sieve unit. (Again recall that if the $\mathrm{CO}_{2}$ content is relatively high e.g. $>1 \%$, a molecular sieve unit alone would not be able to handle the job.)

This concept is illustrated in Figure 21. As in the previous discussion, $\mathrm{CO}_{2}$ and water will be removed by standard DEA and Glycol removal systems. This will lower the $\mathrm{CO}_{2}$ and water content of the gas to levels that are appropriate to mol sieve treatment. This system could be cheaper to build and to operate than the previous one, and it is not completely ruled out at this time.

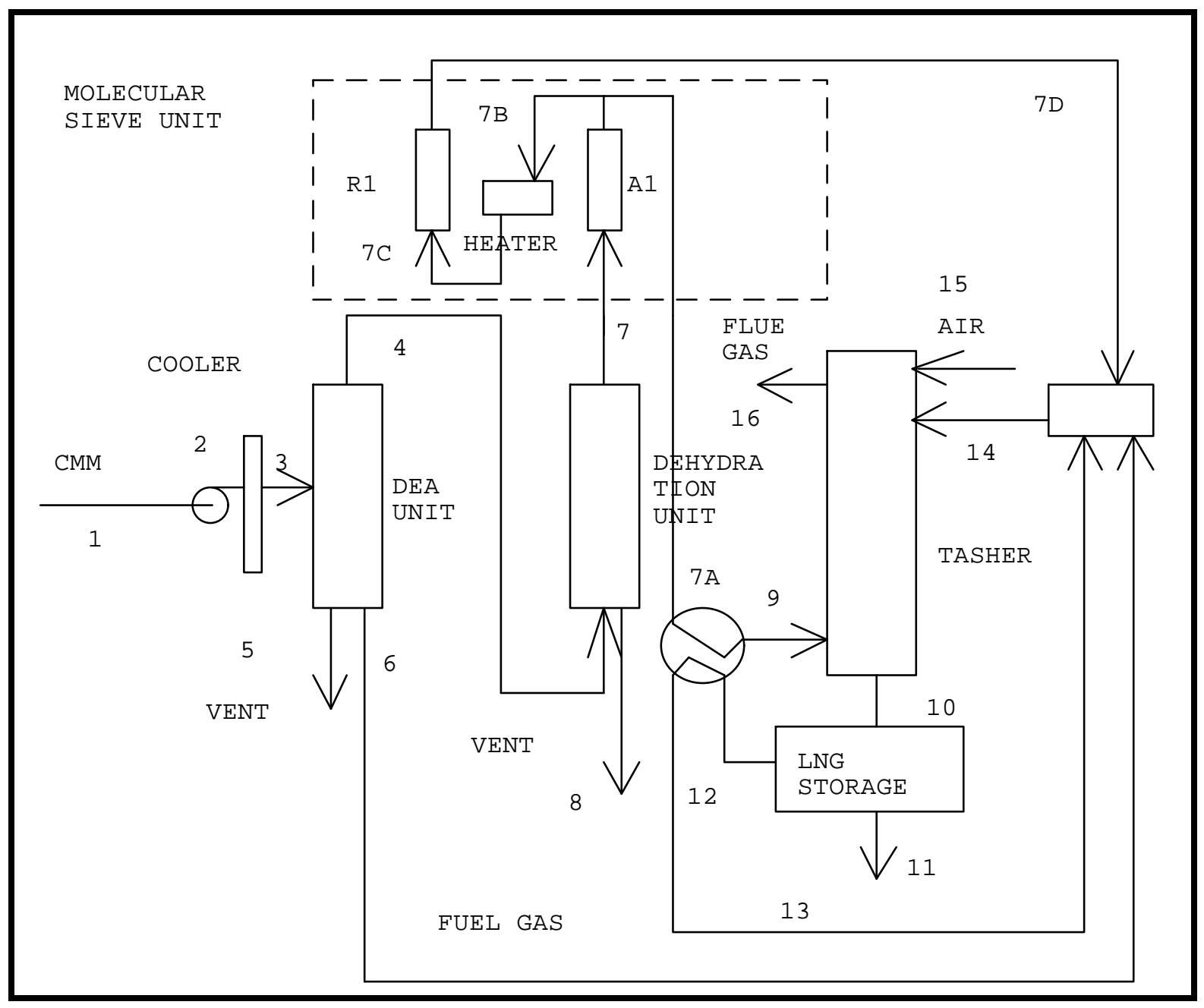

Figure 21 Alternative Gas Conditioning System, Showing the Addition of a Molecular Sieve Unit to Provide a Final Toning to the Conditioned CMM. 


\subsection{Description of individual processes}

\subsubsection{TASHER}

One of the proposed uses for CMM is as a feed source for an LNG plant. The liquefaction of CMM to Liquefied Natural Gas (LNG) for use in the transportation sector has emerged as a viable opportunity. A low cost, highly efficient liquefier is being developed by researchers at Los Alamos National Laboratory (LASL) and Cryenco. The basic feature of this unit is a Thermo-Acoustically Driven power source, which drives the refrigeration cycle involving an Orifice Pulse Tube Refrigerator (TASHER). Cryenco is developing this technology for liquefying natural and industrial gases.

The TASHER appears to offer low capital and operating costs at small scale (ca. $10,000 \mathrm{gal} /$ day) and would be an excellent fit with the needs of CMM projects, promising to produce LNG from appropriate CMM sources at selling prices that will be competitive in the transportation market as well as for on-site gas storage requirements of CMM electric generators.

The TASHER consists of a thermal driver and pulse tube orifice refrigerator. The energy for the thermal driver is provided by the combustion of a fuel such as natural gas or CMM. The specs on this fuel would be similar to those for any combustion device.

The TASHER has been described generally in Section 6.1.

A schematic, provided by Cryenco, of the 10,000 gal. per day unit, is shown in Figure 22.

A more detailed schematic, also provided by Cryenco, of the new recirculation loop is given in Figure 23.

Figures $23 \mathrm{a}$ and $23 \mathrm{~b}$ provide illustrations of the core concepts for the thermal acoustic driver and the orifice pulse tube refrigerator, respectively. 


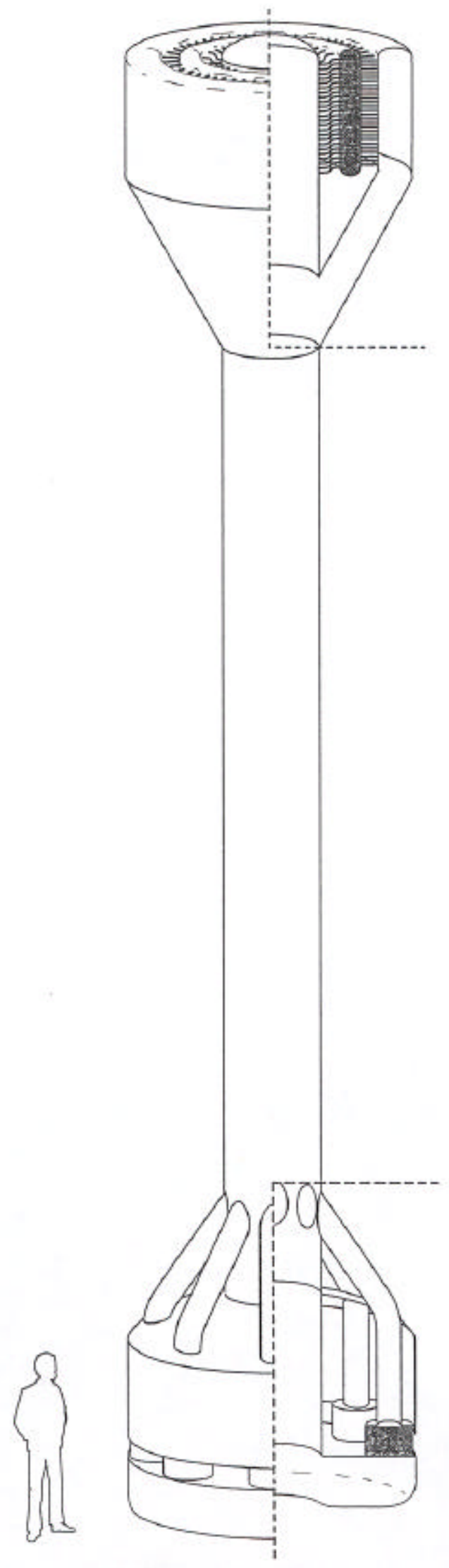

Figure 22 


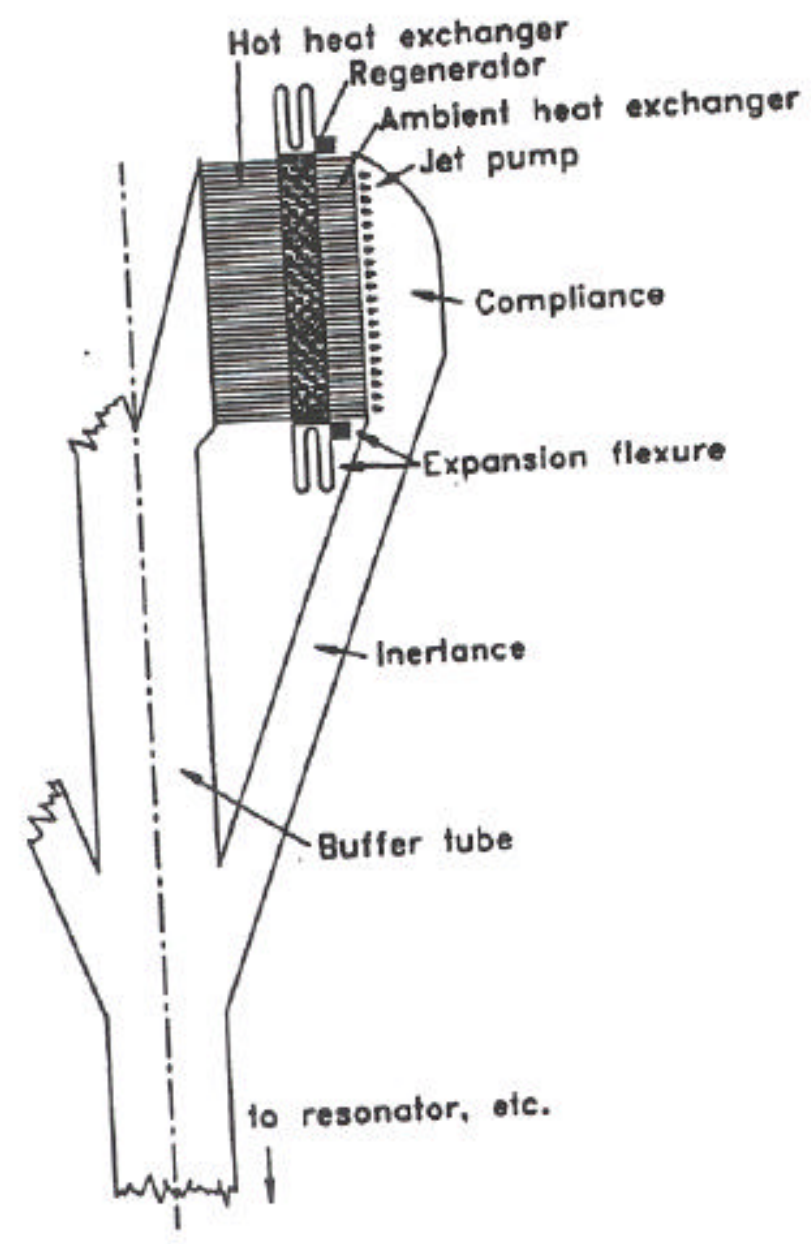

Figure 23 


\section{Thermoacoustic Driver}

- Burner provides power to Hot heat exchanger

- Stack transfers heat into And out of the helium Working gas

- Ambient heat exchanger Rejects heat to water

- System produces and Oscillating Pressure wave

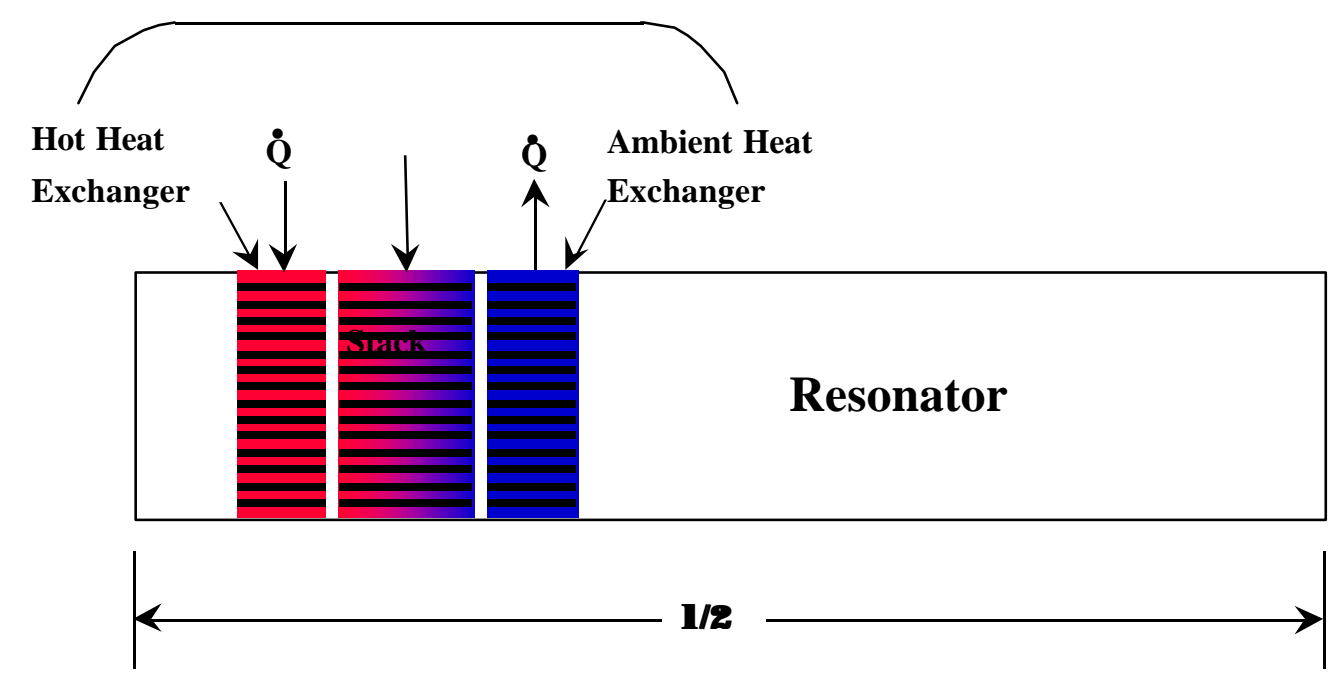

Figure 23a 
Orifice Pulse Tube Refrigerator

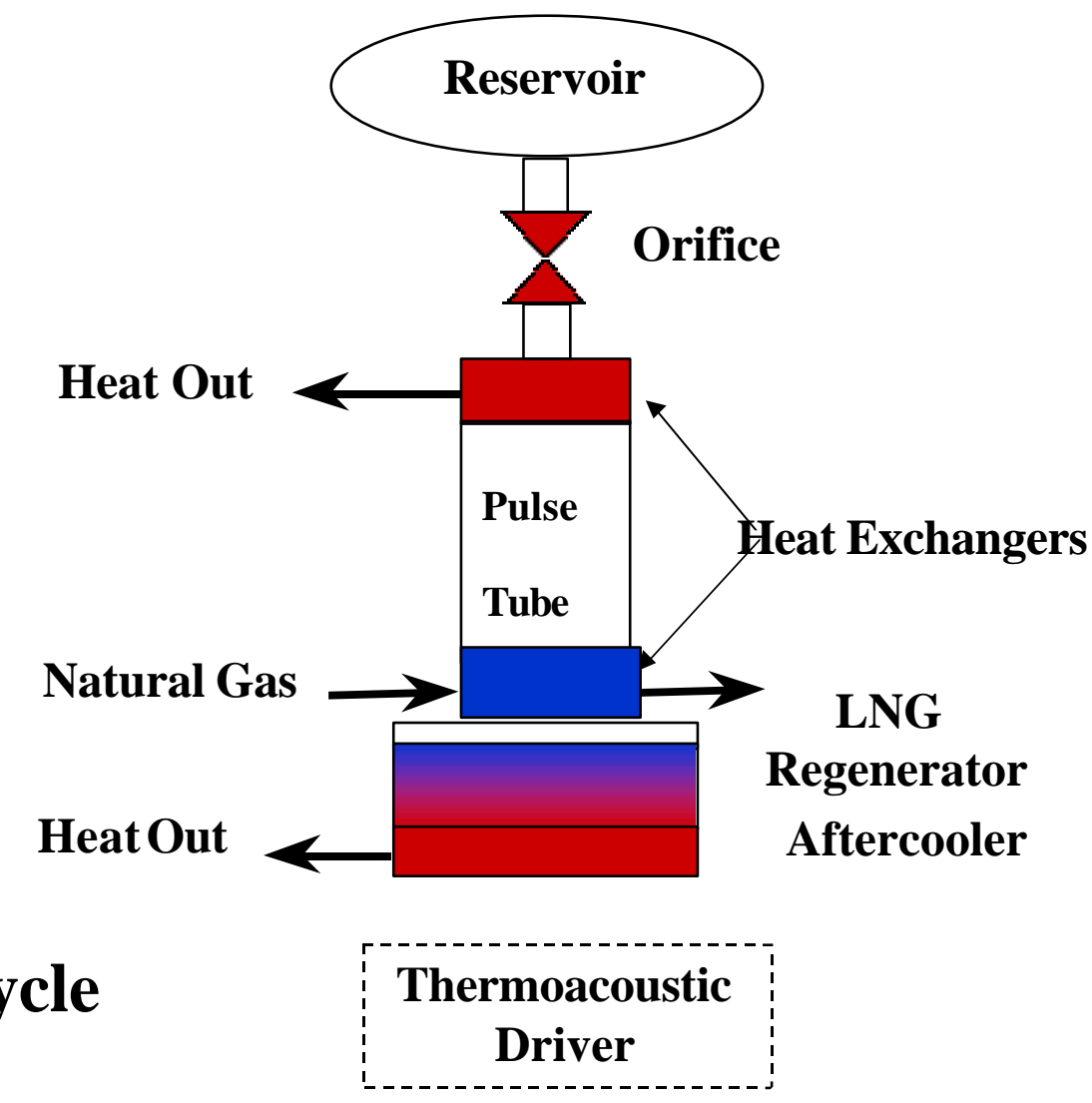

- Variation of stirling refrigeration cycle

- Working gas is expanded and

- compressed in the Pulse Tube

- Orifice/Reservoir System Causes Correct Phasing Between Pressure and Mass Flow Which Produces Refrigeration Power

- Regenerator Provides Thermal Isolation Between Driver And Cold Heat Exchanger

Figure 23b 


\subsubsection{Gas Conditioning System}

CMM would be provided from one or more sources to the Gas Conditioning unit, which would condition the gas to acceptable specs for the process side of the TASHER. The CMM would also be provided as fuel gas to the TASHER combustor and the power unit. In the TASHER combustor, the CMM fuel gas would be burned with air, creating a hot (200-300 deg F) flue gas. Some or all of this flue gas, discharged from the TASHER combustion chamber, could be recycled to the Gas Conditioning Unit to regenerate spent sorbents. Similarly, the CMM fuel gas and air that combust in the power generation units would also create a hot flue gas that could be used as a waste heat source for either the TASHER or the gas conditioning unit.

The CMM, conditioned to meet TASHER specs, would be supplied to the TASHER as process gas, where it would be converted to LNG, stored and shipped to market. The cooling requirements of the TASHER will be provided by cooling water, which is cooled on site by means of a cooling tower.

At this time the project does not show a cat-red unit nor a molecular sieve unit. The team plans a field test on the 500 gpd prototype to verify that these will not be needed. However, discussions have been held with Catalytica (2), and they have informed the team that they do not market a catalytic-reduction unit. But they have further informed the team that it should not be difficult to develop such a unit, and they would be pleased to undertake such an effort should that be desirable for the project. 


\subsection{Project Site}

Maps of the project area are provided on the following pages. Pittsburgh coal seam base elevations and mined out areas of the Consolidated No. 9 mine are identified in Figure 24. While Invitation Energy's host site, the Whetstone portal is indicated on the map, most, if not all, of the feedstock coal mine methane will be delivered to the TASHER by pipeline from adjecent mines.

Figure 25 is a map which delineates the topographic conditions in the immediate project area. Given the surrounding hillsides, special care will be taken to assure adequate drainage away from the demonstration site. Effective storm water management is essential to ensure that there is no interference with project operations and to avoid draining any waste products from the site to surrounding property or a nearby stream.

The last in the series of figures (\#26) illustrates the underlying rock formations at the project site. Data for this illustration was compiled by the West Virginia Geological Survey from actual core samples near the project area. 


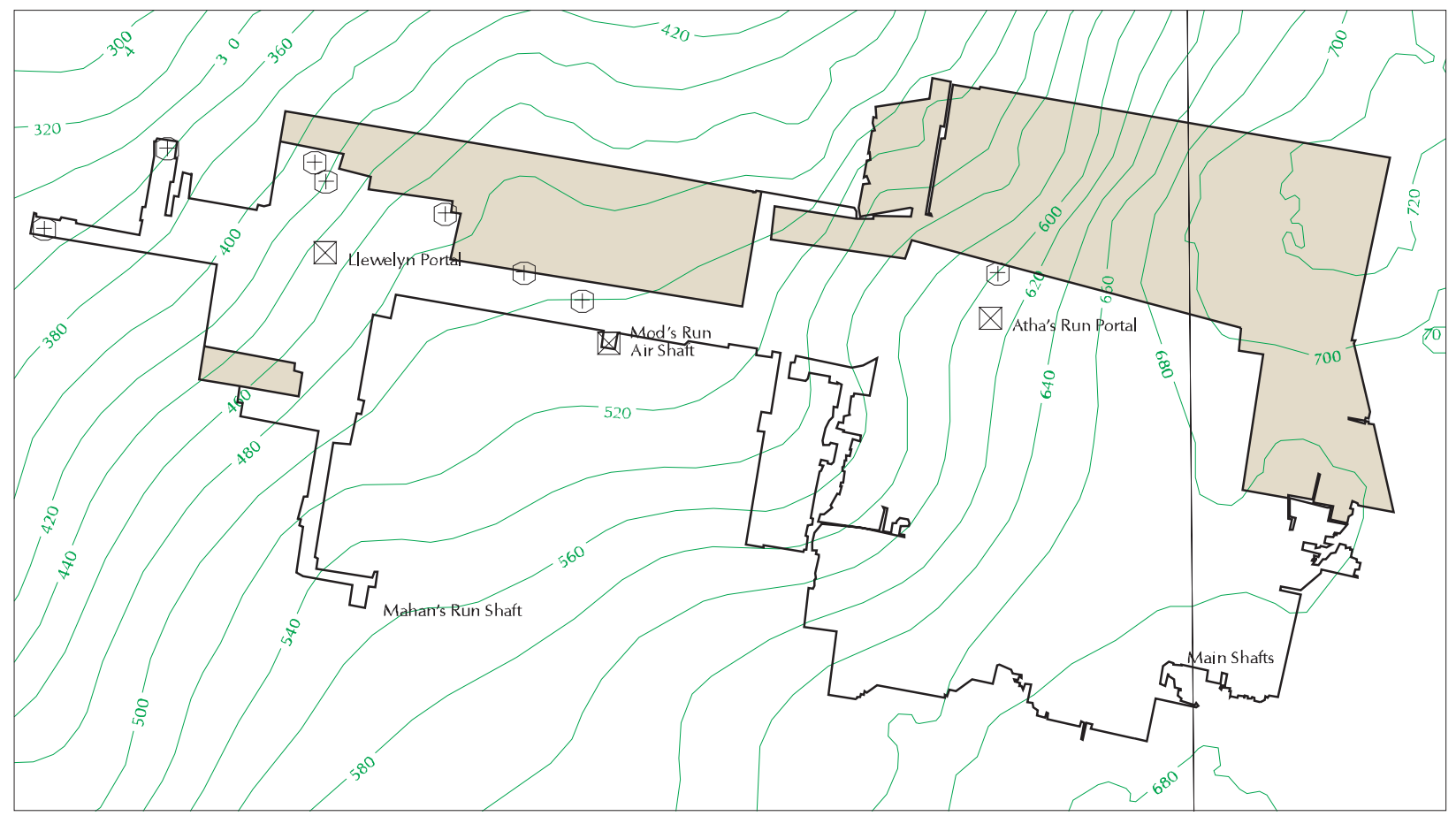

Figure 24 


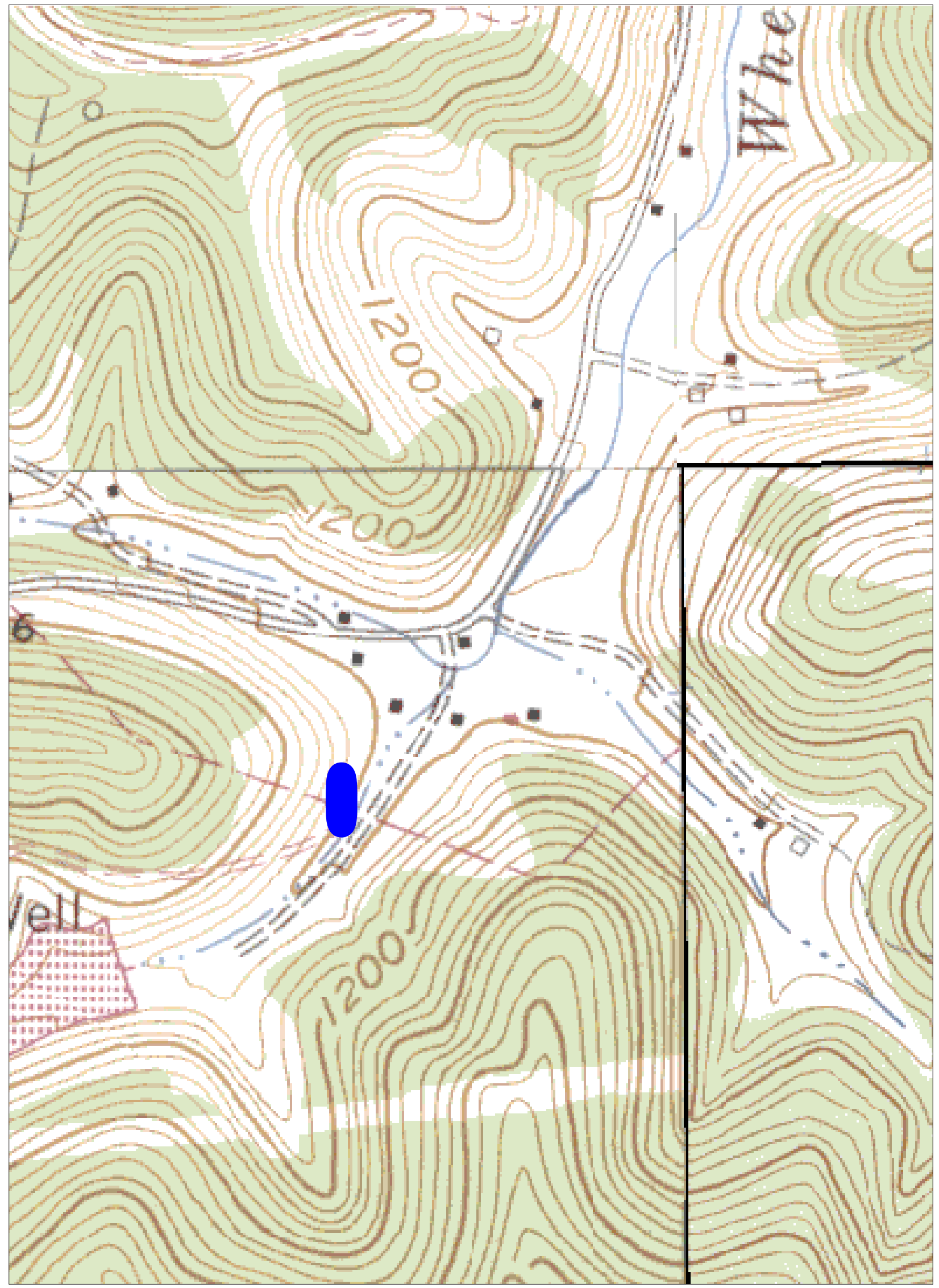

Figure 25 


\section{Plum Run Hole \#6 John C. Myers Farm Cored August 16-24, 1938}

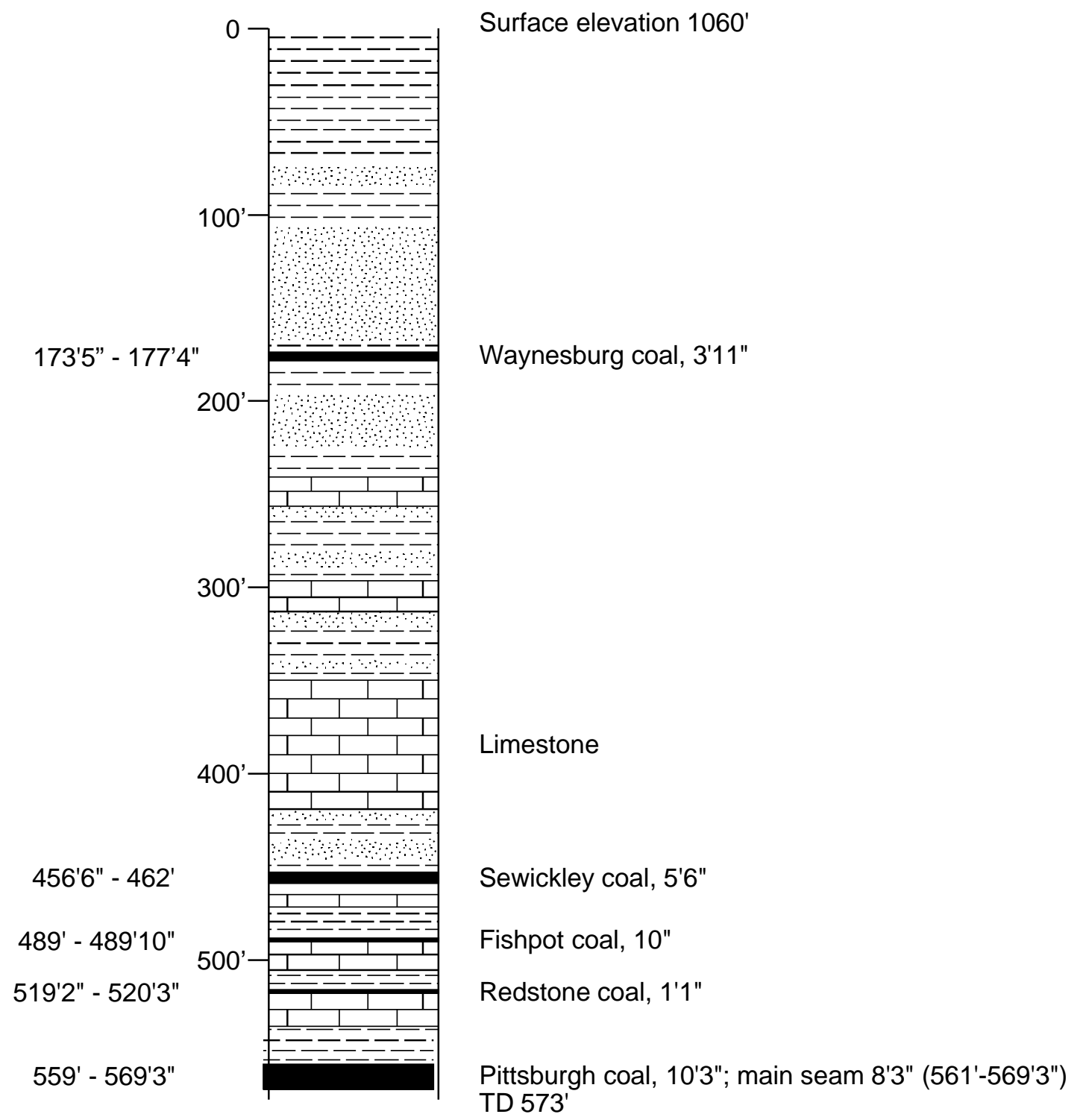

Figure 26 


\subsection{Demonstration Project Utility Requirements, Plot Plan, Installation, Permitting and Financial Considerations}

\subsubsection{Utilities Required for a 10,000 gpd TASHER demonstration}

$\underline{\text { Cooling water }}$

TASHER $\quad-1.5$ to 3 megawatts of cooling water required. (Est. by Cryenco.)

Gas conditioning $\quad-900,000 \mathrm{BTU} / \mathrm{hr}$ for CMM cooler (following compression,

if compression is required/selected)

$\underline{\text { Fuel Gas }}$

- 250MCFDMethane for combustion section of TASHER

Electric power (or equivalent)

- $189 \mathrm{~kW}$ for compression of CMM

- $15 \mathrm{~kW}$ for TASHER combustion blower

- $15 \mathrm{~kW}$ for water circulation pumps

8.1.2 Plot plan for the LNG demonstration equipment (See Figure 27) 
|llustration-2

\begin{tabular}{|c|}
\hline $\begin{array}{c}\text { Proposed Project Layout } \\
\text { on Site-2 }\end{array}$ \\
\hline S
\end{tabular}

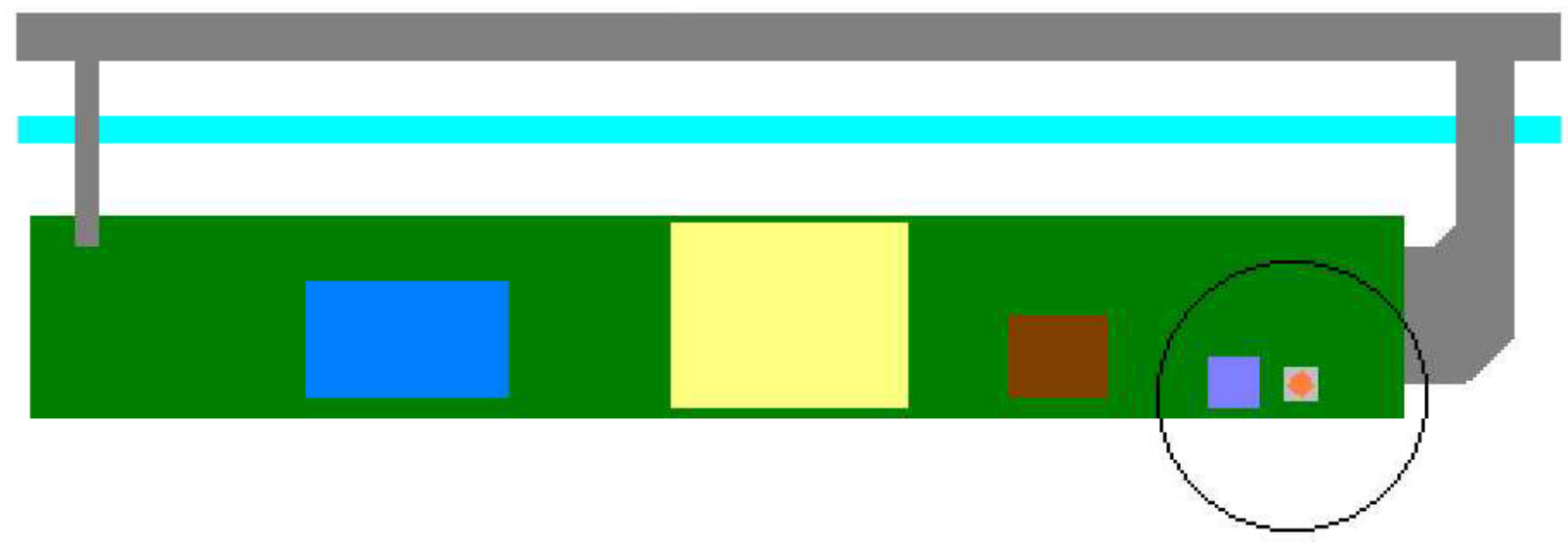

Scale: 1 inch $=50$ feet

Site-2

Road

Drainage area
- Water Cooler

Gas Conditioning Plant

Dffice and Controls
Storage

Cement Pad

Tadopter

Figure 27 


\subsubsection{Alternatives for Siting the Plot Plan at Invitation Energy's Whetstone Portal}

There are five possible sites surrounding the office building that are flat and ready to use, but two of these sites are more suited to the project's needs than the others. Pictures of each site can be seen in the following pages, and a sketch of their relative locations can be seen in Figure 28.

Consultations with the WV Geological Survey indicate that the subsoil in the proposed area is composed of limestone and shale (Dunkard formation) with seven to fifteen feet of clay loam soil (Meigs). Drainage is considered good to excellent at each site, although some portions (which will not be used) of the overall site are within a 100year flood plain.

Picture-1 shows the road that runs behind and to the left of the office building. Site- 1 can be seen on the left side of the road and is occupied by pipes, beams, and an old truck. The dimensions of this narrow site are approximately $50 \mathrm{ft} \times 400 \mathrm{ft}$ and it is capable of supporting some large equipment. This site is not large enough for all of the equipment needed for the LNG process, but it could be used for offices or parking, or combined with other sites. There is a hill beside site-1, seen on the left side of Picture-1, which limits its use. Removing a portion of this hill is not recommended due to the threat of sedimentation of nearby streams.

Behind the office building is the largest flat area, Site-2, which is approximately $60 \mathrm{ft}$ x $400 \mathrm{ft}$. This site can be seen in Picture-2, covered with several drill pipe segments. Site- 2 can support all of the equipment needed, with minimal changes necessary. A level 1 survey indicates no significant hazardous material clean-up issues; and, if needed, the hill to the left can be flattened to extend the width of the site. In addition, the area between the office and Site- 2 contains old mining equipment that can be removed to increase the dimensions of Site-2, but is not recommended because the cost of this clean up will likely be high. The existing flat area should be large enough to accommodate all of the planned equipment, but expansion is possible should it become necessary. There are presently entrances at both ends of Site- 2 that will facilitate construction and, subsequently, operations including the transfer of stored LNG to large tanker trucks for delivery to customers. This seems to be the most desirable location to set up the equipment.

Site-3, shown in Picture-3, is a small fenced area south of Site-2. The site is roughly $30 \mathrm{ft} \times 50 \mathrm{ft}$. It would require extensive clean up and is too small to hold all of the equipment. It might be useful as a possible expansion option for Site-2. In between Site- 2 and Site- 3 there are a few oil drums, seen in Picture-4, that will need to be removed in order to connect the sites.

Site-4 is located on top of the hill seen in Picture-4. There is a large, flat area where the equipment can be set up, but access to this site is constrained due to the steep grade of the hill. This is a less desirable location. 
Picture-5 exhibits a view of Site-5, Invitation Energy's parking lot. The parking lot has dimensions of approximately $100 \mathrm{ft} \times 170 \mathrm{ft}$ and is adequate for all of the planned equipment. While access to this site is excellent, it is deemed less desirable due to its close proximity to the road and the possibility of unwanted curiosity.

Stormwater management is a concern for the preferred site, 1 and 2. To avoid damage, the equipment must be set up in an area that does not flood. The two sites are located in a valley, which likely receives much runoff during storms. There are drainage ditches and pipes below all three sites to help assist with excess runoff. These drainage areas can be seen on both sides of the road in Picture-6. Sites- 1 and 2 are elevated above the road to help the flow of runoff into the drainage areas. However, it is evident from the muddy entrance to Site-2, seen in Picture-6, that the drainage areas do not effectively remove all of the runoff. This problem might be corrected by simply putting down more gravel and improving the existing stormwater channels. 


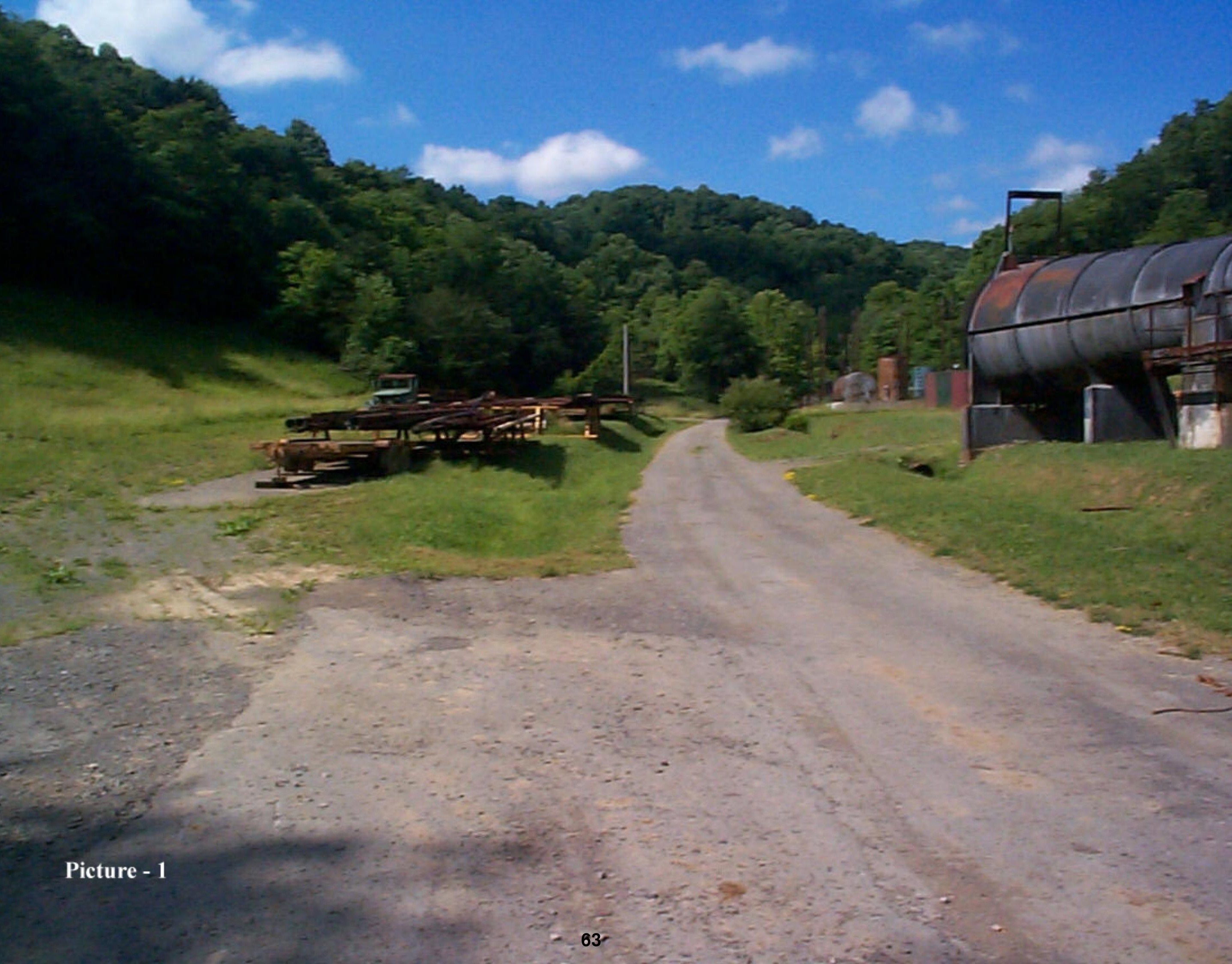





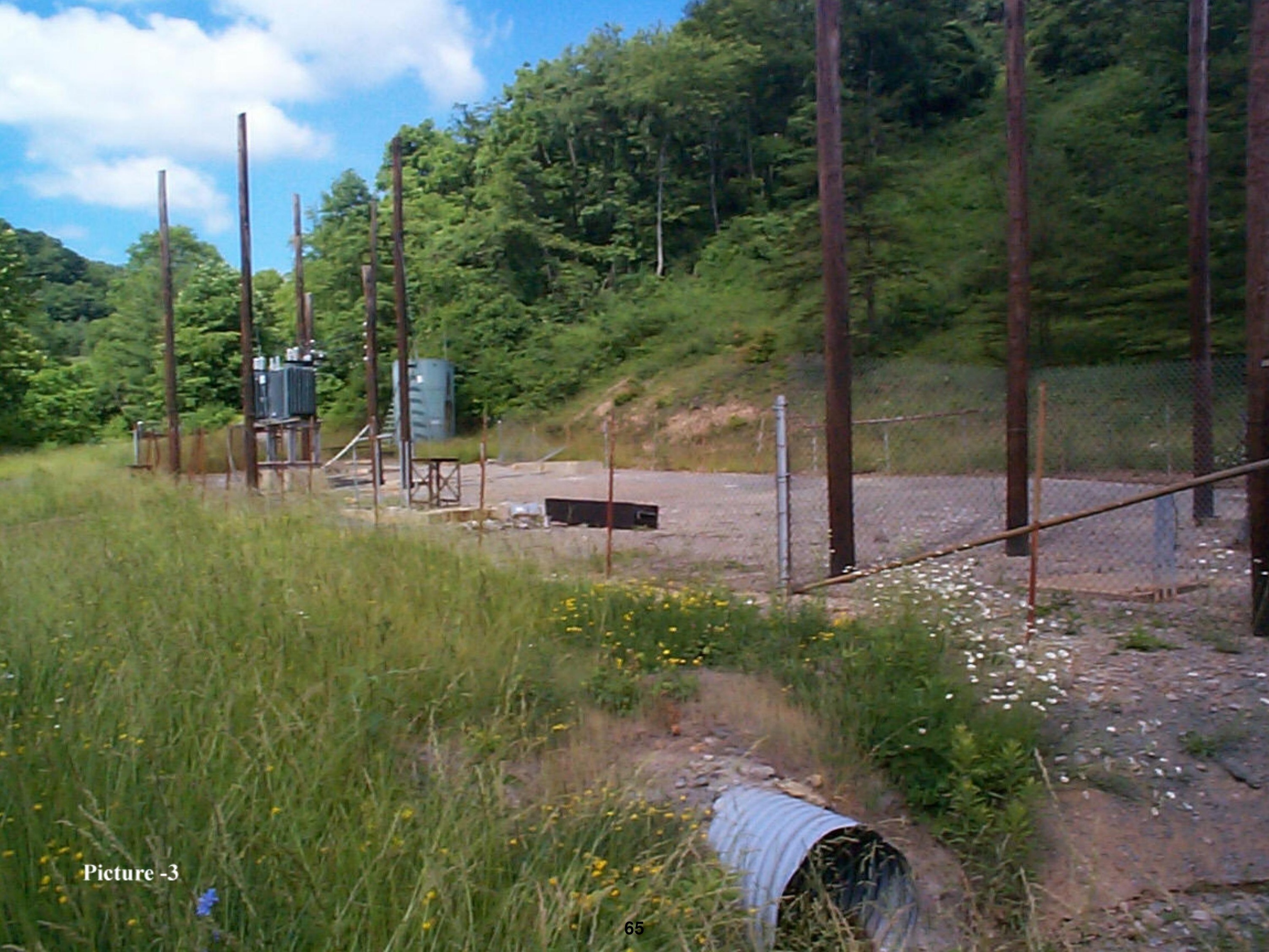




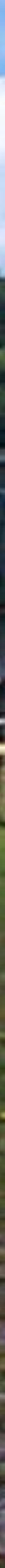




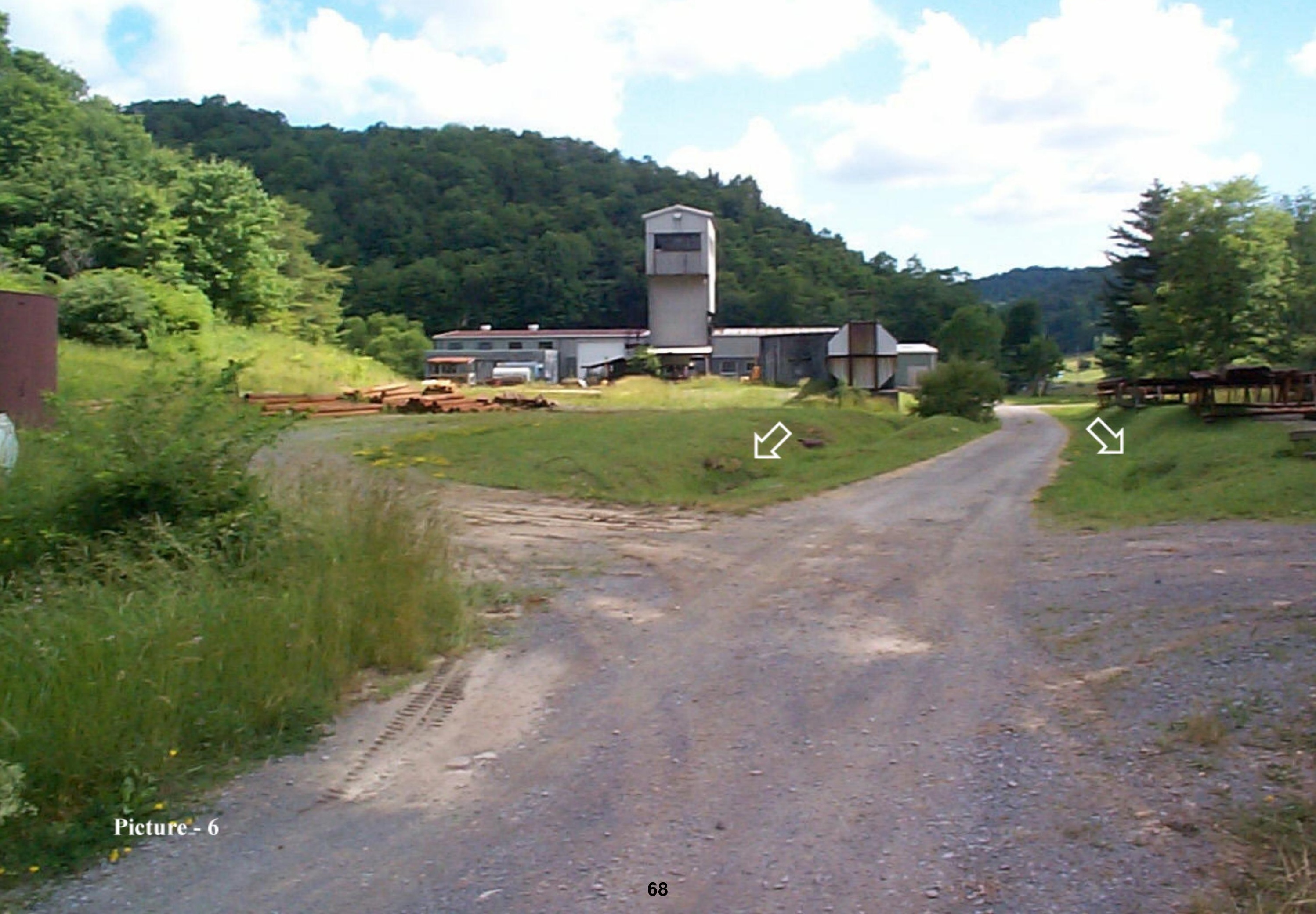




\subsection{Cost Estimates and Evaluations for Site Preparation}

Site-2 is the most desirable location for many reasons. It is large enough to hold all of the equipment, it will require minimum clean up, it is easily accessible, and it is not clearly visible from the road. Of course though, there will be some costs to prepare this site. Cost estimates can be seen below in Table- 8 .

\section{Cost Estimates for Site Preparation}

\begin{tabular}{l|r}
\multicolumn{1}{c|}{ Task } & Cost $\mathbf{( \$ )}$ \\
\hline Removal of debris & 1,000 \\
Concrete, material & 7,590 \\
Concrete, labor & 5,000 \\
Suplimental materials & 10,000 \\
Crane (3 days) & 4,680 \\
Equipment installation, labor & 10,000 \\
Fence, material & 3,000 \\
Fence, labor & 750 \\
Sitedrainage improvements & 10,000 \\
TADOPTER transportation & 2,500 \\
Othertransportation & 2,000 \\
Construction of office & $\underline{20,000}$ \\
& \\
Subtotal & 76,520 \\
Contingency (25\%) & $\underline{19,130}$ \\
Total & 95,650
\end{tabular}

\section{Table-8}


Cleaning the area of debris will not be expensive because there is only a small amount of material to move and it is not toxic or hazardous. This material can be transported by a small truck, such as the one seen in Picture-5, and moved to Site-1 or another area close by. The cost of this work should be insignificant to the project.

Some concrete will be required to form a stable pad for the TASHER. The pad should be eighteen inches thick, halfway buried into the ground to dampen the vibrations from the TASHER and provide stabilization. The pad should have an area of approximately $15^{\prime}$ x $15^{\prime}$ to distribute weight over the soil and provide sufficient room for stabilization cables and bolts. The maximum amount of concrete needed including a margin for contingency will be $14 \mathrm{yd}^{3}$. The cost of the concrete used will be approximately $\$ 69 \mathrm{yd}^{3}$, resulting in a cost of $\$ 966$. The cost of labor to lay down the concrete pad will be approximately $\$ 2,000$. Additional concrete pads might be needed for other pieces of heavy equipment such as the cooling tower and the storage unit. This will increase the total concrete needed to $110 \mathrm{yd}^{3}$, the total cost to $\$ 7,590$, and the total labor cost to approximately $\$ 5,000$.

Supplemental materials, such as supporting cables and bolts, are necessary to stabilize the TASHER in heavy winds. The costs of these materials are estimated to be $\$ 10,000$.

Equipment such as cranes and large trucks will be needed to set up the TASHER and individual units. The cost to rent a crane with operators for eight hours a day is $\$ 1,560$. The crane will be needed for approximately three days, considering that all the pieces of equipment will not arrive on the same date. Additional rental equipment and labor needed to install each piece is estimated to cost $\$ 10,000$.

A fence as well as two gates will be needed to secure the area. The cost of materials to set up an eight foot galvanized chain link fence with a top rail around site-2 is approximately $\$ 3,000$. The cost of labor to erect the fence is approximately $\$ 750$.

There will also be costs for transporting the equipment to the site. The TASHER will require large trucks and special attention when transported. The cost of moving it from Denver to Mannington will be about $\$ 2,500$. The cost of transporting the cooling towers is included in their net cost as shown in the quotation from CFM. The dehydration and DEA units for the gas conditioning plant as well as materials for the office and storage space will also need to be transported. The estimated costs for this are $\$ 2,000$.

There will be costs for construction of the office. Labor and materials are estimated at $\$ 20,000$.

The total cost of site preparation, including $25 \%$ added contingency, comes to $\$ 95,650$. 


\subsubsection{References for Cost Estimates of Site Preparation}

Concrete:

Concrete - Ready Mix:

Arrow Concrete Company; Rt. 5, Morgantown; (304) 291-6211

Concrete Contractors:

Morgantown Landscapers, Inc.; Morgantown; (304) 296-8000

Fences:

Fences 4 Less; www.fences4less.com 1(800) 933-6237

Cranes:

City Crane and Equipment, Inc.; Dents Run Blvd., Morgantown; (304) 292-5438

Trucking:

Estes Express Lines; Richmond; 1 (800) 624-7881 ext. 2269; Quote \# T30000

24/7 Freight; New Jersey; 1(800) 672-7204

\subsubsection{Description of Site Layout}

The proposed layout of the project equipment on Site-2 is seen in Figure 27. The gas conditioning plant is likely to be set up before anything else so it should be placed in the middle, away from the entrances. The office and controls can be built south of the gas conditioning plant and close by so the plant can be easily monitored. The TASHER must also be monitored so it should be close to the office and controls as well. It can be placed near the south entrance with nothing except the storage area built within 40 feet of the TASHER to establish an access and safety perimeter. This is a good location for the TASHER because there is sufficient room in the south entrance for a crane to be used to set up the TASHER. A concrete pad, $15 \mathrm{ft}$ x $15 \mathrm{ft}$ and 18 inches thick, should be set in place here two weeks before the TASHER is delivered so that the concrete has time to cure. The storage tank must be built close to the TASHER so that the LNG does not have to travel far from the system. A good location for the storage tank is between the TASHER and the office, within the 40-foot safety area. The cooling tower does not have to be particularly close to the rest of the equipment, so it can be placed on the north end of the site close to the smaller entrance area.

The layout of the equipment can be rearranged to accommodate the delivery of components to the site in a different order, for example if the TASHER arrives before the gas plant components. If a rearrangement is necessary, certain aspects of the layout must still be observed. Both the gas plant and the TASHER should be close to the office and controls. The TASHER should have a 40-foot clear working area and safety radius excluding the storage tank, which must be nearby. Also, the TASHER must be installed from the south entrance where there is room to install it, so nothing should be built near this entrance until the TASHER has been erected. 
After all of the equipment has been installed, an eight-foot galvanized chain-link fence should be placed around the perimeter of the site. Two gates, wide enough to allow the large LNG tanker trucks to get through, should be installed at each entrance. 


\subsection{Financial Analysis}

\subsection{Capital and Operating Cost Estimates}

\subsubsection{Capital Cost Estimates}

$\$ 7.4$ million is estimated to be the capital cost that would be incurred by all parties to the project, including costs to the State of West Virginia through the $\$ 50,000$ per heavy vehicle tax incentive program. $\$ 4$ million of this amount represents the estimate associated with the state's cost sharing contribution. An additional $\$ 3,431,250$ for project-specific capital costs such as site preparation, the TASHER unit, gas conditioning equipment, and LNG storage and distribution equipment would be shared by $\mathrm{DOE}$ and the project sponsors.

\subsubsection{Operation and Maintenance Cost Estimates}

The operating costs for the project have been estimated, and are provided in Table 10. The cost for the CMM has been taken to be $\$ 2 / \mathrm{MCF}$ and the ratio of combustion gas to process gas for the TASHER and other process heaters is taken from the heat and material balances provided in Table 7. There is provision for three operators per day. Operating costs for the gas conditioning unit have been taken from the factored estimates of Purvin and Goertz. The operating cost estimate is about one-and-one-quarter million dollars a year. The two-year project total is $\$ 2,587,630$.

A summary of all project costs are reflected in Table 12 below.

\begin{tabular}{|l|r|}
\hline \multicolumn{1}{|c|}{ TOTAL PROJECT } & $10,018,879$ \\
\hline STATE (Est. of Tax Credit) & $4,000,000$ \\
\hline TOTAL DOE & $2,950,000$ \\
\hline DIFFERENCE (PAID BY PROJECT) & $3,068,879$ \\
\hline
\end{tabular}

Table 12 Total LNG Demonstration Project Funding (Two year operating Life)

Further details of the project financing are provided in Tables 9, 10 and 11 and in a narrative presentation contained in Appendix 9. These are provided solely for DOE's information under confidentiality instructions. 


\subsection{Market Survey and Analysis of Demonstration Project LNG Sales Issues}

\subsection{Market Survey in Northern West Virginia and Southwestern Pennsylvania}

\subsubsection{Introduction}

Previous research has demonstrated the feasibility of using LNG as a transportation fuel in certain types of vehicles. Vehicles most amenable to using LNG are those found in high fuel use fleets, particularly fleets that consist of larger vehicles that can more easily accommodate the cryogenic fuel storage tanks required for LNG. Since the energy density of LNG is less than diesel or gasoline, LNG vehicles must store more fuel on-board in order to have a driving range that is equivalent to that of diesel or gasoline powered vehicles.

While large LNG fueled vehicles typically can travel in excess of 350 highway miles without refueling, this market study was limited to heavy vehicle fleets whose vehicles that return to "home base" at the end of their daily cycle and travel less than 250 miles per day. The 250 mile daily limit was chosen to ensure a very conservative determination of potential market size and does not represent an actual LNG vehicle limitation. Consequently, the numbers of potential LNG vehicles identified herein represent only the "lowest hanging fruit" and considerably understate the early candidate market.

A survey was conducted of fleets comprised primarily of large (i.e. Class $7 \& 8$ ) vehicles within a 100 mile radius of the Morgantown area. This region includes much of the I-79 Clean Corridor which is supported by FETC, DOE's Office of Energy Efficiency, the States of West Virginia and Pennsylvania and private fleet operators and fuel providers.

\subsubsection{Background Data}

The following points and Table 13 list properties of LNG for reference purposes:

- LNG weighs less than half as much as the same volume of water. Water (8 lb/gal); LNG (3.5 lb/gal). Weight comparisons for diesel fuel and gasoline are $7.3 \mathrm{lb} /$ gallon and $6.2 \mathrm{lb} /$ gallon, respectively.

- One (1) $\mathrm{ft}^{3}$ of LNG is equivalent to approximately $618 \mathrm{ft}^{3}$ of natural gas in terms of contained energy.

- One pound of LNG contains 22,400 Btu, compared to diesel fuel at 19,200 $\mathrm{Btu} / \mathrm{lb}$ and gasoline at 20,300 Btu/lb.

- Btu per gallon volume is 78,400 for LNG, 140,160 for diesel and 125,860 for gasoline. 
- During liquefaction of natural gas, or other LNG feedstock such as coal mine methane, any mercaptan, condensable carbon dioxide, water and other trace components such as hydrogen sulfide are removed.

- The natural gas is passed through a series of refrigeration steps to reduce the temperature to $-259^{\circ} \mathrm{F}$, which liquefies the gas. The major contaminants condense at various temperatures throughout this process and the majority of the contaminants are drawn off.

- Result: 90 - $100 \%$ methane in the liquid form (LNG), with the remaining components of ethane, propane, nitrogen and/or helium at $0-10 \%$. (For the purpose of this study, only LNG which is $\geq 97 \%$ methane will be considered transportation grade fuel.)

- Methane has a relatively simple chemical composition and is the only hydrocarbon that does not photochemically react to form ozone and, due to its "cleanliness," results in an ambient reduction in particulates and other emissions.

- $\mathrm{CNG}$ can be produced from LNG.

\begin{tabular}{|l|l|l|l|l|l|}
\hline & \multicolumn{1}{|c|}{ CNG } & \multicolumn{1}{|c|}{ LNG } & DIESEL & \multicolumn{1}{|c|}{ GAS } & \multicolumn{1}{|c|}{ PROPANE } \\
\hline $\begin{array}{l}\text { Physical } \\
\text { State }\end{array}$ & Gas & Liquid & Liquid & Liquid & Liquid \\
\hline $\begin{array}{l}\text { Storage } \\
\text { Pressure } \\
(\text { PSI) }\end{array}$ & $3000-3600$ & $40-200$ & ATM & ATM & $120-160$ \\
\hline Temp. $\left({ }^{\circ}\right.$ F) & Ambient & $-259 \mathrm{~F}$ & Ambient & Ambient & Ambient \\
\hline $\begin{array}{l}\text { Density } \\
(\text { Lb./gal) }\end{array}$ & $1.3-1.6$ & 3.5 & 7.14 & 6.2 & 4.8 \\
\hline $\begin{array}{l}\text { Energy } \\
\text { Content } \\
\text { BTU/gal }\end{array}$ & 120,000 & $82,000-85,000$ & $128,000-$ & $117,000-$ & 91,700 \\
\hline
\end{tabular}

Table 13 Fuel Properties Comparison (Source: ALT Brochure 1998)

\subsubsection{Background, LNG Equipment Cost and Use}

Producers of LNG vehicle technologies have managed to reduce the costs of their products significantly over the last four years, according to the Zeus Development report. The incremental costs of heavy-duty LNG tractors and transit buses from companies such 
as Mack, Cummins and Caterpillar have dropped by approximately 50-60\%, from $\$ 50,000$ - 60,000 down to $\$ 20,000$ - 35,000.

The West Virginia Legislature passed a bill that pays the costs to convert diesel or gasoline engines to LNG or the incremental cost to purchase alternatively-fueled new, OEM equipment. This incentive eliminates direct conversion costs to fleet owners. (Additional details of the WV tax credit are contained in Appendix 4.) The current legislation providing this subsidy incentive for LNG conversion expires in 2008. This market evaluation recognizes the importance of this legislation and its possible implications after it expires in 2008.

The only current use of LNG for transportation in the survey area is a demonstration project at Waste Management's Washington County landfill operation. This project is supported by DOE's Heavy Vehicle Transportation Program in the Office of Energy Efficiency and the Gas Research Institute. Waste Management employs seven Mack heavy-duty dedicated LNG engines in the 325-350 horsepower range. A 400 horsepower dedicated natural gas engine is currently in development. These power systems can be integrated into either a refuse or highway vehicle.

\subsubsection{Survey Design}

This market survey is for a new LNG production facility, the TASHER, to be constructed near Morgantown, West Virginia. Since transportation adds considerably to the delivered price of LNG, LNG would have the greatest competitive advantage relative to diesel in markets near the LNG production facility. Therefore, the market area for this study was roughly limited to a 100-mile radius of Morgantown.

The SIC code (WV Business Directory) was used as an indicator for the size of the fleet. Although fleet or vehicle size was not referenced in this directory the employee size was used as an indicator. Fleets with employee size greater than 20 were chosen for the survey as a possible indicator of fleet size.

The West Virginia Business Directory and local telephone directories for the Morgantown, Fairmont, and Clarksburg areas were used to identify fleet operators. The WV Business directory and phone books were the primary source as well as networking once a contact was established during the survey.

\subsubsection{Survey Results}

The market survey of all potential users of LNG in the market area indicates that considerable uncertainty is involved in the forecast demand for LNG. This uncertainty is due to (1) unknowns concerning the overall potential growth of vehicular fuel in the market area, (2) the potential for converting a portion of overall fuel requirements to LNG, (3) the percentage of the potential fuel market that could reasonably be captured, and (4) the rate of market capture. A LNG market forecast must consider these inherent uncertainties. Consequently, ranges of market demand quantities are obtained and analyzed rather than discrete quantities. 
Figure 29 shows the high, medium, and low values for the total potential market for LNG assuming small increases in the overall level of fuel use in the Morgantown area. The indicated market for LNG in the Morgantown, West Virginia area over the next fifteen years ranges from 2.3 to 8.1 million gallons of LNG per year (high and low cases). The medium case indicates a market for about 4.2 million gallons of LNG per year. Deviations from the assumed values previously described could change the size of the market. The wide range between the high and low values indicate the present uncertainty that exists in determining a market for LNG in which neither the cost of LNG, the cost of using LNG, or the prices of diesel are known with certainty.

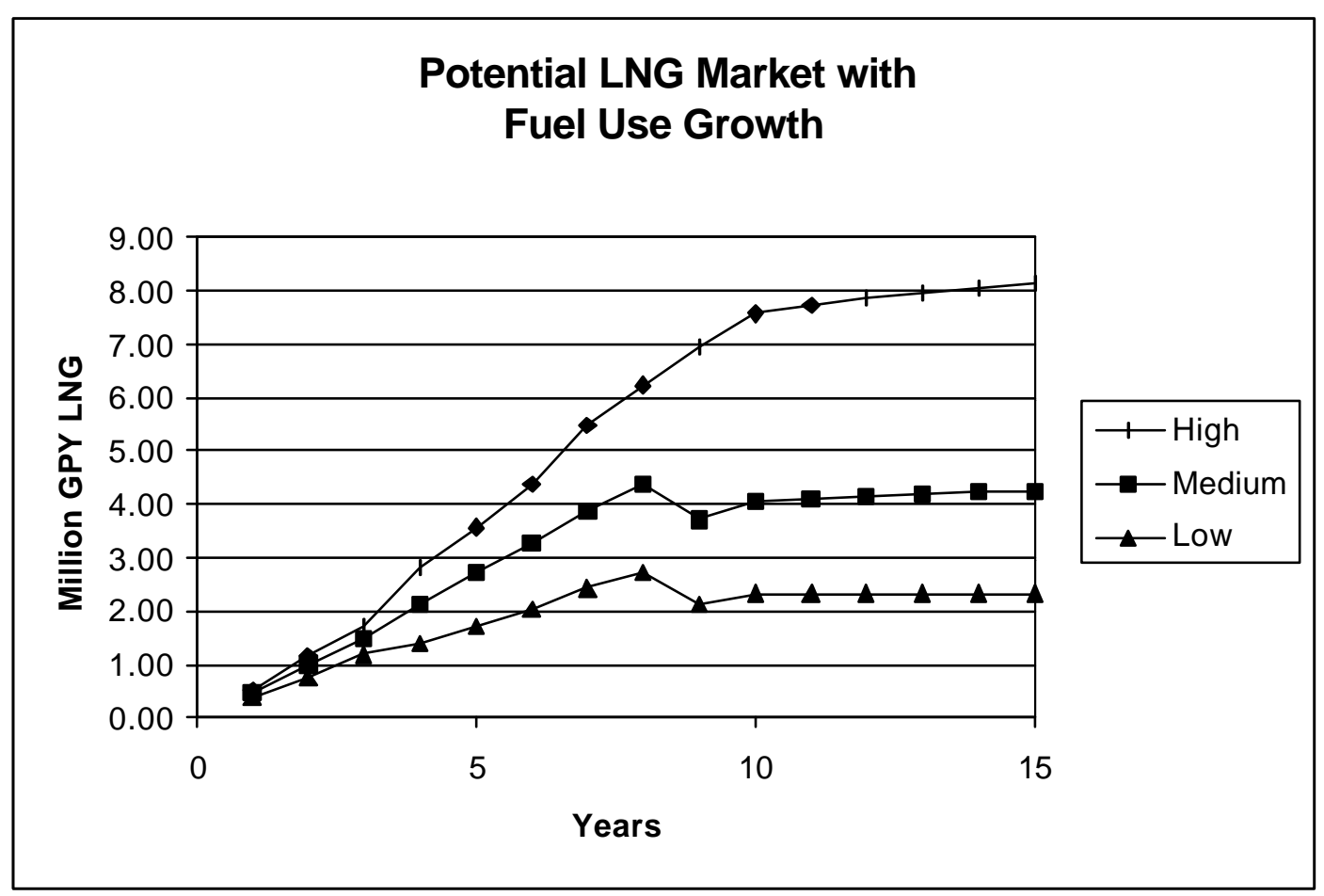

Figure 29 Potential LNG Market with Fuel Use Growth

Further details of the market study are contained in Appendix 11 which is provided solely for DOE's information under confidentiality instructions. 


\subsection{Regulatory Issues}

\subsubsection{Regulatory issues for the Construction and Operation of a 10,000 gpd TASHER in Marion County.}

Due to the unusual nature of this project inquiries to the officials of Marion County for clarification on regulator issue related to construction and operational of the TASHER were met with more questions than answers. Due to their general unfamiliarity with LNG and the specifics of the project itself, it will be necessary to meet periodically state and local regulators to "bring them along" as the project evolves. It will be necessary to provide the County with explicit plans of the TASHER site including equipment to be used at the site for their review and approval. They will require the project to follow typical BOCA construction regulations along with State and National Fire Code and OSHA directives where applicable. None of these requirements are a surprise or out of the ordinary for a new site/structure construction and utilization. Local regulators appear prepared to work cooperatively with us to assure this project stays in Marion County. Since the county inspectors and planners have had the experience of the construction of Three CNG refueling stations by Hope Gas Company with considerable high pressure storage capacity, their expressed comfort level toward the proposed LNG project is comforting. Project personnel also used the typical LPG storage and distribution scenario, which the regulators were familiar with, as an aid in helping them appreciate that the LNG production and distribution project is similar to processes that they may have already seen and have dealt with. However, continuing educational efforts will be necessary before any applications for permits are submitted to the County officials.

\subsubsection{Regulatory Issues Associated with Transporting LNG Through the Fairmont Area, Marion County, and Neighboring Counties and States.}

Transportation issues appear to be the easiest to address. All States involved utilize their specific Departments of Transportation to regulate trucking in their individual states. The project will be required to supply each DOT with documentation that the vehicle in use has been constructed for the task in which it is being used. The vehicle must also pass a state safety inspection for the state in which the vehicle is licensed and registered. Once this is accomplished the application to the various states involved may be completed and a state transportation licensee for the vehicle will be issued. Additionally, the driver(s) of this vehicle must possess the appropriate CDL licensing for the materials being transported.

The City of Fairmont has no specific regulation that would prevent the project from transporting LNG through the city, the only limitation being weight restrictions on the various bridges around the city. These can be addressed adequately with the route in which the transport vehicle will be required to follow. 


\subsubsection{Regulatory issues relating to Distribution from a Mobile Refueling Station in WV and Neighboring States.}

Distribution from a mobile unit may have some issues that will require specific attention once the decision has been made as to which type of fuel sale actually will be made from the truck itself. There appear to be significant differences as far as various states are concerned between bulk transportation of the LNG and bulk wholesale distribution of the LNG versus bulk transportation and retail mobile dispensing. The main area of concern is with the responsibility to the individual States and the Federal Government for the specific excise taxes, road usage taxes, state and local fees and taxes and sales taxes, etc. that will need to be assessed to each "retail" sale. The project team will need to assume responsibility for this submission to each local, state or federal entity. However, if our customers make bulk fuel purchases, the responsibility for the majority of these taxes and fees and their submission will fall directly on that individual end user or retailer. Many companies are currently transporting various fuels to clients and dispensing them into individual vehicles yet invoicing the total fuel purchased as a bulk purchase. This procedure also eliminates the complexity of securing in each state the Weights and Measures official's initial certification and annual licensing of the specific retail dispensing devices being used. Having dealt directly with this issue and having realized it's challenges and expense, project personnel would suggest avoiding it if at all possible.

An additional area to be researched is the responsibility the project will have to the remnants of the Interstate Commerce Commission when state lines are crossed to sell the LNG. Compliance with these responsibilities will require a significant investment in time.

\subsubsection{Regulatory Issues Related to the Use of LNG in Vehicles}

At this time there are no significant issues related to the actual usage of LNG as a motor fuel on the highways across the United States. Both the EPA and the DOE have recognized LNG as a viable Alternate Fuel thereby giving it equal viability when used in the transportation sector.

The new EPA Alt Fuels conversion equipment emissions requirements may be a regulatory issue that could have indirect effects on this program. These regulations may inhibit market development to the extent that initial clients may prefer to convert existing diesel and gasoline vehicles to LNG. By combining existing conversion systems with current OEM offerings there should be an adequate selection of LNG conversions and engines for clients in the project's area. (In any event, the market studies presented earlier in the report are premised on the conservative assumption that only OEM equipment will be utilized by LNG customers of the project. Consequently, the market study assumes relatively slow market growth projections, much slower than may actually be realized.) 


\subsection{Marketing Strategy for Duration of Demonstration Project and Subsequent Commercial Sales}

Details of the project's strategy to market LNG are contained in Appendix 10 and are provided solely for DOE's information under confidentiality instructions 


\subsection{Commercial Potential}

The project itself has a marginal profitability, depending upon the CMM gas purchase price, the efficiency and reliability of the TASHER and the sales price of the LNG. The financial return's sensitivities of to these parameters are shown in Figure 30. Notice that for the project to break even during the period of DOE funding, an LNG selling price in excess of $\$ 0.30 / \mathrm{gal}$ is required. Also note that the effect of gas purchase price is apparently nonproportional beyond the $\$ 2 / \mathrm{MCF}$ Methane level. This is because the level of DOE funding has been limited to approximately $\$ 3$ million, and the higher price of gas (at $\$ 2.25 / \mathrm{MCF}$ Methane) does not secure a proportional increase in DOE support.

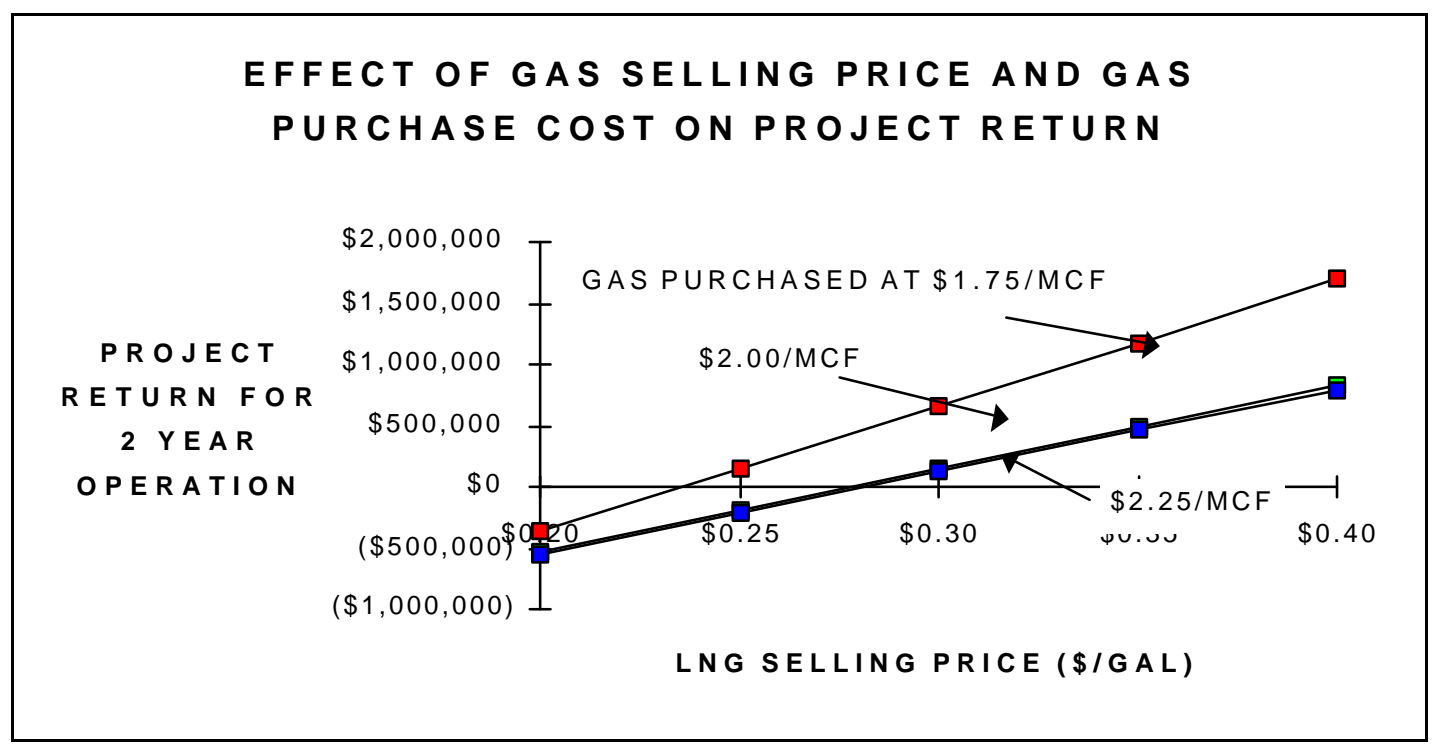

Figure 30 Sensitivity of LNG Project to Gas Purchase Cost and LNG Sales Price

After the DOE funding stops, the project has the potential to be profitable, again depending upon the sales and purchase prices of the product and raw material. These sensitivities are shown in Figure 31.

If the CMM is of high quality, comparable say to pipeline quality gas, then the supplier will expect a price of around $\$ 1.75$ to $\$ 2.00 / \mathrm{MCF}$ Methane. Under this condition, the project must be able to receive over $\$ 0.35 /$ gal for the $L N G$ to be profitable. 


\section{EFFECT OF GAS PURCHASE PRICE AND LNG SELLING PRICE ON PROJECT PROFITABILITY AFTER DOE FUNDING STOPS}

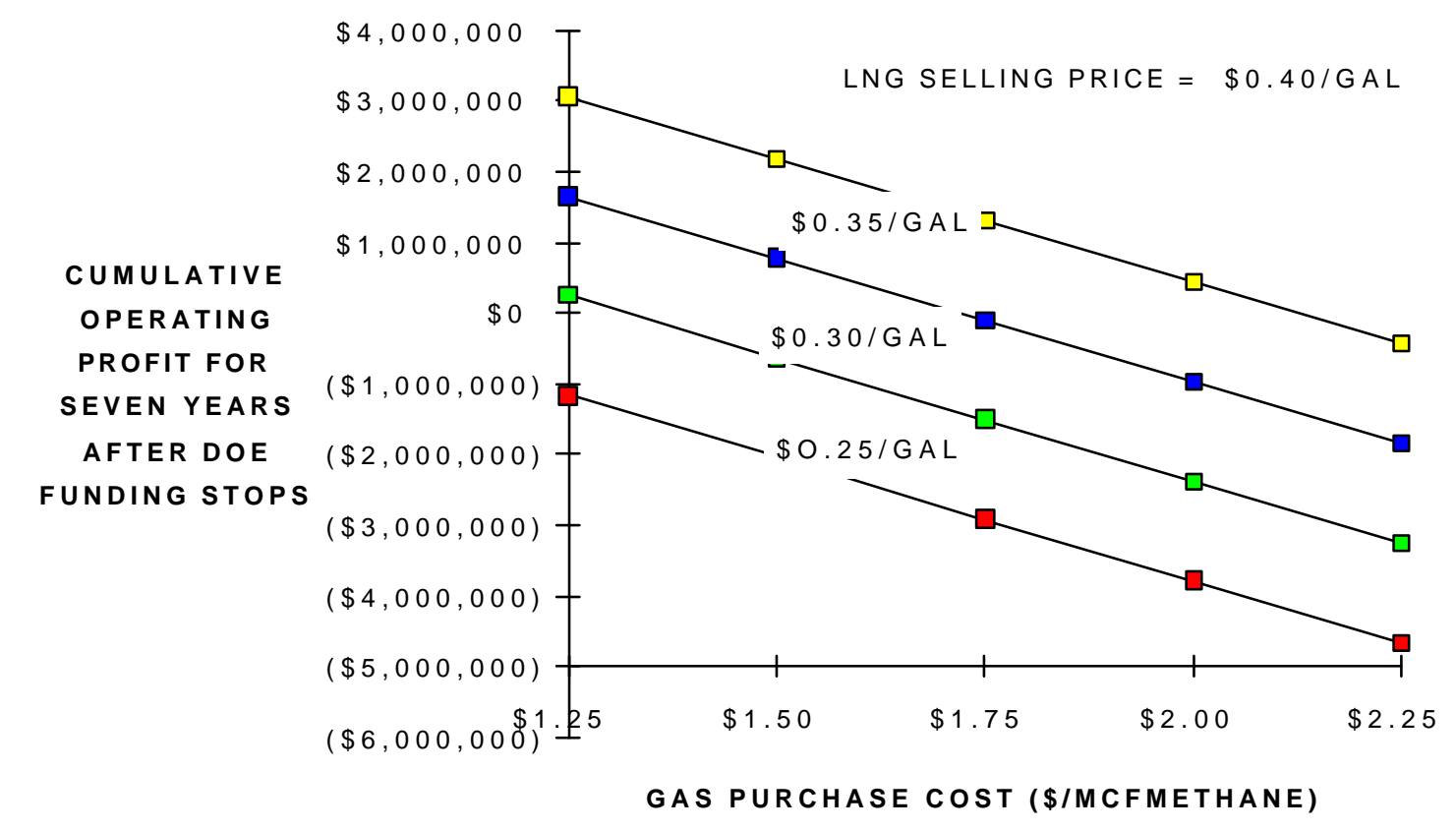

\section{Figure 31 Project Profitability After DOE Funding Ends.}

The ultimate success of the venture depends upon whether the process that evolves from this demonstration is replicable.

If the capital cost of a 10,000 gal/day plant can be kept to $\$ 3 \mathrm{MM} / 10,000$ gpd and if the operating cost can be limited to 5 cents/gal, a commercial plant would return $12 \%$ to the owners, for an LNG selling price of $\$ 0.40 / \mathrm{gal}$.

Appalachian-Pacific, the project sponsor, would plan to pay the DOE back out of the licensing fees for the technology. Five per cent of the licensing fees collected by Appalachian-Pacific for plants like the one demonstrated would be paid to the DOE. Total payment would not exceed the DOE contribution. 


\subsection{Project Development}

\subsection{Organization and Key Personnel}

The proposed demonstration phase of the project will consist of three main parts. The first will consist of the completion of the engineering design, including any modifications needed as a result of the 500 gpd Cryenco test program; the second will involve the procurement and construction of the physical plant. The third will involve a period of start up and test operation, during which time the process viability will be demonstrated and the market for the LNG product solidified.

During the course of the project to date, Estes and Zahradnik have formalized their participation by establishing Appalachian-Pacific Coal Mine Methane Power Company (Appalachian-Pacific, or simply AP), a limited liability corporation whose purpose is the evaluation, acquisition, production and marketing of energy from Coal Mine Methane.

Because the proposed demonstration Project involves many of these aspects, and because it will require considerable cost sharing, debt acquisition, and many commercial relationships, the participant parties for the phase just completed have agreed that Appalachian-Pacific will serve as the prime contractor and project manager for the proposed Demonstration Project.

The organization structure that will be employed for the demonstration phase is shown in Figure 32. AP will manage each phase of the proposed Demo. It will be assisted under agreements with other parties such as the State of West Virginia, which will cost share and support the project in various ways. West Virginia University will provide technical consultants on an as needed basis. (See Appendix 3).

Cryenco will be a participant and will provide the TASHER to the project on commercial terms. Cryenco will also serve as a technical advisor.

Invitation Energy will supply the CMM and the project site, also on commercial terms.

AP will complete the engineering work necessary for the construction of the Demo facility. This work will entail close cooperation with Cryenco, particularly with their 500 gpd prototype unit expected to be in operation later this year. AP may employ an engineering firm for assistance in this aspect of the work.

The second phase of the Demo Project will consist of the procurement and construction of the equipment for the project. The principal piece of hardware is the TASHER itself, and AP will work closely with Cryenco on the scheduling and installation of this unit. AP may continue to use the services of an engineering company to install the gas conditioning plant.

During the operating phase, AP will supply operators, and take general responsibility for the management and operation of the facility. In addition, AP will 
direct the distribution and marketing of the product LNG, under appropriate commercial terms.

The key project personnel for Appalachian-Pacific will be Charlie Estes, President, and Ray Zahradnik. The key person for Cryenco will be John Wollan. Copies of their resumes are included in the Supplemental Material section.

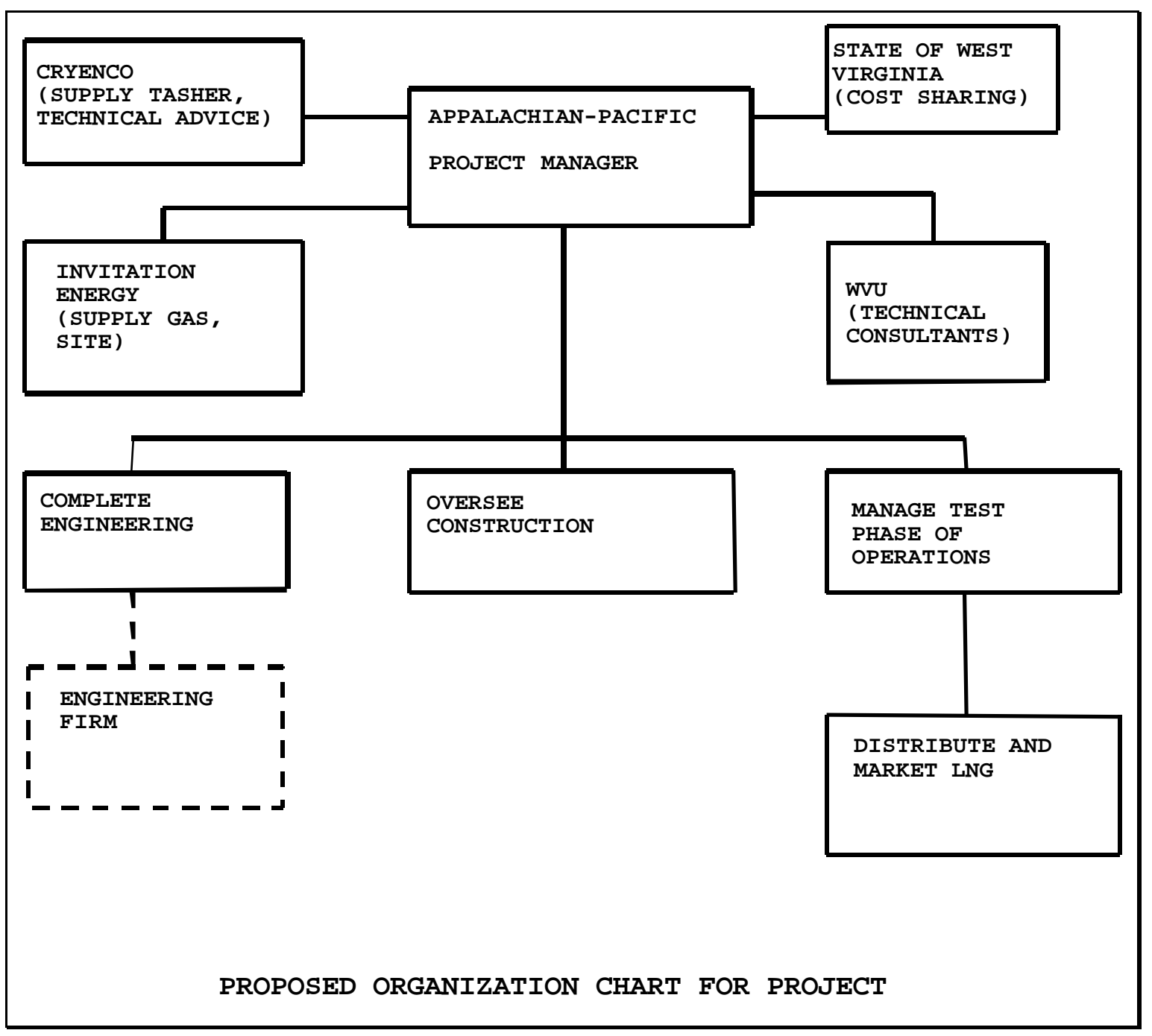




\subsection{Project Schedule}

An overall schedule for the project is provided in Figure 33. On this schedule, the project has been assigned a February 2000 start date. This date corresponds to the time when Cryenco and their Los Alamos colleagues should be completing the operational testing of the 500 gpd prototype TASHER. It also allows the DOE about 6 months to determine if it wishes to proceed with the proposed Demonstration.

In addition to the Cryenco testing of the 500 gpd prototype, AP intends to proceed with a companion program of testing related to the gas conditioning system that will be used in the Demo.

A separate proposal has been made to the DOE/FETC for continued development work on the gas conditioning system. The proposed statement of work for this activity is provided below. The major Tasks are shown in Figure 33. The total costs for these tasks as well as the costs for the major activities in the Demo Project are also shown in Figure 33.

The critical path items on the overall project schedule are the initiation of the Cryenco test program, which has been assumed to be October 1999, and the initiation of the DOE Demo project, assumed to occur in late December of this year. Failure of either of these kickoff dates to be realized will postpone the project proportionately.

The other factor controlling the project schedule is the time for the fabrication and testing of the 10,000 gpd TASHER. Cryenco has provided an estimate of 15 months for this activity, and that duration drives the overall schedule.

A period of 24 months has been chosen as the time to start up, test and operate the facility. This period is long enough to demonstrate the features of the system and to determine the market viability of the LNG product.

\subsubsection{Statement of Work for Cryenco Test Program}

\section{Task 1.System Design}

Task 1.1

Task 1.2

Task 1.3
Establish Design Specifications for TASHER

Identify and characterize additional elements in system

CMM delivery

Gas combustion unit for TAD

Utility Requirements for TASHER

Downstream storage and distribution of LNG

Review existing technologies for conditioning CMM to meet design specs. 
Task 1.4 Comments and discussion about suitability of existing technologies.

Task $1.5 \quad$ Prepare Preliminary system design.

Task 1.6 Estimate Preliminary Capital and Operating costs

$\underline{\text { Task 2.Operational Test Plan }}$

Task 2.1 Ascertain schedule and special requirements of Cryenco Demonstration (ca. 500 gpd) TASHER.

Task 2.2 Develop test plan, schedule and equipment for operational testing o of Gas Conditioning System (GCS) with Demonstration TASHER.

Task 2.3 Procure GCS equipment, deliver and assemble at TASHER site and carry out test plan.

Task 2.4 Evaluate and document results from test

\section{$\underline{\text { Task 3. Final Design Report }}$}

Task 3.1 Complete process design for 10,000 gpd TASHER system

Task 3.2 Complete final report and submit to DOE.

\subsubsection{Statement of Work for Demonstration Project}

\section{$\underline{\text { Task 1.Engineering }}$}

This task involves activities that will incorporate the results of the Cryenco test program into the design and equipment specifications for the Demonstration facility. More detailed evaluations of the CMM composition will be made, and a final design for the gas conditioning system will be established. An engineering firm may be selected to assist in this effort.

During this period, final financial arrangements will be made to secure private financing for the project's share of the project expense. As noted above, the current thinking is that a business loan will be obtained to cover the project's share of the cost, especially for the capital equipment costs. However, other options may be considered and utilized.

Task 1.1 Evaluation of process design from Cryenco Test program

Task $1.2 \quad$ Specification of CMM feed composition

Task $1.3 \quad$ Final System Design completed 
Task 1.4 Equipment Bid Packages prepared

Task $1.5 \quad$ Financing Terms arranged.

\section{$\underline{\text { Task 2.Procurement and Construction }}$}

This task involves the procurement of the various equipment for the facility and the construction of the Demonstration plant itself.

Task 2.1 Procurement

Task 2.1.1 Equipment Bid Packages released/responses evaluated (where necessary)

Task 2.1.2 Firm Orders placed (where necessary)

Task 2.1.3 Equipment received and placed at site

Task 2.2 Construction

Task 2.2.1 Site Preparation

Task 2.2.2 Equipment Assembly

Task 2.2.3 Component Testing

\section{$\underline{\text { Task 3. Operations }}$}

This task involves the start up and continued operation of the facility. Upon completion of the Demo Test period, a final report will be prepared and submitted to the DOE.

\section{Task $3.1 \quad$ Process Start up}

Task 3.2 Equipment acceptance and Start of Demo Operations

Task 3.3 Final Report 


\subsection{Environmental Considerations and Benefits}

\subsection{Demonstration Project Site Impact Analysis}

\subsubsection{Gas Reserve}

The initial coal mine methane potential at this site is presented in the Attachment 1. Presently, the coal mine methane (a greenhouse gas) is vented to the atmosphere. The estimated gas reserve (see attachment 1 ) shows the extent of the environmental problem. The onsite utilization of coal mine gas would reduce the amount of greenhouse gases vented to the environment.

\subsubsection{Potential water pollution}

It is anticipated that the project site will have frequent truck traffic, which may lead to oil and hydrocarbon leaks at the site. The oil can get washed into surface waters from roads and parking lots, and there is potential for groundwater contamination. The water quality in nearby streams can be monitored up stream and down stream of the project site to ascertain the influence of the project site on stream water.

\subsubsection{Potential soil damage from leakage of lubricants}

Low level discharges from urban runoff and treatment of roads contribute to a significant part of the total hydrocarbon discharges. As such, the soil at the project site may get contaminated from leakage of lubricants and petroleum products used at the site and in vehicles. The petroleum products used at the project site may enter surface soils through spills. The retention capacity of soils depends on the particle size distribution and the viscosity of the lubricants.

The contamination of soils by petroleum products can have an influence on plant growth and the quality of runoff water. The potential methods for site remediation of contaminated soils depend on the type of soils, type of lubricants, and the extent of the problem. Biodegradation of petroleum contaminated soils have been used successfully in the past. A site remediation plan needs to be developed for potential soil contamination at the project site. 


\section{REFERENCES:}

1. Echterhoff, L. W. (The M. W/ Kellog Company) "State of the Art of Natural Gas Processing Technologies - Topical Report Task 3, Vol 1, March 1991 GRI Contract No. 5088-221-1753

2. Hajayla, Shirad(Catalytica, Inc.) private communication.

3. National Research Center for Coal \& Energy, and Estes \& Zahradnik, Topical Report, "On-Site Power Generation at the Emerald Mine using Coal Mine Methane:, July, 1995, METC Contract No. DE-AC21-95MC32185

4. Richmond, David (Raytheon Engineers \& Constructors) private communication.

5. Ritzman, Bob (Zeochem) private communication.

6. Tannehill, C. C. and C. Galvin (Purvin \& Gertz, Inc.) 1993, Business Characteristics of the Natural Gas Conditioning Industry, Gas Research Institute.

7. Vapor-Liquid Equilibrium Data by Ju Chin Chu, Shu Lung Wang, Sherman L. Levy and Rajendra Paul, published by J. W. Edwards, Inc. Ann Arbor, Michigan. 
Schedule Name : TASHER Demonstration - 10,000gpd Scale

As-of Date : 16-Jun-99 9:00a

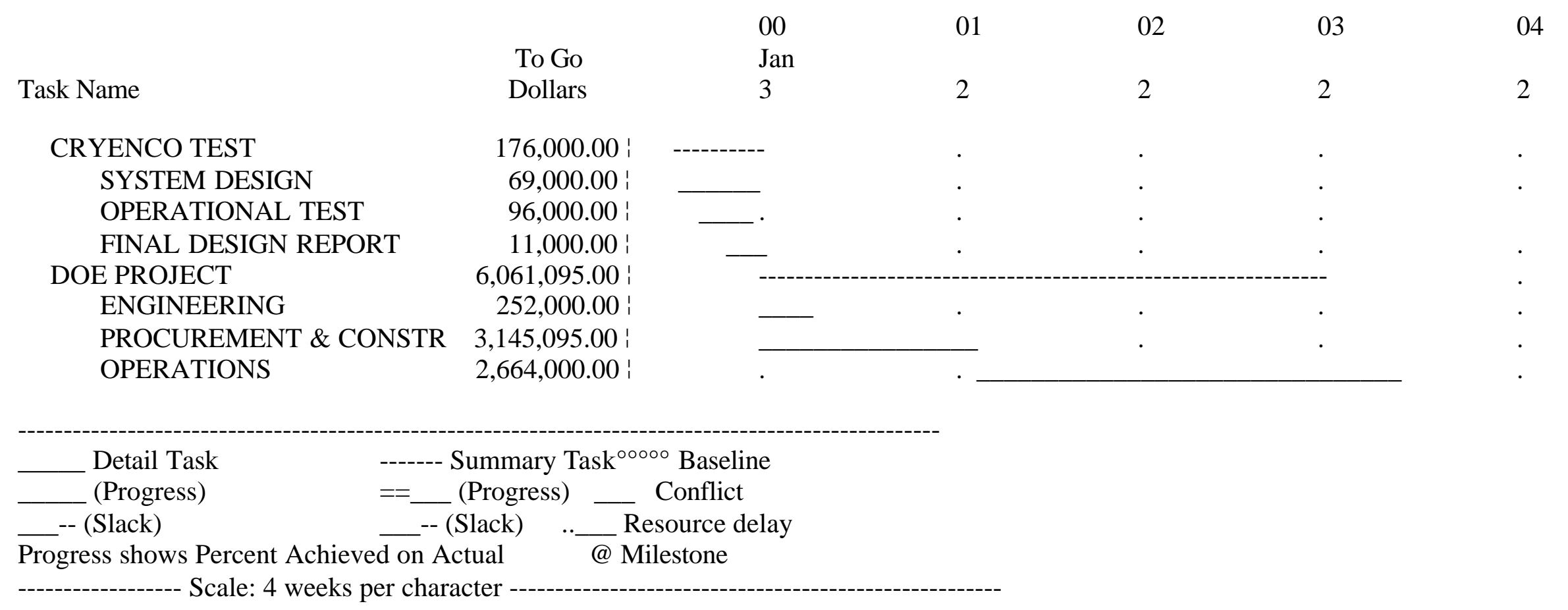

TIME LINE Gantt Chart Report, Strip 1 
Appendicies 


\section{Appendix 1: Resumes of Key Personnel}

\section{RAYMOND L. ZAHRADNIK}

P.O. Box 771814

Steamboat Springs, Colorado 80477

(970) 879-2304

Energy Industry Executive with over 40 years successful management experience in directing the development and commercialization of pioneering energy resources/technologies as industry executive, consultant, government R\&D director, and university professor.

Dr. Zahradnik assisted Energy Research Corporation (ERC) in preparing a successful proposal for the Department of Energy's Clean Coal Technology Program, Round V. The proposal involved the co-location of a $2 \mathrm{MW}$ fuel cell power plant with an Integrated Coal Gasification Combined Cycle Facility. The overall project is expected to produce several hundred megawatts, and cost over $\$ 500$ Million. Dr. Zahradnik's role in the proposal preparation was to contribute to and evaluate the overall process flow scheme for the fuel cell portion of the project, the heat and material balance computations, the process test program and the commercialization plan. In addition, Dr. Zahradnik assisted ERC in finding a partner and site for this fuel cell project.

\section{CAREER HIGHLIGHTS}

1991 to Present MOUNTAIN BAY ASSOCIATES, INC.

President

Engineering consulting firm providing technical and management advisory services to the industrial/energy community.

\section{OCCIDENTIAL PETROLEUM CORPORATION}

President/CEO - Occidential Oil Shale, Inc.

Directed planning, engineering and operations for the commercialization of shale mining, retorting and processing technology on production scale. Let shale mining, retorting and processing technology on production scale. Led company efforts to propose a $\$ 2.19$ billion commercial project to the SFC. Later developed a $\$ 200$ million cooperative proof-of-concept project at Federal Leasehold Tract $\mathrm{Cb}$ in Colorado.

Vice President, Technology - Cities Service Oil and Gas Corporation. Directed technical and service functions for Natural Gas Liquids Division. 9/85 to 2/87. 
General Manager - Occidential Oil Shale, Inc.

Oversaw the successful upgrading and demonstration of the modified in situ technology to product oil on a commercial scale. $3 / 82$ to $11 / 82$.

Director - Occidential Research Corporation

Directed successful corporate research programs in mining, oil and gas production, coal, oil shale and geothermal. 10/78-2/82.

$1 / 78$ to $9 / 78$

$1 / 75$ to $9 / 76$

$5 / 74$ to $1 / 75$

1972 to 1974
RAY ZAHRADNIK CONSULTING, INC.

Energy Consulting.

Served as the principal energy resources development consultant to 10 Fortune 500 Corporations and many other institutions, small businesses and government agencies.

\section{ENERGY RESEARCH AND DEVELOPMENT} ADMINISTRATION

Director

Managed ERDA's growing research and development programs in coal gasification, liquefaction, combustion, as well as advanced power systems.

\section{OFFICE OF COAL RESEARCH, DEPARTMENT OF INTERIOR}

Director

Responsible for directing technical operations for the Interior Department's $\$ 500$ million coal research program.

\section{NATIONAL SCIENCE FOUNDATION}

Acting Deputy Director

Office of Energy R\&D Policy - Provided independent advice and recommendations to the Executive Officer of the President on Energy Research policy issues.

Energy Policy Analyst

Evaluated effectiveness of federal coal and geothermal R\&D programs for the Office of Management and Budget.

Program Director 
Industrial Consultant.

Performed complex technical and economic studies in coal gasification, process control and chemical engineering for over 20 major industrial clients.

1966 to 1974

\section{CARNEGIE-MELLON UNIVERSITY}

Professor

Published 24 pages and a book "The theory and Techniques of Optimization" while teaching a full load of graduate and undergraduate students and courses.

1961 to 1966

\section{WESTINGHOUSE RESEARCH AND DEVELOPMENT CENTER}

Senior Engineer.

Conducted research on fuel cells and computer systems searches in profess modeling, optimal control, etc. Published 15 papers.

\section{EDUCATION}

Ph.D. in Chemical Engineering - Carnegie Institute of Technology M. S. in Chemical Engineering - Carnegie Institute of Technology

B. S . in Chemical Engineering - Carnegie Institute of Technology

\section{PERSONAL}

Date of Birth: September 18, 1936

Health: Excellent

Family of three grown children. Other interests include skiing and biking. 


\section{CHARLES D. ESTES}

1600 Wilson Boulevard

Suite 900

Arlington, Virginia 22209

\section{PROFESSIONAL EXPERIENCE}

3/92 to Present

$1 / 87$ to $3 / 92$

$7 / 81$ to $1 / 87$
FOUNDED CHARLES D. ESTES \& ASSOCIATES

Consulting in energy, natural resources, and budget and appropriations issues. Project development.

\section{STAFF DIRECTOR, U.S. SENATE APPROPRIATIONS SUBCOMMITTEE ON INTERIOR AND RELATED AGENCIES}

Had principal responsibility for analyzing the President's annual budget requests for forty-four agencies totaling roughly $\$ 13$ billion; recommending and defending budget amendments before the Chairman, Senator Robert C. Byrd, and the other fourteen Subcommittee members; and staffing the Chairman during the three to five-day periods when the Interior Appropriations Bill was considered on the Senate Floor, and during the several weeks of pre-conference and formal conference negotiations each year with the House of Representatives conferees. These responsibilities required a detailed knowledge of law, policy, and substance related to federal energy, natural resources, and environmental programs. Each year involved scores of meetings with Members of Congress and thousands of discussions with Congressional staff, Executive Agency staff; representatives from industrial, environmental, and other special interest groups; and with private citizens. As Staff Director, Estes managed a subcommittee staff of three other professionals and one secretary.

In additional to his duties on the Interior Subcommittee, for a period of approximately ten years he provided detailed and primary staff assistance to Senator Byrd for flood protection and inland water navigation issues as well as for economic development matters related to National Parks, Forest, and Wildlife Refuges in West Virginia.

MINORITY STAFF DIRECTOR, SENATE APPROPRIATIONS SUBCOMMITTEE ON INTERIOR AND RELATED AGENCIES 
$2 / 81$ to $7 / 81$

$6 / 79$ to $1 / 81$

$12 / 77$ to $6 / 79$

$4 / 76$ to $12 / 77$

$5 / 71$ to $4 / 76$

$9 / 70$ to $3 / 71$
Responsibilities during this period were similar to those described above but were limited primarily to Democratic interests in the Interior Bill.

\section{BUDGET ANALYST, DEPARTMENTAL BUDGET OFFICE, U.S. DEPARTMENT OF THE INTERIOR}

Worked on budget justification for Secretary Watt's five-year, $\$ 1$ billion plan to rehabilitate building, roads and utilities in the National Park System. Other responsibilities included analysis of agency budget requests for federal minerals management agencies.

\section{PROFESSIONAL STAFF ASSISTANT, SENATE APPROPRIATIONS SUBCOMMITTEE ON INTERIOR AND RELATED AGENCIES}

Principal responsibilities included advising the staff director and the Chairman on budget requirements for most non-nuclear energy programs of the U.S. Department of Energy as well as mineralsrelated R\&D and management programs of the Department of Interior.

\section{CHIEF, NON-NUCLEAR ENERGY TECHNOLOGY BRANCH, DEPARTMENTAL BUDGET OFFICE, U.S. DEPARTMENT OF ENERGY}

Assignment included managing a small staff with budget formulation and execution responsibilities for the coal, oil, gas, solar and geothermal technology programs of the Department.

\section{BUDGET ANALYST, FEDERAL ENERGY ADMINISTRATION}

Position included budget formulation responsibilities for energy conservation's, regulatory and energy resource development programs with some initial planning and review responsibilities for the Strategic Petroleum Reserve.

Employed in Controller's Office: Federal Power Commission (now

FERC), holding several positions including program analyst, management analyst, and, lastly, assistant to the controller.

Active duty with the U.S. Army as part of my commitment to the District of Columbia National Guard. 


\section{EDUCATION}

The American University: BA government, 1970: completed 15 hours in graduate-level economics.

\section{OUTSIDE ACTIVITIES}

Entering second year as chairman of the Accokeek Foundation, a non-profit educational institution and land trust which manages the National Colonial Farm at Piscataway National Park directly across the Potomac River from George Washington's home, Mount Vernon. The Foundation has a staff of twelve and an annual budget of approximately $\$ 1,000,000$.

Founded Friends of the Potomac in 1997. The Friends is a Potomac Basin-wide umbrella organization composed of non-profit organizations, local governments, and business interests including Mettiki Coal, Anker Energy and Westvaco, among others. The Potomac River Basin was designated an American Heritage River by the President in 1998 based on the Friends' application which was scored number one among 124 U.S. river applications considered by the White House advisory committee.

Previously served five years as Vice President, Palisades Citizen Association; Washington, D.C.

Served approximately three years on the Mayor's Task Force to develop a 4(f) statement on rehabilitation and replacement options for The Whitehurst Freeway, Washington, D.C. 
NAME: DOUGLAS GENE PATCHEN

PROPOSED POSITION: Program Coordinator, Utilization of Coal Mine Methane

EDUCATION: Harpur College, 1964

Binghamton, New York

B.A. Geology and Math

State University of New York at Binghamton, 1967

Binghamton, New York

M.A. Geology

Syracuse University, 1972

Syracuse, New York

Ph.D., Geology

\section{YEARS OF RELEVANT EXPERIENCE: 28}

AREAS OF QUALIFICATION: Dr. Patchen has extensive experience in research on oil, natural gas, coalbed methane, stratigraphy, and petrology. He has managed oil and gas research projects in the Appalachian Basin involving the Devonian shales, tight gasbearing reservoirs, coal-bed methane and heterogeneity in oil reservoirs. In addition, he has been selected to manage the Appalachian basin portion of several nationwide studies, including the Correlation of Stratigraphic Units of North America (COSUNA) project for the American Association of Petroleum Geologists (AAPG). He has published more than 100 papers and abstracts dealing with oil and gas geology, stratigraphy, petrology and summaries of drilling activity.

\section{CAREER HISTORY:}

\section{National Research Center for Coal and Energy, Morgantown, WV, 1990 to Present Position: Program Manager Supervisor: John Holmgren (304) 293-2867}

Oversees the planning, research efforts, and reporting of complex projects; acting director of the Appalachian Oil and natural Gas Research Consortium; served as program manager of a three year project entitled "Measuring and Predicting Reservoir Heterogeneity in Complex Deposystems"; currently manages two projects, The Atlas of Major Appalachian Gas Plays, and Enhancement of the Tertiary Oil Recovery Information System.

\section{West Virginia Geological and Economic Survey, Morgantown, WV, 1990 to Present Position: Chief Geologist Supervisor: Larry Woodfork (304) 594-2331}

Oversees all areas of geologic research conducted by the geological survey, including oil and gas, coal, economic and field mapping; chairs the Research Committee which 
approves project proposals, conducts annual reviews of research in progress, and obtains internal and external reviews of all research products prior to publication; serves as the point person on research teams from the proposal writing stage through to the completion of research contracts.

West Virginia Geological and Economic Survey, Morgantown, WV, 1971 to Present Position: $\quad$ Petroleum Geologist and Head, Oil and Gas Section Supervisor: Larry Woodfork (304) 594-2331 (formerly Robert B. Erwin, 19711988)

Oversees the functional operation of the section in both service and research categories; supervises geologists and other staff; is responsible for the compilation of drilling statistics and annual reports for several oil and gas organizations; coordinates the annual Appalachian Petroleum Geology Symposium and serves on various committees; oversees the preservation and utilization of basic data such as maps, drillers' logs, mechanical logs, and the core and sample library.

West Virginia University, Morgantown, WV, 1982 to Present

Position: $\quad$ Adjunct Professor of Geology

Supervisor: Dr. Alan Donaldson (304) 293-5603

Has worked with the Geology Department to obtain research contracts and to host the Annual Appalachian Petroleum Geology Symposium.

West Virginia University, Morgantown, WV, 1973 to Present

Position: Associate member of the Graduate Faculty

Supervisor: Self

Supervises graduate research at the Ph.D. level as well as the masters level.

West Virginia Geological and Economic Survey, Morgantown, WV, 1979-1985

Position: $\quad$ Chief, Fossil Fuels Division

Supervisor: Dr. Robert Erwin (retired)

Administrative duties included budget preparation for both the Oil and Gas and Coal sections of the survey; was responsible for all research in these two sections.

West Virginia University, Morgantown, WV, 1977-1982

Position: Adjunct Associate Professor of Geology

Supervisor: Dr. Alan Donaldson (304) 293-5603

Served on graduate student committees and chaired two Ph.D. committees and several MS committees.

West Virginia University, Morgantown, WV, 1973-1977

Position: $\quad$ Adjunct Assistant Profess or of Geology 


\section{Supervisor: Dr. Alan Donaldson (304) 293-5603}

Served on numerous graduate student committees; occasionally taught classes in well logging.

West Virginia Geological and Economic Survey, Morgantown, WV, 1969-1970

Position: Cooperating Geologist

Supervisor: Dr. Robert Erwin (retired)

Worked on special projects leading to survey publications; compiled drilling statistics; performed subsurface geology and petrographic work on several Silurian sandstones.

\section{West Virginia Geological and Economic Survey, Morgantown, WV, 1966-1968 Position: Mineralogist-Petrographer Supervisor: $\quad$ Dr. Paul H. Price (deceased)}

Combined core and sample descriptions with subsurface mapping and correlation; produced four circulars dealing with current exploration and development of Devonian and Silurian gas reservoirs.

\section{PROFESSIONAL AFFILIATIONS: $\quad$ Society of Sigma Xi \\ New York State Geological Association American Association of Petroleum}

Geologists

Appalachian Geological Society Pittsburgh Geological Society

Pittsburgh Association of Petroleum

Geologists

\section{COMMITTEES AND AWARDS:}

Past President, Vice President, Secretary and Treasurer of the West Virginia University Chapter of the Society of Sigma XI.

Current Vice President, former Treasurer and Secretary, Eastern Section of the American Association of Petroleum Geologists.

Member, Committee on the Preservation of Cores and Samples for AAPG.

Former member, Committee on Correlation of Stratigraphic names for AAPG. CSD Chair (alternate) and API Respondent (alternate) for the Committee on Statistics of Drilling for AAPG, 1971-1990.

Coordinator of Oil and Gas Development Papers for Pennsylvania, Ohio, Maryland, Virginia, and West Virginia and author of West Virginia papers. Member, Coalbed Methane Subcommittee for the Federal Power Commission (now FERC).

Best Paper Award, Eastern Section AAPG, 1974.

Public Service Award, Eastern Section AAPG, 1989. 


\section{SHORT RESUME \\ HEMA J. SIRIWARDANE}

Affiliation: Professor of Civil Engineering Telephone: 304-293-3031 ext. 620

7109

Department of Civil Engineering Fax: 304-293-

West Virginia University

Morgantown, West Virginia 26506

Expertise: Geotechnical Engineering, Geomechanics, Rock Mechanics, Computer Methods in Geotechnical Engineering.

Education: $\quad$ B.Sc(Honors), University of Ceylon, Peradeniya, Sri Lanka, 1975

Ph.D. Virginia Polytechnic Institute and State University, 1980

(Grade Point Average: 4.0)

Citizenship: United States Citizen

Professional Experience:

1988 - Present: $\quad$ Professor of Civil Engineering, West Virginia University, Morgantown, West Virginia

1984 - 1988: $\quad$ Associate Professor of Civil Engineering, West Virginia University

1981 - 1984: $\quad$ Assistant Professor of Civil Engineering, West Virginia University

$1977-1980 \quad$ Research Associate/Doctoral Student, Department of Civil Engineering, Geomechanics Group, VPI \& SU, Blacksburg, Virginia

\section{Related Experience:}

During the last 14 years, the major thrust of Pro. Siriwardane's research work has been on numerical modeling in geomechanics. He has extensive experience on Computer modeling and code development. Professor Siriwardane has served in a number of national and international committees dealing with rock mechanics and geomechanics. $\mathrm{He}$ ahs held membership in a number of professional organizations and honor societies including the International Society for Soil Mechanics and Foundation Engineering, International Society for Rock Mechanics, American Academy of Mechanics, Society of Engineering science, Society of Petroleum Engineers, and the International Association for Computer Methods and Advances in Geomechanics. He is currently a member of the Rock Mechanics committee of ASCE. He also serves as a member of the editorial board 
for the International Journal for Numerical Methods in Geomechanics. Professor Siriwardane serves as a member of the Board of Directors for the International Association for Computer Methods and Advances in Geomechanics. He has also been a reviewer for numerous journals in the area of geomechanics, and for a number of funding agencies. Recently, one of his papers dealing with longwall mining was selected for the best paper award by the American Association for Petroleum Geologists. Professor Siriwardane served as the Chairman for the Eighth International Conference on Computer Methods and Advances in Geomechanics, which was held in the USA in 1994; this conference was last held in the USA in 1976. 


\title{
SUMMARY RESUME
}

\author{
K. AMINIAN, Ph.D. \\ PETROLEUM \& NATURAL GAS ENGINNEING DEPARTMENT \\ WEST VIRGINIA UNIVERSITY \\ MORGANTOWN, WV 26506 \\ TELEPHONE (304) 293-5695
}

\section{PROFESSIONAL EXPERIENCE:}

7/92 to Present $\quad$ Professor of Petroleum and natural Gas Engineering

7/87 to 7/92 Associate Professor of Petroleum and Natural Gas Engineering

8/83 to 7/87 Assistant Professor of Petroleum and natural Gas Engineering

7/79 to 8/83 Reservoir Engineer Specialist, MichCon, Detroit, Michigan

\section{EDUCATION:}

Ph.D. Chemical Engineering, The University of Michigan Ann Arbor, Michigan, 1982.

M.S.E. Chemical Engineering, The University of Michigan, Ann Arbor, Michigan, 1978.

\section{RESEARCH GRANTS:}

1. Development of Standard Test Protocols and Barrier Design Models for In Situ Formed Barriers project EDTO7, DOE/METC, 8/94-10/95, \$1,000,000.

2. The Atlas of Major Appalachian Gas Plays, Grant No. DE-RP2-91MC28135, DOE/METC, 10/91 to 5/95, \$3,000,000.

3. Measuring and Predicting Reservoir Heterogeneity in Complex Deposystems, Grant No. DE-AC22-90BC14675, DOE/PETC, 10/90 to 10/93, \$5,000,000.

4. Co2 Enhanced Oil Recovery Mobility Control by In-Situ Chemical Precipitation, Grant No. 85MC2044, DOE/METC, 1/86 to 8/89, \$357,085.

5. Technology/Database Development for Eastern Gas Bearing Formations, Grant No. 85MC22189, DOE/METC, 11/85 to 8/87, \$149,575.

\section{PUBLICATIONS (a partial list):}

1. Predicting the Production Performance of Gas Reservoirs Using Production Type Curves, Scientia Iranica, Vol. 1, No. 3, pp. 13-20, 1994.

2. A Simple Method for Modeling Megascopic Heterogeneities in Fluid Flow Models in Porous Media, Math, Comput. Modelling, 1994.

3. Permeable Rock Model Using An Array of Pores, Powder Technology, Vol. 75, pp. 107-112, 1993. 
4. Pressure Analysis of an Unstimualted Horizontal Well Using type Curves, Journal of Petroleum Technology, Vol. 43, No. 8, pp. 988-993, 1991.

5. Recovery of Oil from Underground Drill Sites, Energy Sources, Vol. 13, pp. 417-431, 1991.

6. Production Decline Behavior of Gas Wells in Multi-Well Reservoirs, Journal of Petroleum Technology, Vol. 42, No. 12, pp. 1573-1579, 1990.

7. Simultaneous Calculation of Pressure and Temperature in Flowing Gas Wells, SPE Computer Applications, May-June Issue, pp. 25-28, 1990.

8. Production History Analysis in Predicting Dry Gas-Well Performance, International Journal of Petroleum Science and Engineering, Elsevier Science Publisher, Netherlands, Vol. 2, pp. 13-26, 1989.

9. Determining Gas Pseudo-functions, SPE Computer Applications, September-October Issue, pp. 12, 1989.

10. Phase-Equilibrium and Reservoir Depletion Calculations on PC Using the PengRobinson, Equation of State, SPE Computer Applications, May-June Issue, pp. 20-21, 1989.

A Production Forecasting Model for Gas Wells, Math, Comput, Modelling, Vol. 11, pp. 391-395, Pergamon Press, 1988.

11. The Evaluation of Silurian-Niagaran Reef Belt in Northeastern Michigan, SPE Formation Evaluation, Vol. 2, No. 4, pp. 428-434, 1987.

\section{PROFESSIONAL ACTIVITIES}

1. General Chair For 1995 SPE Eastern Regional Conference and Exhibition

2. Officer of Northern West Virginia SPE Section (1990-95)

3. Coordinator and member of Steering Committee for North American Coalbed Methane Forum

4. Member of Conduct Committee for SPE 1992 annual Technical Conference

5. Member of SPE International Computer Applications Committee (86-89)

6. Technical Editor for SPE Computer Applications (88-90).

7. Technical Program Committee for 1988, 1989, 1991 SPE Eastern Regional Conference

8. Technical Program Committee for 1988 SPE/PIAM Conference 


\section{WILLIAM H. MCGLINCHEY}

8 Ashwood Lane

Morgantown, WV 26505

304.296.6568 - Home

304.293.7882 - Office

OBJECTIVE To be associated with a progressive organization where successful engineering and management experience will be value.

TRAINING

NATIONAL ALTERNATIVE FUELS TRAINING PROGRAM

West Virginia University (11/93 - present)

1460 Earl Core Road

Morgantown, WV 26505

\section{Facility Manager}

- Curricula Development (NGV, LPG, Forklifts, Transient Emissions)

- Government and Industry Liaison

DOE Clean Cities Program

EPA Office of Mobil Sources

- Moderated nationally broadcast Alternative Fuel

Teleconferences

- Development of National Alternative Fuels Training Center

Facility, Equipment Specification and Training

PUBLIC LIASON NATIONAL ENERGY SERVICE COMPANY, LP (6/92 - 11/93) 18 Harrison Street

Zanesville, $\mathrm{OH} 43702$

\section{Manager, Customer Service}

- Technical support in-house conversions and telephone "hot-line"

- Dealership network start-up and training

- Corporate "troubleshooter"

- Industry participation:

AGA CNG NGV-3 Systems Certification Taskforce EPA 40 CFR-84-86 NGV Emission Standards FTP-75 Federal Emission Testing

ADMINISTRATION METROPANE, INC. (1/91 - 6/92)

2772 Sawbury Boulevard

Columbia, $\mathrm{OH} 43235$ 


\section{Director of Technical Services}

- Staffing and training of NGV conversion facilities

- Developed corporate training program

- AGA/ASE committee for NGV Technician Certification

- Various Industry certifications

Alternative Fuels Institute-Hocking Tech College

Railroad Commission of Texas, CNG/LPG

Automotive Natural Gas Inc. (ANG)

IMPCO Technologies, Inc.

Gaseous Fuel Injection Systems, Inc. (GFI)

SALES

TEACHING

MANAGEMENT
ALLEN GROUP, TESTPRODUCTS DIVISION, (1985 - 1991)

6360 Promier Ave. NW

North Canton, $\mathrm{OH} 44720$

\section{Manufacturers' Representative}

- Developed Central Ohio (6 country) sales organization

- Average Annual sales volume - \$250,000

- National Accounts activity:

Columbia Gas, Goodyear, Firestone, Precision Tune

- Advisory Boards: Ohio EPA Program, ASA of Ohio Ed. Comm.

- Taught latest automotive computer technology classes

COLUMBUS PARAPROFESSIONAL INSTITUTE (1982 - 1986)

1516 West Broad St.

Columbus, $\mathrm{OH} 43216$

\section{Senior Instructor}

- Developed automotive curriculum for one year program, ASE certification

- Specialized in:

Fuel injection, computer controls,

Electronics, chassis and suspension

- Consultant with local service shops

- WOSU Radio Open Line - "Car Doctor” (3 Years)

\section{COMBUSTION ENGINEERING (1979 - 1982)}

810 Slocum Street

Lancaster, $\mathrm{OH} 43130$

\section{Quality Control Manager}

- Established company quality policies and major quality objectives

- Designed organizational structure needed to carry out objectives 
- Obtained U.S. patent - Impact Resistant Paint Formulation

\section{EDUCATION}

- Ohio State University, Columbus, OH, Industrial Engineering 1964-1967

- Western Electric In-Service Course: Quality Control I, II 1970 1972

- $\quad$ Ohio Teaching Certificate - Automotive Mechanics 1977 1983

- National Institute for Automotive Service Excellence (ASE)CMAT 1983

References are available upon request. 


\section{Appendix 2: Introduction of Appalachian-Pacific Coal Mine Methane Power Company, LLC}

Appalachian-Pacific Coal Mine Methane Power Company is a limited liability company chartered in West Virginia in 1996. The Company is wholly owned by Charles Estes of Washington, DC and Dr. Raymond Zahradnik of Steamboat Springs, Colorado.

Formation of Appalachian-Pacific, a company created to develop commercial opportunities for the capture and utilization of waste methane from coal mines, was stimulated by the Department of Energy's Coal Mine Methane Program. In turn, Appalachian-Pacific is currently designing a project which is a catalyst for cooperation and achievement of mutual goals among four separate programs in the DOE: The Coal Mine Methane and TASHER Cryogenic Liquefier programs in Fossil Energy and the Heavy Vehicles and Clean Cities programs in the Office of Energy Efficiency. The project also supports specific clean air objectives of West Virginia, Pennsylvania and EPA and certain key technical objectives of the natural gas vehicle industry.

Appalachian-Pacific holds rights for the use and marketing of the TASHER liquefier technology for all applications associated with Coal Mine Methane in much of the world. The company also holds rights to use and market the TASHER technology for transportation appilcations using any feedstock is several eastern US states. These rights are held under agreement with the technology owner, a subsidiary of Chart Industries. It is anticipated that firm orders for commercial units may be placed in late 2001.

In related business, Appalachian-Pacific hopes to initiate the commercial sale and distribution of LNG (from conventional suppliers) throughout northern West Virginia and southwestern Pennsylvania prior to 2001.

Appalachian-Pacific is a Steering Committee member of the West Virginia Clean State Coalition. 
$\begin{array}{ll}\text { Appendix 3: } & \text { Letters of Cooperators } \\ & \text { Letters of Endorsement } \\ & \text { Other Supporting Material }\end{array}$ 
Mr. Charles Estes

Estes \& Associates

Suite 900

1600 Wilson Boulevard

Arlington, VA 22209

Dear Mr. Estes:

West Virginia University welcomes the opportunity to partner with Appalachian-Pacific in pursuing funding for a Phase III continuation of our joint program on coal mine methane funded through the Office of Fossil Energy of the US DOE.

We are excited about the prospect of developing a new technology which will stimulate spin off applications providing clean transportation fuels. Under Phase I and Phase II of the coal mine methane project, our joint efforts were directed toward research, development, and design studies to utilize methane escaping from coal mines as a positive resource instead of being released as a greenhouse gas which could damage the environment. These efforts have evolved to a concept using an advanced refrigeration design to produce liquid natural gas [LNG].

Under Phase III of the DOE program, a demonstration unit will be built to prove out the technical and economic feasibility of using this new system for producing LNG at remote sites. The project will also include applications for providing liquid natural gas as a transportation fuel for fleets operating in West Virginia. The benefits of this project include improved efficiency in mining operations, environmental protection, increased use of our natural gas resources in meeting needs for clean transportation fuels, and the opportunity to launch the Appalachian-Pacific Coal Mine Methane Power Company, LLC as a major new small business in West Virginia.

West Virginia University team members can contribute in areas such as systems and design studies, alternative fuel vehicle operations, training, and maintenance, economic studies, mine operations, and natural gas production, among other areas. Our National Alternative Fuels Training Laboratory will serve as a resource for familiarizing fleet managers with the benefits of using alternative fuels and will be available to provide training to service technicians. The Engines and Emissions Laboratory can provide expertise regarding the operation of vehicle engines using LNG as a fuel. The West Virginia Geological and Economic Survey and our Petroleum Technology Transfer Council Resource Center for the Appalachian Region can provide assistance with finding methane resources. We welcome the opportunity to work with your team members in demonstrating a successful project that both utilizes an important resource and adds to our capability of using natural gas as a transportation fuel in our State. 
As envisioned in our initial discussions starting in 1994, West Virginia University sees a natural transition of our role in the program as the work phases shift from conceptual studies and design to construction and demonstration. We believe it would be in the bests interests of the program if Appalachian-Pacific would assume a lead role for the Phase III effort. The demonstration project would best be managed under the auspices of a commercial company such as Appalachian-Pacific which would own the project and be responsible for other business aspects of operating the demonstration plant and providing fuels to other West Virginia businesses for transportation needs.

To that extent, West Virginia University proposes the following alternative scenarios regarding our submission of a joint proposal to pursue Phase III funding. If the US DOE elects to continue the project as a cost extension of the previous Phase I and Phase II efforts, WVU would seek the approval of DOE to reverse roles whereby Appalachian-Pacific would become the prime contractor and WVU would become a subcontractor to the project. If the US DOE elects to treat the Phase III solicitation as a new award, we would be pleased to participate as a subcontractor on a joint proposal submitted to DOE under the auspices of Estes \&Associates.

Our past relationship on this project has been mutually beneficial. We believe the Phase III continuation will favorably extend that relationship and bring added benefits to the State in establishing a suite of new businesses which use one of our great natural resources.

We look forward to working with you on this exciting project. Please respond to our above proposal regarding our respective roles in a Phase III continuation.

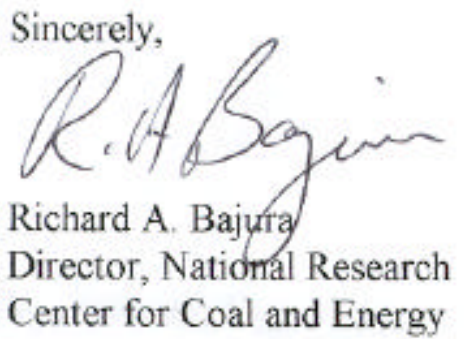

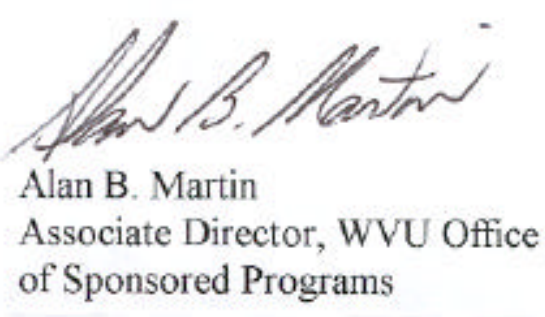

Alan B. Martin

of Sponsored Programs

9913. cmmag 


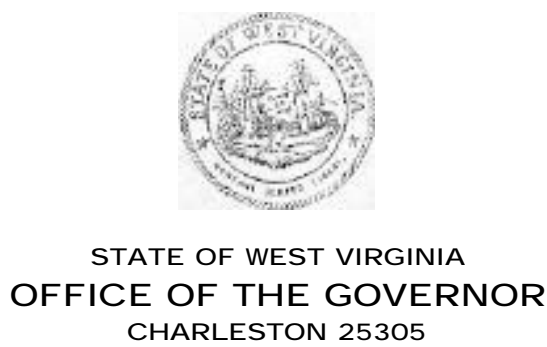

CECIL H. UNDERWOOD

GOVERNOR

The Honorable Robert Gee

June 18, 1999

Assistant Secretary for Fossil Energy

US Department of Energy

1000 Independence Ave., SW

Washington, DC 20585

Dear Secretary Gee:

I am pleased to indicate my support for Appalachian-Pacific and West Virginia University's proposed demonstration of a novel thermoaccoustic process to liquefy coal mine methane gasses presently venting from a mine in Marion County, West Virginia. The project sponsors indicate that the liquefied natural gas (LNG) product would be sold as transportation fuel to heavy vehicle fleet operators in the region.

As the first Clean State partner with the US Department of Energy (DOE), West Virginia is a national leader in the promotion and use of clean, alternative fuels. Our state ranks second in per capita private investment in alternative fuels infrastructure with 26 natural gas refueling stations. West Virginia's alternative fuel vehicle conversion tax credit establishes us as second to none in the state government's commitment to alternative fuels. I am proud to note that West Virginia University developed the acclaimed mobile dynamometer project which supports DOE's alternative fuels program testing and verification efforts throughout the Nation. The University also created and administers the National Alternative Fuels Training Consortium of some 20 sites across America where personnel are trained and certified to teach alternative fuel vehicle maintenance and safety.

Clearly, demonstration of the thermoaccoustic liquefaction technology would complement a distinguished commitment that we in the Mountain State have already made to the use of alternative transportation fuels. I am pleased to learn that the proposed demonstration also supports West Virginia's strategies for economic development and the wise use of our resources in multiple ways. First, Appalachian-Pacific was chartered in West Virginia. Second, its expressed purpose is to develop economic uses for coal mine methane, a plentiful state resource which is underutilized and often wasted. Third, the possible commercial production of LNG would create a new industry and new jobs in West Virginia while reducing American dependence on foreign oil. And, fourth, capturing 
The Honorable Robert Gee

June 18, 1999

Page Two

methane vented to the atmosphere from coal mines and converting it to clean transportation fuel would be a double benefit for the environment.

In closing, a successful demonstration, as proposed, will cause the loss of considerable sums from the State Road Fund as a consequence of the alternative fuel vehicle conversion tax credit program noted earlier. This lost revenue could total as much as $\$ 7,500,000$, and would not occur absent the demonstration. Whatever the eventual amount, which the State Tax Department will document later, I understand that these costs incurred by the State of West Virginia are in excess of the cost sharing percentage required of the demonstration project sponsors. Consequently, I ask that any excess cost share generated by the State be reserved to match possible cost sharing requirement on some subsequent State-sponsored project with the federal government.

My Administration is committed to facilitating the proposed demonstration in any manner that is appropriate and to the extent that the project is in compliance with all applicable laws and regulations. I wish Appalachian-Pacific and West Virginia University every success in this endeavor, and encourage the US Department of Energy to give this proposal every favorable consideration.

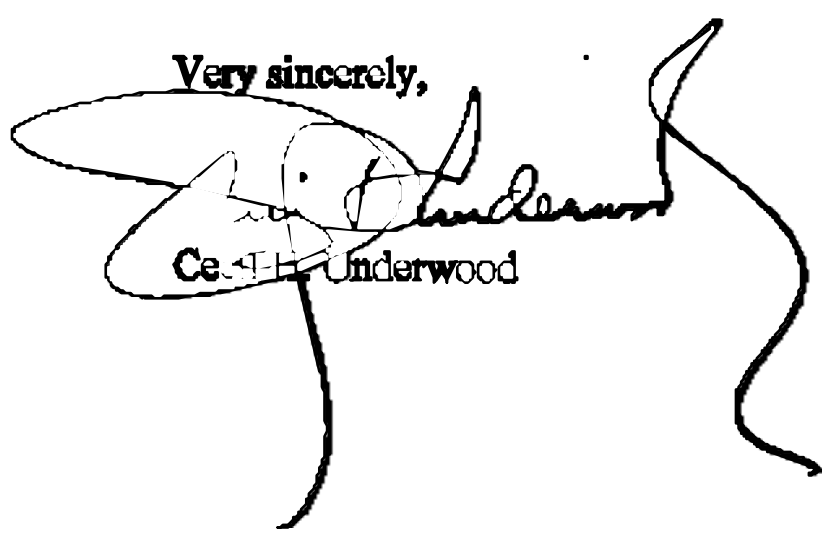

$\mathrm{CHU} / \mathrm{lc}$ 
P.O. Box BC

200 Rangos Lane

Washington, PA 15301

(724) 228.4200

(724) $225.2630 \mathrm{Fax}$

Mr. Charles D. Estes

Appalachian-Pacific

1600 Wilson Boulevard, Suite 900

Arlington, Virginia, 22209-2510

Dear Mr. Estes:

Waste Management of Washington, Pennsylvania is pleased to indicate its support, for and willingness to cooperate with, Appalachian-Pacific and West Virginia University's proposed demonstration to convert coal mine methane into liquefied natural gas (LNG),

Waste Management has been a corporate leader in the use of clean, alternative fuels. Our facility in Washington, Pennsylvania is acknowledged as one of the Nation's premier demonstrations of LNG use in heavy-duty fleet vehicles. The US DOE, the Gas Research Institute, Mack Trucks and Waste Management's commitment to a cleaner environment support our demonstration. Presently, we have converted seven of our refuse haulers to dedicated LNG engines with Mack L7G engines. We also operate a CVI refueling station on our site to dispense LNG to our fleet.

Our experience using LNG over the past 3 years has been very positive. The LNG-fueled vehicles have required no additional maintenance compared to their dieselfueled counterparts. While the range of the LNG trucks is currently less than that of the diesels, it is acceptable and is expected to improve with the introduction of new LNG engine technology.

The principal concern for us at present is the high cost of LNG fuel delivered to our site from Wyoming. The majority of that cost is for transportation and delivery. It is our hope that Appalachian-Pacific's successful demonstration of the thermoaccoustic liquefier in the region may provide environmentally superior $\mathrm{LNG}$ at a price which is more competitive with diesel fuel. Based on our own ongoing demonstration, we believe that there should be a substantial market for competitively priced LNG in the Western Pennsylvania - Northern West Virginia area.

Waste Management would be pleased to cooperate with Appalachian-Pacific and WVU during the demonstration phase of your proposed project as long as it coincides with the timing of our project, by sharing our insights on issues such as fuel quality and fuel management, among others. In addition, we are willing to host tours of our facility and discuss our practical experience using $\mathrm{LNG}$ as a transportation fuel with other companies that may wish to consider this option.

Thank you for offering to keep me informed on the progress of your proposed coal mine methane conversion demonstration. I look forward to our mutual cooperation and benefit in the future.

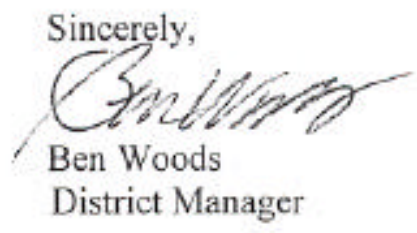




\section{INVTTATION ENERGY - APPALACHIAN.PACPNCF I D E N T I A L Pormal Agreement}

Invitation Energy, a company incorporated in West Virginia, and Appalachian-Pacific Coal Mine Methane Power Company, limited liability company registered in West Virginia and hereinafter referred to as A.P, wish to enter into a formal Agreement for the mutual benefit of both Invitation Energy and A.P (the Parties).

Whereas Invitation Energy owns rights to significant resources of coal mine methane (CMM) and expects to have the ability to deliver significant duily volumes of CMM for a period of at least ten years;

Whereas A-P is a participant, together with West Virginia University, in a Department of Energy (DOE) rcscarch and demonstration program to vtilize CMM and is interested in the conversion of coal mine methane to Liquetied Natural Gas and electricity;

Whereas A-P is interested in securing a supply of CMM throughout an anticipared 36 month demonstration period and for any subsequent commercial operation of the demonstrated liquefaction technology;

Whereas the demonstration project may begin construction on or about January 1,2001 and may begin demonstration operations in West Virginia approximutely six months later and inay be continued as a commercial scale project within 36 months of demonstration startup; and,

Whereas Invitation Energy is interested in supplying CMM for the demonstration and commercial projects;

Now therefore the Parties agree that:

1 Invitation Energy will make available not less than 1.3 billion Btu $(1,300,000,000)$ each day for use by A-P during a demonstration period of up to 36 months;

2 Invitation Energy will provide, at no additional cost, up to two acres of fenced area at its Whetstane site for A-P's use and equipmeat-siting during the demonstration and commercial periods, and A.P shall confer with Imvitation Energy to minimize any interference with the either Party's operations on the site;

3 Invitation Energy will supply to A-P at the above named site CMM that is free of hydrogen sulfide and with an hourly average Btu content not less than eight hundred and fifty (850) Btu per cubic foot;

4 During the demonstration period, the gas supplied will not have been blended with other, non-CMM gases without the prior written consent of A-P; 


\section{Appendix 4: West Virginia Alternative Fuels Tax Credit}

\section{WEST VIRGINIA ALTERNATIVE FUEL VEHICLE INCENTIVES AND LAWS}

West Virginia is the proud home of the West Virginia Clean Cities Coalition.

\section{Overview}

Compressed natural gas (CNG) and liquefied petroleum gas (LPG) powered vehicles are required to pay an annual fee, based on gross vehicle weight (gvw), instead of motor fuel excise taxes. The fee is $\$ 85$ for light-duty vehicles. Electric, LPG, and CNG vehicles are exempt from emission control inspections. Grant allowances were established under law with vocational and technical institutes to certify clean fuel mechanics. However, no funds have been appropriated for this grant program.

\section{Highlights}

Up to $\$ 3,750-\$ 50,000$ tax credit is available for the purchase or conversion of an alternative fuel vehicle (AFV), as of June $30,1997$.

Up to $\$ 10,000$ is available for state and local governments, school boards, and transit authorities to convert fleets to alternative fuels; this requires $50 \%$ in local matching funds.

\section{State Incentives}

The state of West Virginia will offer a tax credit for the incremental cost of purchasing an original equipment manufacturer (OEM) AFV, or for the cost of converting a vehicle to run on alternative fuels. The tax credit will apply to tax years after June 30,1997 , for either personal or corporate income tax. The maximum credit depends on the type and gvw of the vehicle, as shown below, and cannot exceed the actual incremental or conversion cost. The credit is taken in three equal increments over 3 years and expires June 30, 2007.

grw/Vehicle Tvpe
$10,000 \mathrm{lb}$ or less
$10,000-26,000 \mathrm{lb}$
Truck or van more than $26,000 \mathrm{lb}$
Bus seating 20 or more adults

\begin{tabular}{c} 
State Tax Credit \\
\hline 33,750 \\
$\$ 9,250$ \\
$\$ 50,000$ \\
$\$ 50,000$
\end{tabular}

The West Virginia Development Office Energy Efficiency Program has in place an alternative fuels grant program to assist local governments to convert their fleets to alternate fuels. Each governmental entity may receive up to $\$ 10,000$ to convert fleet vehicles to CNG or electricity, install CNG or methanol refueling equipment or an electrical recharging system, or to pay for incremental costs associated with the purchase of AFVs. Grants must show'at least a $50 \%$ match. The local match must be in cash or donation. Donations must be directly related to the vehicle conversions (i.e., donated fuel tanks, conversion kits, or both).

Grant monies are provided for approved projects on a reimbursement basis only. Eligible applicants are limited to county governments, incorporated municipalities, transit authorities, and school boards. For a copy of the application or for additional program information, contact Judith Dyer or Jeff Herholdt, Energy Efficiency Program, at (304) 558-0350.

West Virginia has received a State Energy Program grant from the U.S. Department of Energy (DOE). The project will put 30 OEM CNG vehicles on the road via a competitive grant program for governmental entities, which are members of the Clean State Program, and provide emissions testing data to DOE.

\footnotetext{
(From: "Incentive and Laws: Guide to Alternative Fuel Vehicle Incentives and Laws," USDOE, September 1998, p. 140)
} 
Appendix 5:

\section{Comparison of Greenhouse Gas Benefits of Silver Maple Trees and 10,000gpd TASHER (LNG)}

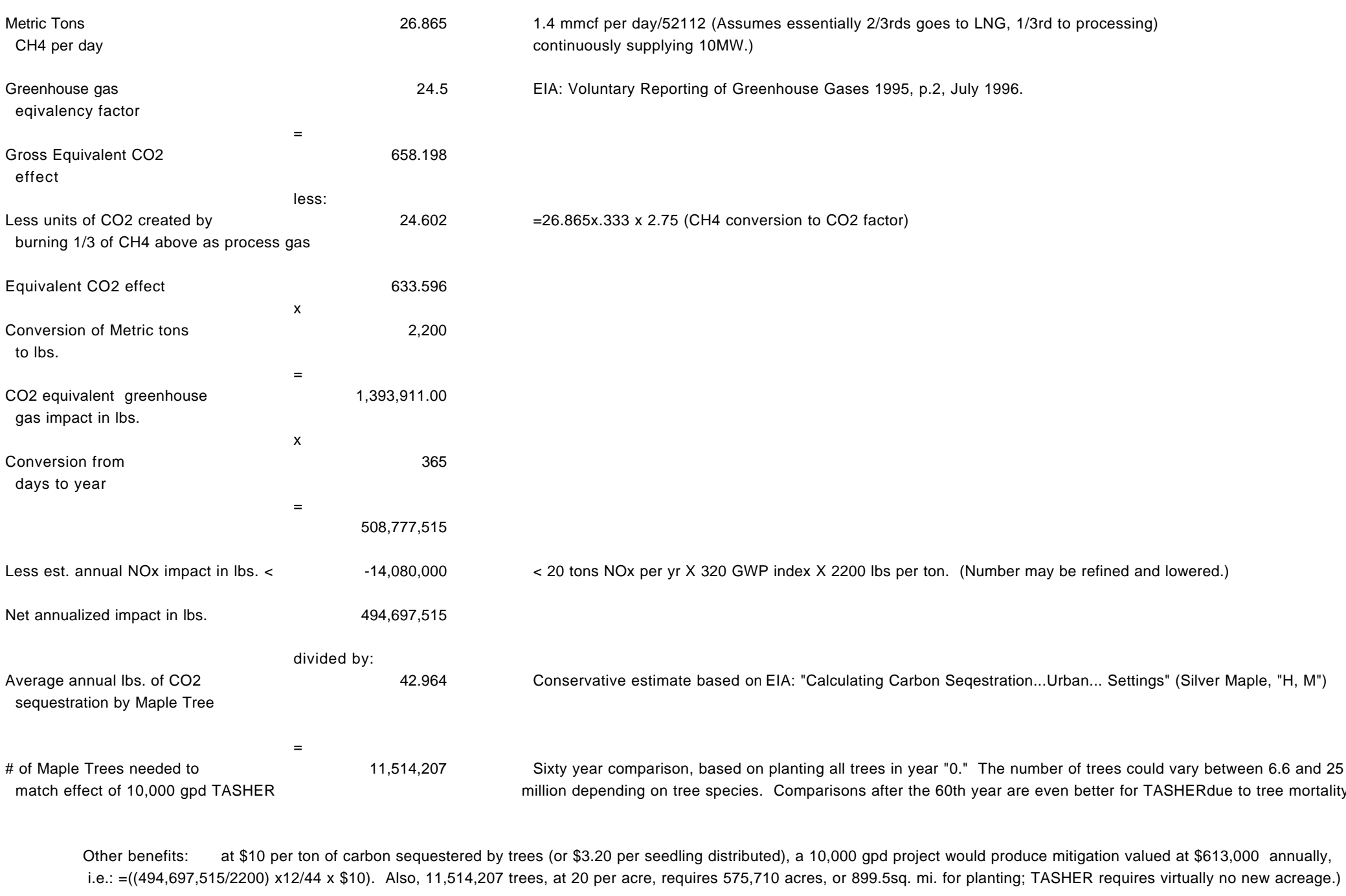

633.596

$508,777,515$

Less est. annual NOx impact in lbs. <

Net annualized impact in Ibs. 
Appendix 6: Technical Papers Related to Thermoacoustic Liquefier Technology 
Thermoacoustic Natural Gas Liquefier

Progress report, October, November, December 1998

Prepared for Brad Tomer and Ralph Avellanet

by Greg Swift (Los Alamos) January 16, 1999

This report summarizes current status and progress on the thermoacoustic natural gas liquefier since the last report (three months ago). It is organized around two main topics: the liquefier itself (at Cryenco) and fundamental technology development (at Los Alamos). I'll discuss administrative, financial, and logistical matters in a separate appendix, sent only to Brad and Ralph, because the distribution list for the main report is long and the non-technical subjects are best kept somewhat private.

\section{Liquefier}

This quarter we began in earnest working on the 500 gal/day production prototype, thanks to the availability of a meaningful development budget at Cryenco. When we double that budget, we will be progressing at a comfortable rate.

Rich Jaeger and I worked together at Cryenco to make a detailed design of our first large feedback pulse tube refrigerator (FPTR). This design builds very strongly on the previous OPTR, keeping essentially the same regenerator and pulse tube dimensions and keeping the same shell-and-tube heat exchanger designs except for more/smaller helium tubes and improved water and methane paths in the shell. The main change is the elimination of the two orifices, inertance, and compliance, replacing these with an acoustic-feedback pipe and an adjustable streaming-control gadget based on last summer's research at Los Alamos. The design is complete, and some 50 parts are now being machined.

In anticipation of liquefying much more gas than in the past, David Gardner at Los Alamos has designed a more sophisticated instrumentation and LNG handling and measurement system this quarter. In the past, we simply vented the methane that we liquefied. The new recirculation system will let us recycle the same methane over and over, accurately controlling the flow rate and measuring the temperatures. All of the components of this system have arrived at Cryenco, and assembly has begun.

Dan Olsen finished his preliminary burner-design work, thanks in part to a video telecon and further consultation with Geo Richards and Todd Sidwell at FETC Morgantown. Dan's contract with Cryenco is almost in place; we expect that he will start on detailed design work February 1. A spectrum of efficiencies and NOx emissions are possible for this burner: high efficiency requires good 
recuperative preheat of the combustion air, which produces high combustion temperatures and attendant high NOx production. We will probably pick a design toward the high-efficiency, high-emission end of this spectrum, because at this stage of development efficiency is a more visible benchmark than NOx, and this decision will keep blower cost and power low. (Expect efficiency around $85 \%$, NOx around $500 \mathrm{ppm}$. )

Repairs to the existing burner and thermoacoustic driver were made this quarter. We will use these to test the feedback refrigerator.

Fundamentals (Los Alamos)

Since their invention in 1815, Stirling heat engines have shown great promise, due to the Stirling cycle's inherent reversibility and, hence, high efficiency. Despite this promise, Stirling engines do not enjoy widespread commercial success, because they need multiple sliding seals capable of high-speed, high-stress operation. On the other hand, the intrinsically irreversible thermoacoustic engines we have developed at Los Alamos have no sliding seals or other moving parts, so they are inexpensive and reliable; their only shortcoming has been a relatively modest efficiency, thus far limited to $18 \%$. (This is the ratio of acoustic power produced to heat consumed. This record was set at Tektronix and later tied at Cryenco.) At Los Alamos this quarter, postdoc Scott Backhaus has demonstrated the best of both worlds: a hybrid thermoacoustic-Stirling engine, employing the inherently reversible Stirling cycle in an acoustic device having no moving parts. This first small laboratory prototype (approx $600-800 \mathrm{~W}$ acoustic power) has achieved an efficiency of $29 \%$ (again, the ratio of acoustic power produced to heat consumed). This efficiency is actually comparable to that of the common gasoline internal combustion engine, with its efficiency defined as the ratio of shaft power to heat of combustion of the fuel.

Talk of this type of hybrid has been in the acoustic community for decades, but we figured out the two keys to actually making it work, described in the enclosed short paper, which we have submitted to the journal Nature. These two key improvements are novel, so we have filed a patent. Expecting this patent to be more important than all our other thermoacoustic patents, we plan to apply for international coverage in due course.

Postdoc Phil Spoor completed his investigation of phase locking between two coupled thermoacoustic systems, as a vibration-cancelling technique, this quarter, and wrote up most of the results in a long paper, which we have submitted to the Journal of the Acoustical Society. He will write up a second paper on other aspects of this work soon. 


\title{
Thermoacoustic Natural Gas Liquifier
}

\author{
John J. Wollan and Mark Allen \\ Cryenco, Inc. \\ 3811 Joliet Street \\ Denver, CO 80239 USA \\ Gregory W. Swift \\ Los Alamos National Laboratory \\ Mail Stop K764 \\ Los Alamos, NM 87545 USA
}

\section{Introduction}

Cryenco, Inc. and Los Alamos National Laboratory (LANL) are collaborating to develop a natural gas powered, natural gas liquefier that will have no moving parts and require no electrical power. It will have good efficiency, remarkable reliability, low cost and will be transportable.

The liquefaction of natural gas, which occurs at $-161^{\circ} \mathrm{C}\left(-259^{\circ} \mathrm{F}\right)$ at atmospheric pressure, has previously required rather sophisticated refrigeration machinery. The 1990 invention of the thermoacoustically driven orifice pulse tube refrigerator (TADOPTR) provides cryogenic refrigeration with no moving parts for the first time. In short, this invention uses acoustic phenomena to produce refrigeration from heat. The basic refrigerator consists of nothing more than helium-filled heat exchangers and pipes, made of common materials, without exacting tolerances. In the Cryenco-LANL collaboration (with the LANL tasks supported by the US Department of Energy), we are developing a version of this invention suitable for use in the natural-gas industry. The project is known as "acoustic liquefaction" for short.

Our program plans call for a multi-phase development. Phase I will achieve a capacity of 500 gallon per day (i.e., approximately 42,000 standard cubic feet per day (scfd), requiring a refrigeration power of about $7 \mathrm{~kW}$ ), which is large enough to illuminate all the issues of large-scale acoustic liquefaction without undue cost, and to demonstrate the liquefaction of about $70 \%$ of input gas, while burning about $30 \%$. 
Phase II will develop versions of approximately $10^{6} \mathrm{scfd}=10,000$ gallon per day (gpd) capacity with a projected liquefaction rate of about $80 \%$ of the input gas. Phase III will be directed toward significantly larger systems. In parallel LANL will continue fundamental research on the technology directed toward increased efficiency.

\section{Objectives}

Although most natural gas is still carried from well to user as gas in pipelines, the use of liquefied natural gas (LNG) [1] has been increasing 5-10\% per year. A typical modern, large liquefaction plant costs a billion dollars, liquefies $10^{9} \mathrm{scfd}$, uses $15 \%$ of its throughput to power itself, and has substantial operating and maintenance costs. There are, however, a number of market applications where the need for smaller, reliable, inexpensive liquefaction equipment is clear. The objective of this program is to develop a new acoustic, natural gas liquefier with its inherent advantages - high reliability, low maintenance, natural gas burner powered, transportable - to address new and emerging LNG market opportunities.

\section{Technology}

\section{Background:}

Scientists at Los Alamos National Laboratory and the National Institute of Standards and Technology (NIST) invented the TADOPTR $[2,3]$ and built a small experimental version [4] directed toward cooling of infrared sensors on satellites. This invention and development follows a long evolution of related devices, each directed toward elimination of moving parts from heat engines and refrigerators.

Pulse tube refrigeration is a variation of the Stirling cycle. Stirling-cycle refrigeration [5], over a century old, has historically required two moving pistons, one of which is in contact with the cold temperature. In 1963 Gifford and Longsworth [6] discovered a refrigeration technique which eliminated the cold piston. They called this new technique pulse tube refrigeration. In 1984 Mikulin made a significant fundamental 
advance, adding a flow resistance; such "orifice" pulse tube refrigerators [7], developed largely at NIST in Colorado, now routinely reach $-220^{\circ} \mathrm{C}$. Subsequent improvements have brought the efficiency of pulse-tube refrigerators near that of Stirling refrigerators. The pulse tube refrigerators importance is primarily due to the elimination of the cold piston, a significant simplification leading to high reliability.

Until recently, pulse tube refrigerators still required one moving piston or valve(s), at ambient temperature. LANL and NIST eliminated this last moving part, substituting for it a thermoacoustic engine. Thermoacoustic engines $[8,9]$ generate an acoustic standing wave from heat, thus producing oscillating pressure at the frequency of the standing-wave resonance. Although thermoacoustic devices were discovered and explained qualitatively a century ago, research at LANL has led to quantitative understanding and the initiation of practical implementations.

\section{Description:}

The acoustic liquefier has three major components:

1. The power source - a natural gas burner.

2. A thermoacoustic driver (TAD), or engine, which converts the thermal input power (heat of combustion of the burner) to acoustic power, i.e. a pressure oscillation. (Fig. 1)

3. An orifice pulse tube refrigerator (OPTR) which converts the acoustic power into heat removal or refrigeration power. (Fig. 2)

The thermoacoustic driver consists of three heat exchangers and a resonator tube. Heating one of the driver heat exchangers to about $750^{\circ} \mathrm{C}$, or higher, while maintaining another heat exchanger at ambient creates a large temperature gradient across an intermediate heat exchanger (the "stack") of the resonator which induces a spontaneous pressure oscillation within the working gas (typically helium). These oscillations are sustained by maintaining the required temperature gradient from the burner heat input. 
The OPTR replaces the cold, moving displacer in a Stirling system with a gas column (in the pulse tube) and a compliance network (the orifice and reservoir volume) - all static components. The refrigerator has four heat exchangers and some associated tubes and piping. As the thermoacoustic driver alternately compresses and heats, then expands and cools the working helium gas in the pulse tube, the compliance network causes the gas to cycle with the appropriate phasing between the cold, heat extracting heat exchanger and the warm, heat rejection heat exchanger. Thus the OPTR pumps thermal energy from a cold reservoir to a warm reservoir, like any refrigeration device. Multiple OPTRs can be used, operating at staged cold temperatures, to improve system efficiency.

The length of the acoustic liquefier is determined by the operating frequency and the speed of sound in the working gas; the cross sectional area is proportional to the system power. The optimal operating frequency is a tradeoff between the desired machine size and practical limitations set by characteristic dimensions within the heat exchangers. The nominal length chosen is about 12 meters; this allows the system to be mounted on a standard flatbed trailer for transporting. This results in an operating frequency of approximates $40 \mathrm{~Hz}$. For a $500 \mathrm{gpd}$ system the resonator diameter is about $20 \mathrm{~cm}$. For a $10,000 \mathrm{gpd}$ system this increases to about $90 \mathrm{~cm}$.

\section{Project Description}

From the beginning of the Cryenco-LANL-NIST collaboration in 1994, the development of a practical acoustic liquefier appeared very challenging. Even the 500 gpd prototype represents a scale-up of a factor of 1600 in cooling power over the best previous TADOPTR, which used much simpler electric heater power for the engine and had an efficiency implying that it would have liquefied only $9 \%$ of a natural-gas stream while burning the other $91 \%$. To address this great challenge, our project encompasses three parallel thrusts:

1. Phased Prototype Development. As described in the introduction, we chose to break the development into several phases, with target capacities of 500 gallons per 
day in Phase 1, 10,000 gallons per day in Phase II and over 10,000 gallons per day in Phase III.

2. Interaction and Cooperation. To develop the Phase I prototype as quickly as possible, by using the strengths of each partner, we have adopted a highly interactive working relationship. LANL personnel have been at Cryenco one-third of the time, and daily telephone contact is the norm at other times. Most physics design and test-andmeasurement duties have been LANL responsibilities, while most engineering and almost all hardware and test-facility construction have been Cryenco responsibilities.

3. Science and Fundamental Invention. Because TADOPTR technology is so new, opportunities still exist for dramatic improvements based on fundamental understanding. Hence, LANL continues fundamental applied research on TADs and OPTRS, with a focus on patentable inventions leading to improved efficiency without sacrificing high reliability or low cost.

\section{Accomplishments}

The 500 gallon per day prototype will comprise two identical thermoacoustic engines and three identical orifice pulse tube refrigerators, sharing a common resonator. In the past year, we designed, built, and assembled the first pieces of this prototype: one engine and one refrigerator on the resonator. Testing of this assembly with a burner heating the engine began in January 1997, and by March the assembly produced LNG at a rate of 100 gallons per day. Testing is ongoing, but it appears certain that $500 \mathrm{gpd}$ capacity design goals will be met, and probable that efficiency goals will be met in the 500 gpd prototype.

This important milestone has demonstrated for the first time that TADOPTR technology works at a capacity suitable for practical liquefaction of natural gas.

Construction and assembly of the engine, refrigerator, and resonator were difficult, and many engineering challenges were discovered and overcome in all three components. Each problem was regarded as an opportunity to reduce the projected cost to manufacture the acoustic liquefier. The resulting dramatic reduction in projected 
costs achieved this year was unexpected, and is a milestone as important as the 100gallon-per-day capacity demonstration.

Fundamental work at LANL this year broke new ground in several areas. A new type of thermoacoustic heat exchanger with shell-and-tube geometry was tested successfully. Turbulent limitations to the use of variable acoustic impedance in OPTRS were explored, and a control method was invented (patent in process). Both these developments were completed in time to be used in the Cryenco prototype, where they are working as well as predicted. A third invention, use of a tapered pulse tube to suppress streaming-driven convection (patent in process), was also demonstrated at small scale at LANL and incorporated into the Cryenco prototype; testing of this feature at Cryenco has verified the expected performance improvement.

\section{Applications}

The efficiency of small acoustic liquefiers will be reasonable, although not initially as high as that of conventional large-scale liquefiers, which have enjoyed decades of engineering development. We expect the first 500 gallon per day production units to liquefy $70 \%$ of throughput, and the first 10,000 gallon per day production units to liquefy $75-80 \%$ of throughput. Ongoing research will lead to improved efficiency.

The acoustic liquefier will offer unsurpassed reliability. Because it has no exotic materials or close tolerances anywhere (it is nothing more than welded piping and heat exchangers), its cost will be low, and it will be economical at a size far smaller than that of existing LNG equipment. These features are suited to a wide range of applications at small, medium, and large capacity:

Small Capacity (approximately 500 gallons per day): Local liquefaction of pipeline gas at fleet-vehicle fueling stations, recovery of landfill gas and other bio-waste gas, recovery of associated gas from small oil wells, recovery of coal bed gas, boiloff recovery at seasonal peak-shaving facilities, and liquefaction of gas for storage near emergency facilities such as hospitals. 
Mediurn Capacity (approximately 10,000 gallons per day): Production from shut-in wells, recovery of associated gas from offshore oil wells, liquefaction at seasonal peakshaving facilities, and most of the applications listed above for small capacity.

Large Capacity (much larger than 10,000 gallons per day): It is premature to predict the acoustic liquefier's efficiency, reliability, and cost at such large scales, but it is possible that large-scale gas production in extremely hostile environments will be enabled by this technology's intrinsic high reliability.

\section{Future Activities}

We will complete testing the present one-engine, one-refrigerator subsystem of the 500 gpd prototype, and then complete the $500 \mathrm{gpd}$ prototype. The $500 \mathrm{gpd}$ will incorporate numerous improvements to vital auxiliary subsystems necessary for production. Near the completion of the 500 gallon per day prototype, we will begin design and analysis of the I 0,000 gallon per day prototype.

We will continue research directed at improved efficiency. So far, we have identified four potential improvements to OPTR technology and three potential improvements to TAD technology. Inertance and tapered pulse tubes (discussed above) are the first two of these that we have completed. Each of these seven improvements can potentially contribute about a $20 \%$ increase in system efficiency; hence, if all of them worked, this would represent a $(1.2)^{7}=3$-fold improvement in TADOPTR efficiency (i.e. the 500 gpd target of burn $30 \%$ would improve to burn about $10 \%$ ), which would imply an acoustic liquefier efficiency comparable to that of the best existing large-scale conventional LNG plants. That is probably too optimistic, but we expect that most of the seven potential improvements will indeed succeed.

\section{Acknowledgments}

We are grateful to the Los Alamos National Laboratory Program Contracting Officer's Representative, Rod Malone at Morgantown, West Virginia, for his continued 
encouragement. DOE Fossil Energy's financial support for this project began in March 1995.

Important technical support has been provided by Dr. Ray Radebaugh, NIST, Boulder CO, and by Gene Zwick, Zwick Energy Research, Huntington Beach CA.

\section{References}

[1] John McDermott, Liquefied Natural Gas Technology. Noyes Data Corporation, Park ridge, NJ, 1973.

[2] G. W. Swift, R. A. Radebaugh. Acoustic Cryocooler, September 4, 1990. U.S. Patent number 4,953,366.

[3] A computer animation and short description of the essential thermodynamic and acoustic processed on the TADOPTR can be obtained from Greg Swift or via Internet at http://roft.esa.lani.gov by selecting "Educational demonstrations".

[4] R. Radebaugh, K. M. McDermott, G. W. Swift and R. A. Martin. Development of a thermoacoustically driven orifice pulse tube refrigerator. In Proceedings of the Interagency Meeting on Cryocoolers, page 205. October 24, 1990, Plymouth, MA, David Taylor Research Center, publication 91/003, Bethesda, MD, 1990.

[5] G. Walker. Cryocoolers. Plenum, New York, 1983.

[6] W. E. Gifford and R. C. Longsworth. Pulse Tube Refrigeration. Trans. ASME, J. Eng. Ind., 86:264-270,1964.

[7] R. Radebaugh. A Review of Pulse Tube Refrigeration. Adv. Cryogenic Eng., 35:11911205, 1990.

[8] G. W. Swift. Thermoacoustic Engines. J. Accost. Soc. Am., 84:1145-1180, 1988.

[9] G. W. Swift. Thermoacoustic Engines and Refrigerators. Physics Today, pages 22- 28. 


\section{Appendix 7: $\quad$ CRYENCO/Chart Industries}



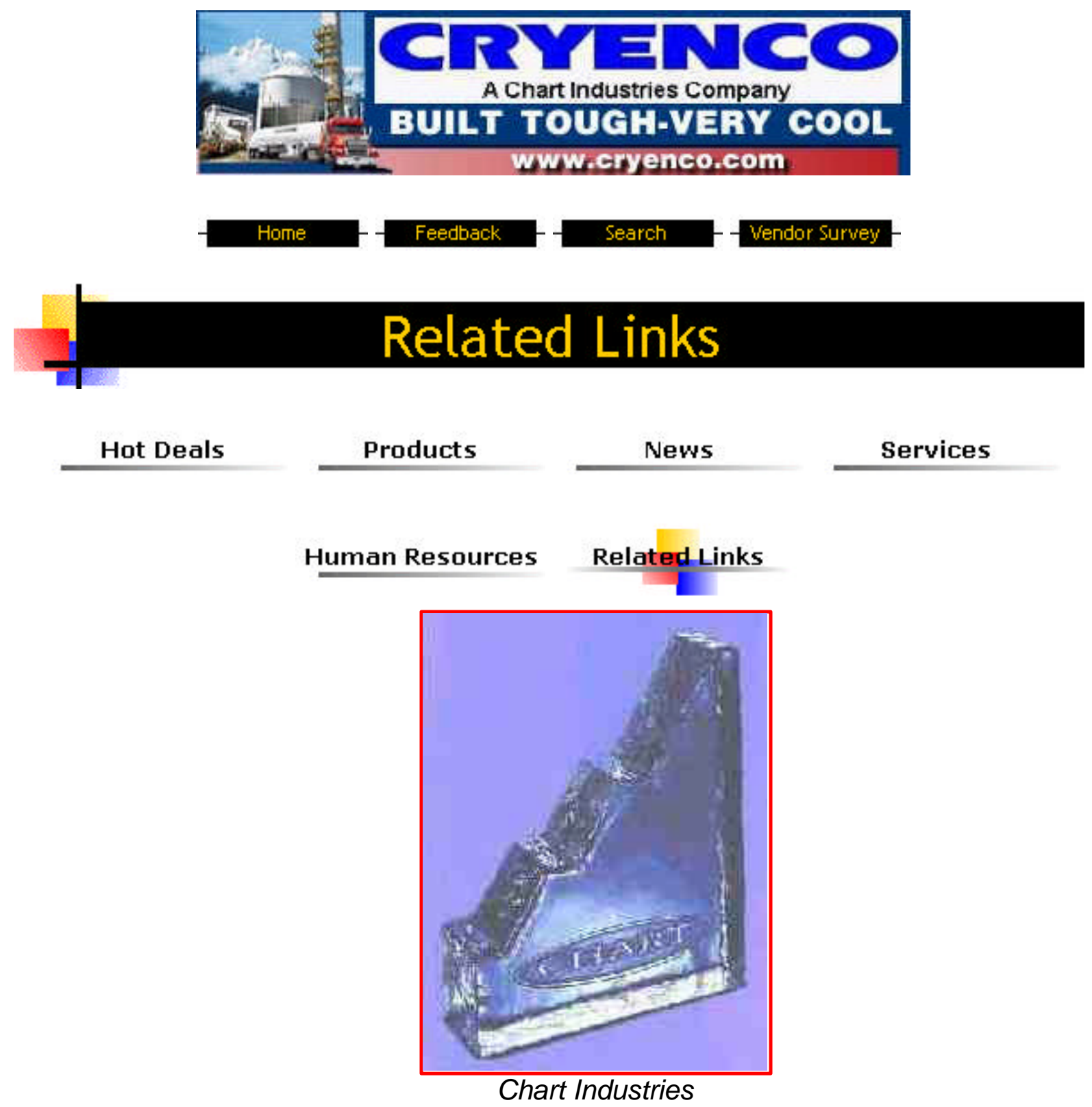

Other Chart Industries Companies

ALTEC International

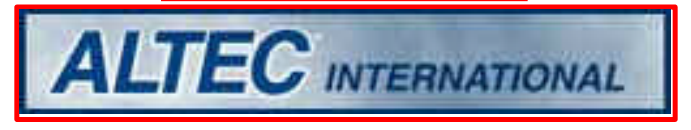

Greenville Tube Corporation

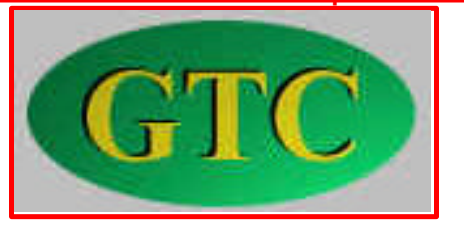

Process Systems International, Inc 

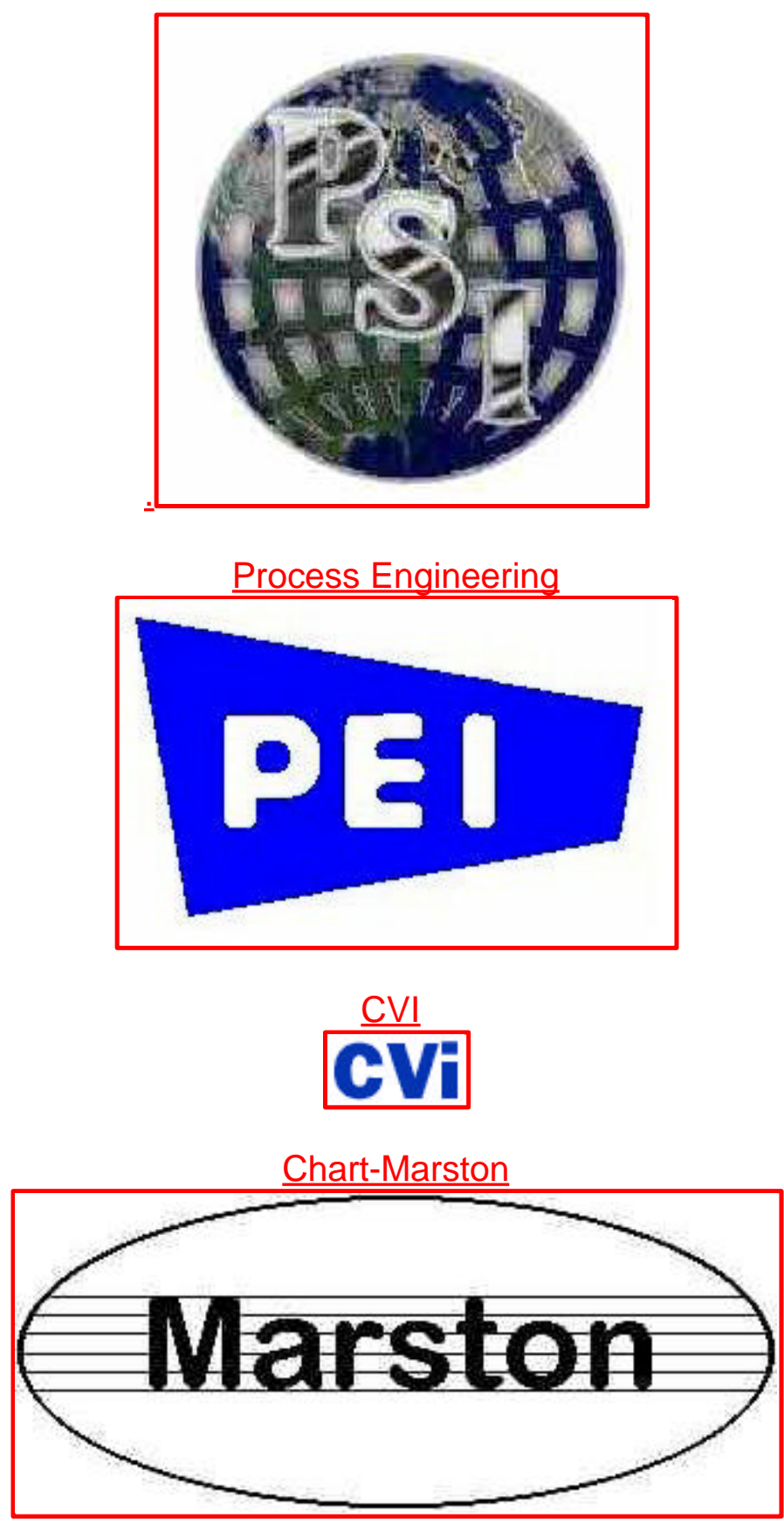

\section{揭}

Send mail to Webmaster with questions or comments about this web site. Last modified: June 29, 1999 


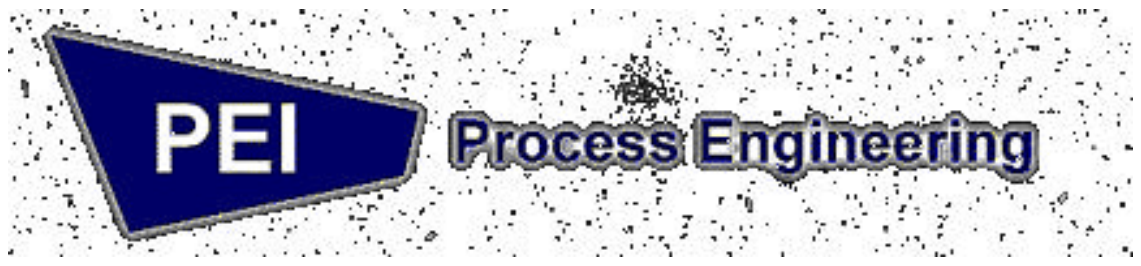

Process Engineering designs and manufactures stationary tanks and railroad tank cars for the storage and transportation of cryogenic liquids. We serve a national and international customer base from our manufacturing plant in Plaistow, NH, 40 miles north of Boston. PEI has been supplying the industrial gas industry with high quality cryogenic tanks and transportation equipment since 1938.

Our Facilities:

Our 200,000 square foot, Plaistow, $\mathrm{NH}$ facility is divided into five main fabrication bays:

- Bay A is used to fabricate the inner and outer cryogenic tank sub-assemblies;

- Bay B is used to complete the cryogenic tank assemblies, including the external piping;

- Bay $\mathbf{C}$ is used to fabricate electronics grade vessels, and it contains our new clean room and passivation system;

- Bay $D$ is used for metal prep and to fabricate sub-assemblies; and it is adjacent to our new blast room;

- And Bay $E$ is our newly renovated rail car assembly and repair bay.

At PEI we have extensive ability and experience in producing the highest quality welds on a wide variety of materials, using state of the art welding techniques. We maintain and continually upgrade our welder qualifications in accordance with Section IX of the ASME Code. A variety of non-destructive weld examination methods are used throughout the fabrication of your tank, including radiography.

- Electronics Grade tanks are finished in the finely controlled atmosphere of our world class clean room.

- Passivation with nitric acid, when required, is accomplished in house with our new passivation system.

- Our new indoor blast room and 'plural' paint system with electrostatic spray guns, combine to provide a superior finish that is as durable as it is attractive. Our standard finish is white, DuPont imron; and customer-supplied decals may be factory installed.

- One of the most important aspects of any cryogenic tank is the quality or integrity of the vacuum in the annular space. Thermal performance of any of the available insulation materials is much better at low vacuum. The 'leak tightness' of all of our tanks is ensured through use of helium mass spectrometer testing. Every PEI tank is helium leak checked to a criteria of 'no discernible leak' with equipment sensitive to a leak rate as small as 1 x $10-9 \mathrm{cc} / \mathrm{sec}$.

Finished tanks are shipped from our plant to your facility by either truck, rail or water service. Our on-site rail sidings make rail shipping particularly desirable for large tanks. Local rail service is provided by Springfield 
Terminal Railway (the old Boston \& Maine Railroad). Port access at Portsmouth, New Hampshire, Boston, and New York provide sea routes for water shipments

Process Engineering offers state of the art cryogenic tanks made to the highest quality standards. We strive continually to offer these products to the market at the best possible pricing and delivery, all while maintaining a superior level of quality and functionality. Our superior design and workmanship provide you with a cryogenic tank which is rugged, durable, easy to operate and maintain, and which you will be proud to own.

Our facilities in Plaistow, NH are certified by the ASME Code, the National Board of Boiler and Pressure Vessel Inspectors, and the Association of American Railroads Tank Car and Quality Assurance Committees. Our ASME 'U' stamp authorizes us to stamp vessels that we design, fabricate and test in accordance with Section VIII of the ASME Boiler and Pressure Vessel Code.

We are registered with the US Department of Transportation (DOT) for building cargo tanks (highway trailers) for cryogenic products and hazardous materials and have worked with the DOT extensively on both highway and rail car projects involving cryogenic products and hazardous materials.

At Process Engineering, our mission is "To Exceed Our Customers' Expectations of Quality, Value and Superior Service." We cut no corners in our efforts to comply with both the letter and the spirit of all applicable regulatory and customer requirements, to provide you, our customer, with safe, economical and durable cryogenic tanks for your cryogenic liquid storage and transportation needs.

[ㅂome] [Products] [ales] [What's New] [About PEI] [Shipping] [Certifications] [Contact PEI][Text Mode] 


\section{ALTEC Products}

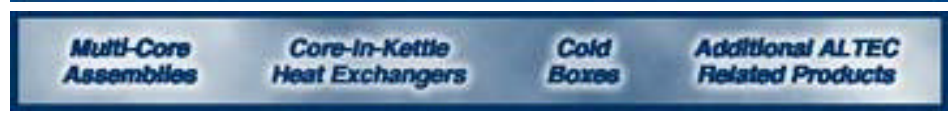

Multi-Core Assemblies, Core-In-Kettle® Heat Exchangers, Cold Boxes, $\underline{\text { Additional ALTEC Related }}$ Products

\section{ALTEC International is an active member of The Brazed Aluminum Plate-Fin Heat Exchanger Manufacturers' Association (ALPEMA).}

ALTEC Heat Exchanger's Basic ConstructionThis sketch shows the basic components

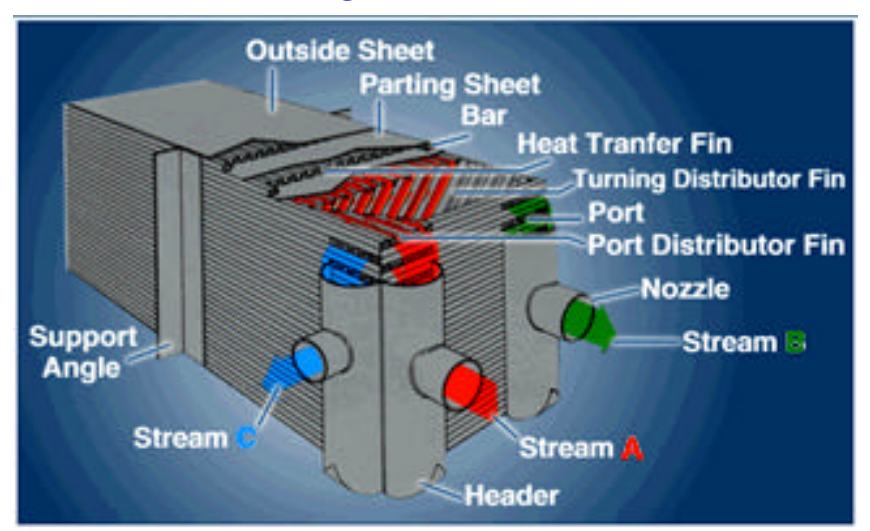
and operation of a brazed aluminum heat exchanger (BAHX). The BAHX is shown in the horizontal orientation for descriptive purposes only and will actually be mounted in the vertical position from the support angles on each side of the exchanger. The cut-away view illustrates the warm end or top of the exchanger with one warm stream ("A") entering and two

cold streams ("B" \& "C") leaving.

Stream "A" enters the exchanger through the nozzle and header and is introduced to the exchanger block at the port. After flowing through the port, stream " $\mathrm{A}$ " is directed across the width of the exchanger by means of the distributor fin. Good distribution of flow is needed for proper thermal and hydraulic performance of the exchanger. Stream "A" then enters the heat transfer fin section. Heat transfer fins are selected by ALTEC engineers to create an optimum balance between pressure drop and heat transfer performance of each stream. The heat transfer fin enhances the stream flow characteristics in order to transfer heat across the primary heat transfer surface, the parting sheet. Parting sheets separate each individual layer and provide the surface for all piece parts (bars and fins) to braze together when placed in ALTEC's brazing furnace. Flow continues through the heat transfer fin then through the outlet distributor fin, port, header and nozzle.

The design and construction of BAHXs allow an infinite number of design configurations considering the exchanger's size, geometry, number of streams, types of fins, etc. ALTEC is confident that we are able to meet any requirement specified for a BAHX application. 


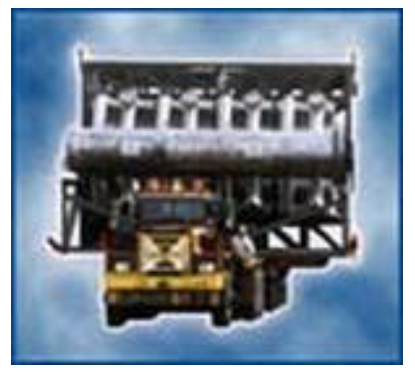

\section{ALTEC strives to provide their worldwide list of customers with the lowest evaluated cost solutions to heat transfer needs.}

ALTEC Heat Exchanger CoresALTEC heat exchangers are manufactured to rigorous quality standards as well as the requirements of the American Society of Mechanical Engineers (ASME) code for unfired pressure vessels.

ALTEC is a registered ISO 9001 company that designs and manufactures exchangers to most other internationally recognized pressure vessel codes.

ALTEC manufactures block sizes that are among the largest in the industry. Pressure ratings range from full vacuum up to $1751 \mathrm{psig}(121.7 \mathrm{bar} \mathrm{G})$ at design temperatures of $-452^{\circ} \mathrm{F}\left(-269^{\circ} \mathrm{C}\right)$ to $+400^{\circ} \mathrm{F}\left(+204^{\circ} \mathrm{C}\right)$. The company has manufactured hundreds of brazed aluminum heat exchangers rated for pressures of 1000 psig (69 bar G) and above. 


\section{ALTEC Advantages}

\section{ALTEC Global Heat Transfer Solutions}

ALTEC International was formed in 1985 through an acquisition from The Trane Company's brazed aluminum heat exchanger operation in La Crosse, Wisconsin. ALTEC International was founded in 1949 and is a wholly owned subsidiary of Chart Industries, of Mayfield Heights, Ohio. ALTEC heat exchangers offer numerous advantages over other heat transfer equipment.

\section{Lower Operating Temperatures}

ALTEC heat exchangers are well suited for the low temperature requirements of cryogenic applications since the $100 \%$ aluminum construction can withstand temperatures as low as $-452^{\circ} \mathrm{F}\left(-269^{\circ} \mathrm{C}\right)$ and pressures as high as $1751 \mathrm{psig}(121.7 \mathrm{bar}$ $\mathrm{G})$.

\section{Lower Capital Costs}

ALTEC brazed aluminum heat exchangers are compact and lightweight. ALTEC exchangers provide 300 to 450 square feet of heat transfer surface per cubic foot of exchanger volume (1000 to $\left.1500 \mathrm{~m}^{2} / \mathrm{m}^{3}\right)$ which is six to ten times higher than that of a comparable shell-and-tube heat exchanger. This characteristic, coupled with the enhanced heat transfer performance of plate-fin construction, produces as much as ten to 20 times greater heat transfer performance (UA) than shell-and-tube exchangers of equal size. This higher efficiency can correlate to an ALTEC heat exchanger costing approximately $25-50 \%$ less and weighing $95 \%$ less than a stainless steel shell-and-tube exchanger.

\section{Flexible Design}

ALTEC heat exchangers can be designed with more than ten streams and nearly an unlimited number of configurations by varying parameters such as block size and shape, fin type, layer stacking arrangement and flow scheme. This multiple stream advantage is realized in the potential of combining numerous heat exchanger services into a single compact heat exchanger.

\section{Lower Installation and Operating Costs}

ALTEC's multi-stream design can result in significant cost reduction in:

- Engineering

- Insulation

- Support systems

- Installation

- Testing

- Documentation 
- Transportation

- Plot plan requirements

Additionally, ALTEC heat exchangers allow temperature approaches as low as $2^{\circ} \mathrm{F}$ $\left(1^{\circ} \mathrm{C}\right)$ that result in lower compressor horsepower requirements and lower plant operating costs.

\section{ALTEC Heat Transfer Fins}

ALTEC design and engineering teams constantly challenge the variables in heat exchanger fin design, analysis and testing. Heat transfer fins are experimentally tested for both heat transfer and pressure drop performance and cover a wide range of characteristics. The company has developed improved heat transfer and fluid flow performance correlations for both single-phase and two-phase fluids.

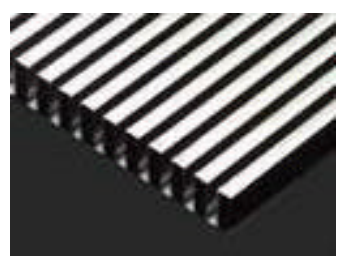

Straight Fin

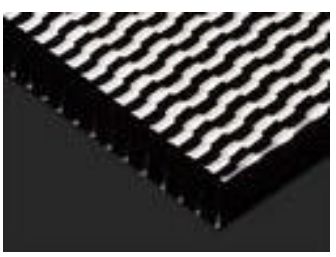

Serrated Fin

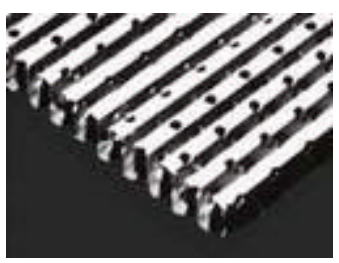

Perforated Fin 


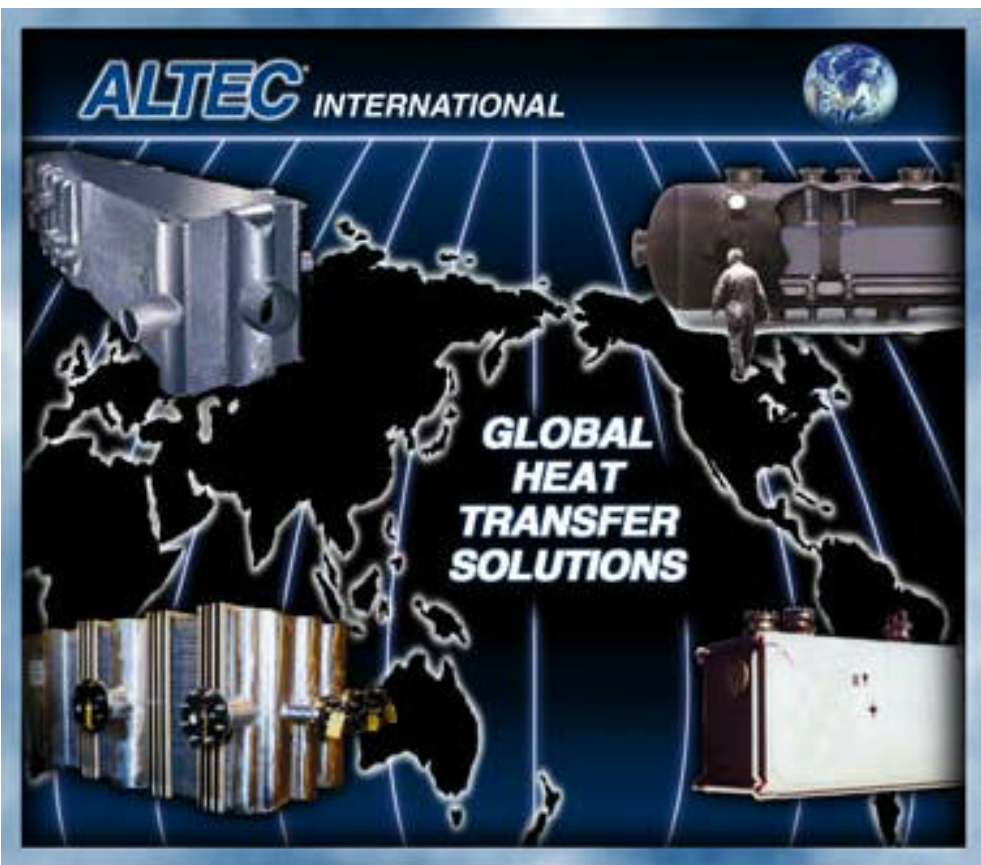

Typical ALTEC applications include:

- Air separation

- Petrochemical

- Natural gas processing

- LNG

- Helium liquefaction and recovery

- Off-shore gas processing

- Large refrigeration systems

- Synthetic fuel (i.e., coal gasification)

- Ethylene

- Hydrogen recovery

- Nitrogen rejection

- MTBE
Welcome to ALTEC International, the originator and world leader in the design and manufacture of brazed aluminum heat exchangers for cryogenic applications. ALTEC pioneered the application of brazed aluminum in the air separation industry back in 1949. Today, thousands of ALTEC heat exchangers are used for a wide variety of applications serving the chemical and process industries worldwide.

Click here to view detailed plant types and applications

Please click on ALTEC Advantages and Products for an extensive review of why ALTEC brazed aluminum heat exchangers outperform carbon or stainless steel shell-and-tube heat exchangers in the ability to achieve low operating temperatures, greater efficiencies, lower capital and operating costs, and a more compact size. 
Appendix 8: Price Quote on Cooling Towers 


\section{QUOTATION No. B99-183}

\section{Cryenco/MVE}

Attn: Gary Wheeler
Date: April 7, 1999

Name of Job: Close approach fluid cooler

Location:

\section{We offer equipment listed below for use in the project named above, as follows:}

Shipenouss ate P.O.B poiat of manuficture with freight sillowed.

Tamx: NET 30 DAYS
All quotations and allas are made in acoecdance with the terme and conditions on tho last page of quotation.

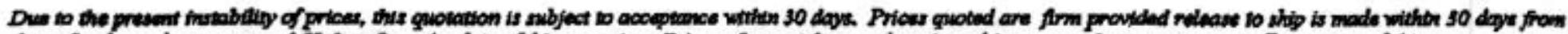

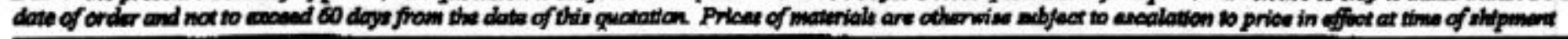

:

Qty-2, BAC \# FXV-663-OM, Closed Circuit Cooling Tower. Capacity of 2,500,000 BTUH/ea. heat rejection. Cooling 500 GPMea. from $78^{\circ} \mathrm{F}$ to $68^{\circ} \mathrm{F}$ when using $63^{\circ} \mathrm{FWB}$. Hybrid Counter/Cross flow style, single air inlet, indurced draft, top discharge, axial fans. G-235 galvanized steel construction with "Baitibond" fuse bonded copolymer corrosion protection. 3-15 HP fan motors, 460/3/60, 1780 RPM, TEFC . 7.5 HP spray pump, electric sump heater, 5-year mechanical parts warranty, ISO-900182 quality control assurance, factory authorized startup and training assistance. Approximate dimensions/ea.: $20^{\prime} \mathrm{L} \times 12 \mathrm{~W} \times 16^{\prime} \mathrm{high}$. Weight/ea.: 18,690 lbs.-dry, 31,590 lbs.-wet. Unit ships in two pieces, upper section is heaviest piece with the coil at 12,870 lbs.

PRICE: \$ 88,501 Net, Freight Allowed, 6-7 weeks

Altemate "A": One unit, less capacity.

Qty-1, BAC \# FXV-664, Closed Circuit Cooling Tower. Capacity of 3,692,821 BTUH heat rejection. Cooling $1000 \mathrm{GPM}$ from $78^{\circ} \mathrm{F}$ to $70.6^{\circ} \mathrm{F}$ when using $63^{\circ} \mathrm{FWB}$. Hybrid Counter/Cross flow style, single air inlet, indurced draft, top discharge, axial fans. G-235 galvanized steel construction with "Baltibond" fuse bonded copolymer corrosion protection. 3-15 HP fan motors, 460/3/60, 1780 RPM, TEFC . 7.5 HP spray pump, electric sump heater, 5-year mechanical parts warranty, ISO-9001\&2 quality control assurance, factory authorized start-up and training assistance. Approximate dimensions.: $20^{\prime} \mathrm{L} \times 12 \mathrm{~W} \times 16^{\prime}$ high. Weight: $20,280 \mathrm{lbs}$.-dry, 33,810 lbs.-wet. Unit ships in two pieces, upper section is heaviest piece with the coil at 14,460 lbs.

PRICE: \$ 48,470 Net, Freight Allowed, 6-7 weeks

Sincerely Yours,

fore<smiles>CC(=O)C[C@H]1CC[C@H]2CC[C@H]1C2</smiles>

Lou Grounds, CFM Company. 

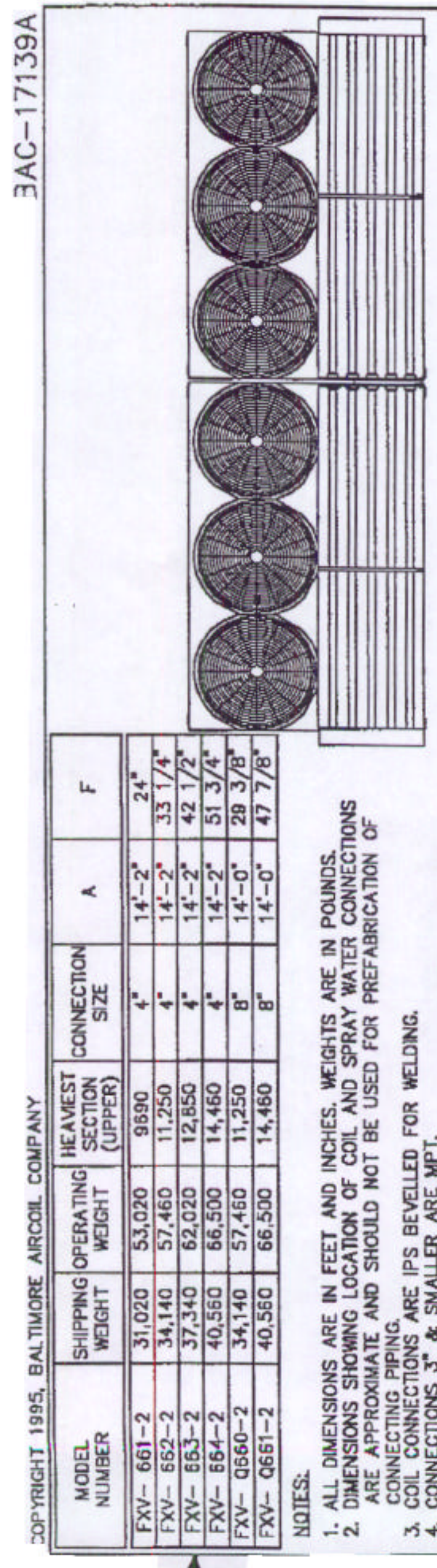
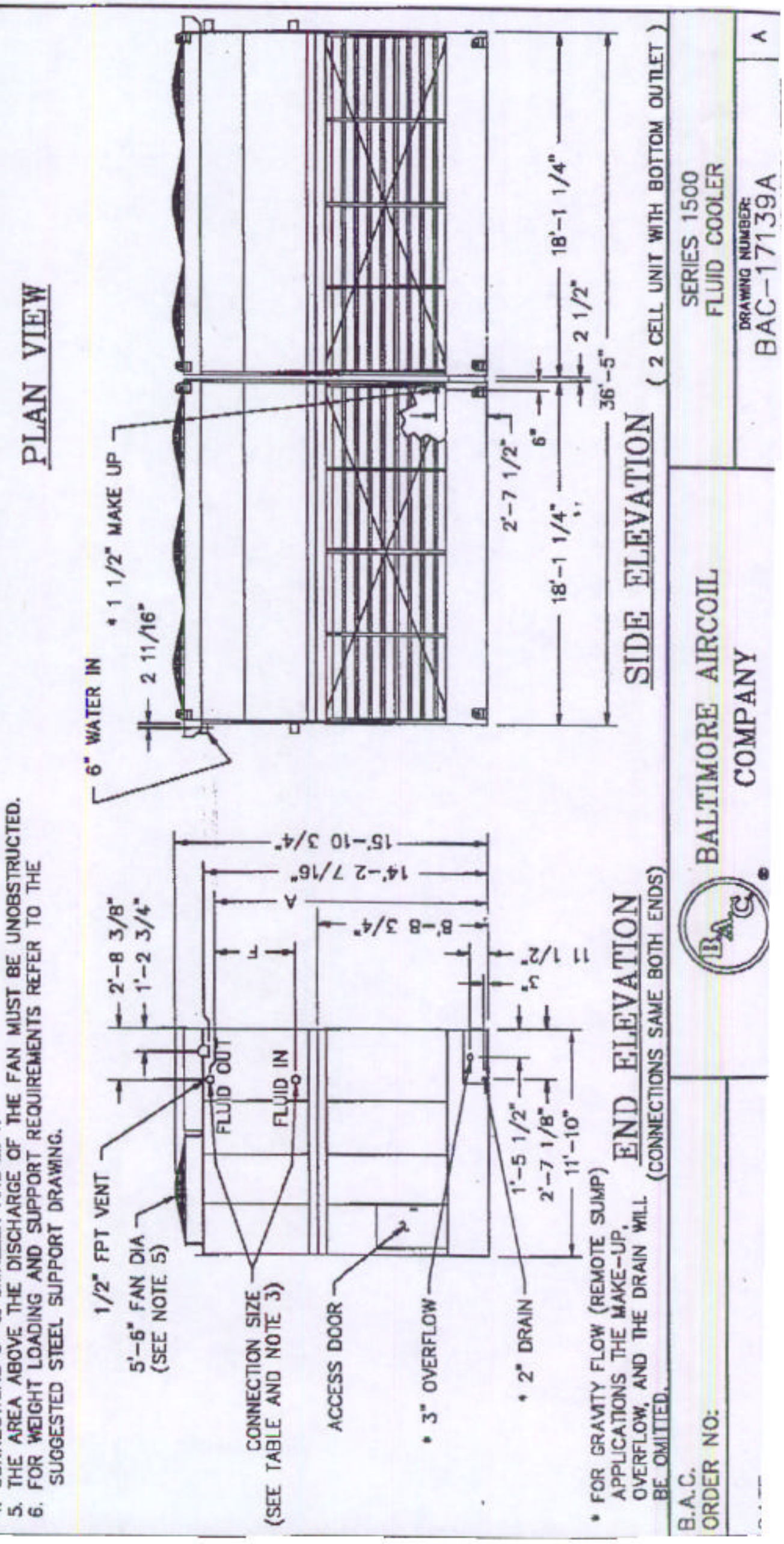
BALTIMORE AIRCOIL COMPANY

\section{INDUSTRIAL FLUID COOLER SELECTION PROGRAM}

\section{Release 2.0 - January 1998}

To : Cryenco

DATE : 04/07/1999

ATT : Gary Theeler

FROM : Lou Grounds

PROJECT INFO : Close approach closed circuit cooling tower

\section{DESIGN SELECTION DATA :}

Fluid inlet temperature : Fluid outlet temperature : Wet bulb temperature Fluid Flow

Capacity

coil Arrangement
$: \quad 78.0^{\circ} \mathrm{F}$ $70.9 \circ \mathrm{F}$ $63.0^{\circ} \mathrm{F}$ 1000.00 GPH TOTAL (OOOSH) 1000.00 GPH, TOTAL ( SDOEAH)
$: 2528226-B T U H$ $5,000,000$ Brat : Standard

SELECTED MODEL : FXV663-OM

Design thermal performance is within the limits of CTI STD-201. Maximum cooling capacity for above temperature conditions : 992.99 GPM Pressure Drop: $2725 \mathrm{psi} 7.4 \mathrm{psi}$ SDO GPM

TECHNICAL DATA : 4WO REOUIRTD!

Unit height : $15 \cdot 10.750^{\prime \prime}$

Unit width : $11 \cdot 10.000^{\prime \prime}$

Unit length $: 18^{\prime} 1.250^{\prime \prime}+1{ }^{\prime} 8.250^{\prime \prime}$ (pump) $=19^{\prime} 9.500^{\prime \prime}$ (Total length)

Height :

Approx. shipping weight : $18690 \mathrm{lb}$

Heaviest section : 12870 1b

Approx. operating weight : standard : 31590 ib

Remote sump : $31030 \mathrm{Ib}$

Airflow

(Remote sump conn.: $8.000^{n}$ )

Fan Motor $141250.0 \mathrm{CFM}$

Spray watarflow:
Pump Motor

Coil Volume

$30.00 \mathrm{HP}+15.00 \mathrm{HP}$

900.0 GPM

$7.50 \mathrm{HP}$

$409.0 \mathrm{gal}$

Base Sound Data at $50 \mathrm{ft}$ : AIR INLET : $83 \mathrm{~dB}(\mathrm{~A})$

END : $77 \mathrm{~dB}(\mathrm{~A})$

BACK : $80 \mathrm{~dB}(\mathrm{~A})$

TOP : $87 \mathrm{AB}(\mathrm{A})$

Consult your local B.A.C. representative if lower sound levels are required. 


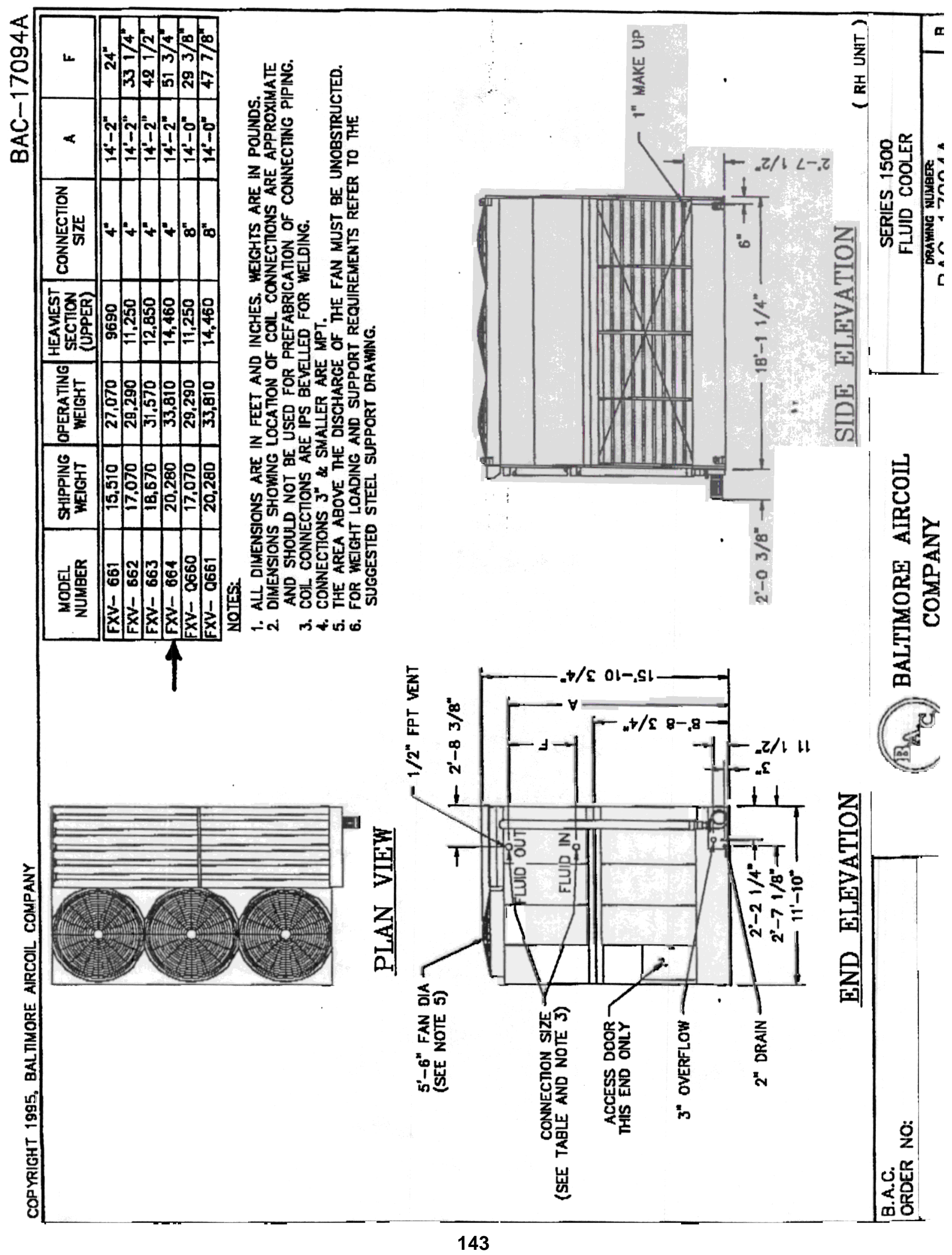


BALTIMORE AIRCOIL COMPANY

INDUSTRTAL FLUID COOLER SELECTION PROGRAM

Release 2.0 - January 1998

To : Cryenco

DATE : 04/07/1999

ATT : Gary theeler

FROM : Lou Grounds

PROJECT INFO : Close approach closed circuit cooling tower

\section{DESIGN SELECTION DATA :}

Fluid inlet temperature : Fluid outlet tomperature : Wet bulb temperature Fluid Flow

Capacity

Coil Arrangement

$\begin{array}{cc}: & 78.0 \circ \mathrm{F} \\ : & 70.60^{\circ} \mathrm{F} \\ : & 63.00^{\circ} \mathrm{F} \\ : & 3600.00 \mathrm{GPM} \\ : & \text { standard }\end{array}$

SELECTED MODEL : FXV664

Design thermal performance is within the limits of CTI STD-201.

Maximum cooling capacity for above temperature

conditions : 1000.01 GPM Pressure Drop: 31.89 psi

TECENICAL DATA :

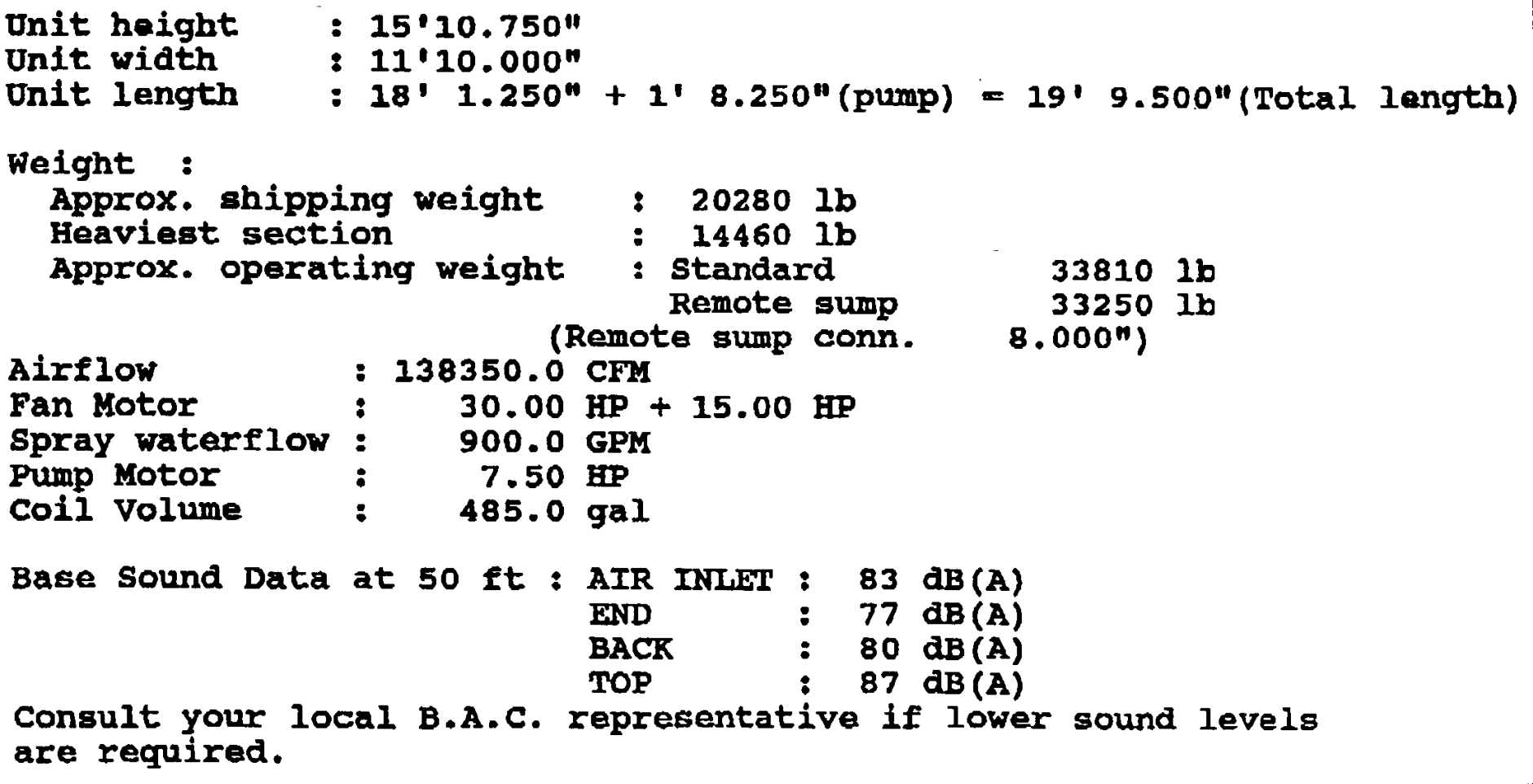




\section{Appendix 9: Financial Estimates for Project}

Appendix 9 contains company proprietary information which is not reprinted in this public document.

\section{Appendix 10: Marketing Strategy}

Appendix 10 contains company proprietary information which is not reprinted in this public document.

\section{Appendix 11: Identification and Quantification of Potential Market for LNG for Transportation Fuel in the Morgantown, West Virginia Area}

Appendix 11 contains company proprietary information which is not reprinted in this public document. 